NBER WORKING PAPER SERIES

\title{
OPTIMAL TAXES ON CAPITAL IN THE OLG MODEL WITH UNINSURABLE IDIOSYNCRATIC INCOME RISK
}

\author{
Dirk Krueger \\ Alexander Ludwig \\ Working Paper 24335 \\ http://www.nber.org/papers/w24335 \\ NATIONAL BUREAU OF ECONOMIC RESEARCH \\ 1050 Massachusetts Avenue \\ Cambridge, MA 02138 \\ February 2018
}

We thank Daniel Harenberg, Marek Kapicka, Yena Park and Catarina Reis as well as seminar participants at SED 2015 in Toulouse, University of Cologne, EIEF Rome, University of Tilburg, CERGE-EI Prague for helpful comments and Leon Huetsch for his excellent research assistance. Dirk Krueger thanks the NSF for continued financial support. Alex Ludwig gratefully acknowledges financial support by the Research Center SAFE, funded by the State of Hessen initiative for research LOEWE. The views expressed herein are those of the authors and do not necessarily reflect the views of the National Bureau of Economic Research.

NBER working papers are circulated for discussion and comment purposes. They have not been peer-reviewed or been subject to the review by the NBER Board of Directors that accompanies official NBER publications.

(C) 2018 by Dirk Krueger and Alexander Ludwig. All rights reserved. Short sections of text, not to exceed two paragraphs, may be quoted without explicit permission provided that full credit, including $(\odot$ notice, is given to the source. 
Optimal Taxes on Capital in the OLG Model with Uninsurable Idiosyncratic Income Risk Dirk Krueger and Alexander Ludwig

NBER Working Paper No. 24335

February 2018

JEL No. E21,H21,H31

\begin{abstract}
$\underline{\text { ABSTRACT }}$
We characterize the optimal linear tax on capital in an Overlapping Generations model with two period lived households facing uninsurable idiosyncratic labor income risk. The Ramsey government internalizes the general equilibrium feedback of private precautionary saving. For logarithmic utility our full analytical solution of the Ramsey problem shows that the optimal aggregate saving rate is independent of income risk. The optimal time-invariant tax on capital is increasing in income risk. Its sign depends on the extent of risk and on the Pareto weight of future generations. If the Ramsey tax rate that maximizes steady state utility is positive, then implementing this tax rate permanently generates a Pareto-improving transition even if the initial equilibrium is dynamically efficient. We generalize our results to Epstein-Zin-Weil utility and show that the optimal steady state saving rate is increasing in income risk if and only if the intertemporal elasticity of substitution is smaller than 1 .
\end{abstract}

Dirk Krueger

Economics Department

University of Pennsylvania

160 McNeil Building

3718 Locust Walk

Philadelphia, PA 19104

and NBER

dkrueger@econ.upenn.edu

Alexander Ludwig

Goethe University Frankfurt

House of Finance

Theodor-W.-Adorno-Platz 3

D-60629 Frankfurt am Main

Ludwig@safe.uni-frankfurt.de 


\section{Introduction}

How should a benevolent government tax capital in a neoclassical production economy when households face uninsurable idiosyncratic labor income risk? Partial answers to this question have been given in Bewley-Huggett-Aiyagari style general equilibrium models with neoclassical production and infinitely lived consumers, starting from Aiyagari (1995)'s characterization of the optimal steady state capital income tax rate, and continuing with recent work providing partial, and often numerical, characterizations of the optimal path of capital income taxes by Panousi and Reis (2015, 2017), Açikgöz (2015), Gottardi et al. (2015), Hagedorn et al. (2015), Dyrda and Pedroni (2016), Chen et al. (2017) and Chien and Wen (2017).

In this paper we complement this literature by providing a complete analytical characterization of taxes on capital in a canonical Diamond (1965) style Overlapping Generations model with uninsurable idiosyncratic labor income risk in the second period of life. We characterize the optimal linear tax on capital chosen by a Ramsey government (Ramsey 1927) that uses the tax revenues to finance lump-sum transfers to households. The Ramsey government places arbitrary Pareto weights on different generations born into this economy, and has to respect equilibrium behavior of households. For logarithmic utility we provide a complete analytical solution of the optimal dynamic Ramsey tax policy problem, and for more general preference structures in the Epstein-Zin-Weil class we still obtain a full analytical characterization of optimal taxes on capital when the Ramsey government maximizes lifetime utility of generations living in the steady state, and thus places all weight in the social welfare function on generations living in the long run.

For logarithmic utility the Ramsey allocation is characterized by a constant (over time) aggregate saving rate, the share of aggregate (labor) income devoted to capital accumulation. This constant saving rate is independent of the magnitude of idiosyncratic income risk, and can be implemented as a competitive equilibrium with a proportional tax on capital that is also constant over time, but strictly increasing in the extent of income risk. Our complete analytical characterization of the solution

to the Ramsey problem allows us to show explicitly that the optimal constant saving rate is shaped by three distinct forces: i) a standard precautionary savings force in partial equilibrium, ii) a general equilibrium current generations effect through which a change in the household saving rate today when young impacts wages and interest 
rates tomorrow when the same generation is old, and iii) a general equilibrium $f u$ ture generations effect, in that higher saving rates by current generations increase the future capital stock, future wages in general equilibrium and thus welfare of future generations in the economy. By characterizing all three effects in closed form we show analytically that with logarithmic utility income risk does not affect the optimal saving rate chosen by the Ramsey planner, because a general equilibrium effect exactly offsets the standard partial equilibrium precautionary savings effect.

To understand this finding, first turn to the current generations effect, i.e., assume for now that future generations do not receive any weight in the Ramsey planner's objective function. In the absence of income risk the current generations effect simply captures that the Ramsey government chooses the optimal saving rate, internalizing how this allocation affects wages and interest rates. In the presence of income risk, private households also do not internalize that increasing savings raises wages and thus the risky income component in the next period. Since this wage risk is uninsurable by assumption, this additional wage risk is welfare reducing. The Ramsey planner internalizes this negative side effect from private precautionary saving when setting tax rates on capital which in turn impact the saving rate chosen by private households, and through it, factor prices in general equilibrium. ${ }^{1}$ With logarithmic utility, this general equilibrium effect exhibits exactly the opposite effect on the optimal saving rate as the partial equilibrium precautionary savings effect so that the two effects of idiosyncratic income risk precisely cancel out. The benevolent Ramsey government implements the optimal allocation by offsetting the negative precautionary savings externality through taxes on capital, thereby reducing the saving rate and capital formation. Hence, more broadly, our optimal tax result is shaped by the Pigouvian taxation principle (Pigou 1920) aimed at correcting externalities. Since the individually chosen (socially suboptimal) saving rate is increasing in income risk, so is the tax rate on capital correcting the externality from these choices.

Now assume that the Ramsey government additionally values future generations. As with the own generations effect, the general equilibrium future generations effect reflects that the Ramsey planner internalizes the general equilibrium feedback on wages and returns for future generations and, in general, how this affects their

\footnotetext{
${ }^{1} \mathrm{~A}$ subset of the literature emphasizes that private precautionary savings behavior creates a pecuniary externality that has first order welfare implications in models with incomplete markets, see e.g. Davila et al. (2012) or Park (2017). In this paper we consistently refer to this effect, both on current as well as on future factor prices, as general equilibrium effects.
} 
exposure to idiosyncratic wage risk. With logarithmic utility, however, all risk terms again cancel out, and the optimal allocation is not affected by risk at all. With logarithmic utility future generations therefore unambiguously benefit from a higher capital stock which pushes up the optimal saving rate desired by the Ramsey planner. In the presence of the future generations effect the tax rate implementing the optimal allocation may therefore by positive or negative, depending on how strongly the Ramsey government values current and future generations.

A perhaps surprising finding emerges when the government maximizes steady state utility, i.e., when the future generations effect has maximum potency. If the associated optimal long-run Ramsey tax rate is positive (which is true if income risk is sufficiently high), then a government implementing this constant tax rate along the transition generates a Pareto-improving, policy induced transition from the unregulated steady state equilibrium. This holds true even if the original equilibrium is dynamically efficient and thus the tax on capital reduces aggregate consumption along the transition path. The optimal saving rate (and capital tax) which maximizes steady state utility of course acknowledges the welfare losses induced by the crowding out of capital. Since the capital stock monotonically decreases along the transition, welfare losses from this crowding out effect monotonically increase from zero (in the first period of the transition when the capital stock is predetermined) to the long-run maximum along the transition. At the same time, the utility gains from a reduction of the saving rate are constant for all cohorts that live through the transition. Consequently, setting the tax rate in all periods to the long-run welfare maximizing rate induces welfare gains for all transitional generations and thus constitutes a Pareto improvement. This result therefore builds a natural bridge between the thus far quite separate literatures on capital taxation and dynamic inefficiency of equilibrium in OLG economies on the one hand, and uninsurable income risk and capital income taxation in Bewley style economies on the other hand.

In the last part of the paper we extend our results concerning the steady state welfare maximizing policy to arbitrary Epstein-Zin-Weil utility (EZW utility, see Epstein and Zin $(1989,1991)$ and Weil (1989)) and show that the optimal steady state saving rate is increasing in the amount of income risk if and only if the intertemporal elasticity of substitution (IES) is smaller than 1. The intuition is that with EZW utility the objective of households (and thus the Ramsey government) is to maximize utility from safe consumption when young and from the certainty equivalent of utility 
from risky consumption when old. When risk increases, the certainty equivalent from consumption when old decreases. In response the Ramsey government finds it optimal to increase mean old age consumption by increasing the saving rate if the willingness to inter-temporally substitute consumption is relatively low. The reverse is true if the IES is relatively high, with an IES of unity serving as the watershed case. The associated optimal steady state tax rate implementing this saving rate is increasing in income risk unless both the IES and risk aversion (RA) are large ${ }^{2}$, in which case the Ramsey tax rate might be declining in income risk. A necessary condition for this to happen is that households in the competitive unregulated equilibrium decrease their saving rate in response to an increase in income risk. They may choose to do so if they have high RA and high IES because of the low utility value from oldage consumption (high RA) and the high willingness to inter-temporally substitute consumption (high IES) in response to an increase of risk. Unlike households, the Ramsey government internalizes the associated feedback on capital formation through the future generations effect and may therefore find it optimal to dampen the private household saving reaction by cutting the tax on capital.

This paper contributes to various strands of the literature that study optimal allocations and optimal Ramsey capital income tax policies in models with uninsurable idiosyncratic income risk. The first strand analyzes the role of uninsurable idiosyncratic labor income risk for capital accumulation and optimal capital income taxation in variants of infinite horizon Aiyagari (1994), Bewley (1986), İmrohoroğlu (1989) and Huggett (1993) economies. Within this literature, the paper by Davila et al. (2012) is most relevant for our approach. The authors characterize constrained efficient allocations in which the planner can directly choose allocations, but cannot transfer resources across households with different idiosyncratic shock realizations to provide direct insurance against the idiosyncratic risk. ${ }^{3}$ Davila et al. (2012) emphasize three drivers of the optimal allocation: how uninsurable risk affects precautionary savings of private individuals, how general equilibrium prices affect the total income risk of a consumer as well as how the distribution of incomes, in particular the income composition of consumption- and wealth-poor agents in the economy, affect aggregate

\footnotetext{
${ }^{2}$ Thus, this result never emerges with standard CRRA utility.

${ }^{3}$ The notion of constrained efficiency follows Diamond (1967) who also studies a social planner problem in which the planner cannot directly overcome a friction in the economy implied by missing markets. A similar approach is taken by Geanakoplos and Polemarchakis (1986).
} 
welfare. ${ }^{4}$ In contrast to their work we study an overlapping generations economy, where, rather than the cross-sectional distribution of factor incomes at a given point of time, it is the distribution of factor incomes across generations that is crucial for the determination of optimal policy. To obtain closed form solutions we deliberately shut down within-generation heterogeneity so that the inter-generational distribution effect is the only distributional effect in the model. In addition, we characterize the optimal solution of the Ramsey tax problem with linear taxes on capital, rather than focusing on constrained efficient allocations as they do. However, we show that with our choice of policy instruments (linear capital income taxes and lump-sum transfers), the Ramsey government can in fact implement constrained efficient allocations.

The work on Ramsey taxation in Aiyagari-Bewley-Huggett-İmrohoroğlu models starts with Aiyagari (1995). He assumes that government spending is endogenous, that the optimal Ramsey allocation converges to a stationary equilibrium, and finds that in this stationary equilibrium the capital income tax is positive and restores the modified golden rule. ${ }^{5}$ Recent work by Chen et al. (2017) reassesses Aiyagari (1995)'s main finding of positive capital income taxes in models where government spending is exogenous, as in the standard Ramsey optimal taxation literature. The paper argues that treating government spending as exogenous has fundamental consequences for Aiyagari (1995)'s analysis. Depending on the IES there either is no Ramsey steady state with interest rate lower than the discount rate, or if it exists, the Lagrange multiplier on the resource constraint diverges in that steady state. In both cases Aiyagari (1995)'s argument establishing an optimal positive capital income tax in the long run in the economy with endogenous government spending does not extend to the canonical infinite horizon incomplete markets model with exogenous government

\footnotetext{
${ }^{4}$ In Davila et al. (2012) asset-income poor households benefit from an increase of the capital stock and thus wages. Park (2017) introduces endogenous human capital accumulation to this environment so that welfare of human-capital poor households might be improved by lower wages, which adds an additional distribution effect, with welfare implications of changing factor incomes opposite to those studied by Davila et al. (2012).

${ }^{5}$ Building on this work Chamley (2001) develops a partial equilibrium model to clarify that the Chamley-Judd (Judd 1985; Chamley 1986) result of zero optimal capital taxes depends on the assumption of complete markets and breaks down if households face income risk and a borrowing constraint. In Chamley (2001)'s partial equilibrium analysis, the general equilibrium effects that are crucial to our results are missing by construction.
} 
spending. ${ }^{6,7}$ We can characterize, at least for the log-utility case, the entire time path of optimal Ramsey allocations analytically in the OLG model with idiosyncratic income risk, and thus we can demonstrate that the allocation indeed converges to a steady state. Furthermore we obtain a complete characterization of optimal capital tax rates not only in the steady state, but along the entire transition path.

Quantitative work in infinite horizon economies by Dyrda and Pedroni (2016) analyzes optimal fiscal policy along the economy's transition from the status quo to the long-run optimum. They find that the capital income tax is positive and decreasing along the transition, with a long-run optimum of 45 percent. $^{8}$ A similar finding is obtained by Gottardi et al. (2015) in a model with risky human capital originally proposed by Krebs (2003). Açikgöz (2015) also compares optimal long-run with optimal transitional policies. ${ }^{9}$ Whereas idiosyncratic labor income risk plays a key role in these papers, none of them emphasizes how the general equilibrium price effects affect the optimal allocation chosen by the Ramsey planner as we do. A related literature studies optimal capital income taxes in models with idiosyncratic investment risk, see Evans (2014), Panousi (2015), and Panousi and Reis (2017). The key focus of this work is on the role of capital income taxes in providing insurance or redistribution; none of these papers emphasizes the role of general equilibrium feedback from precautionary saving behavior on optimal capital income taxation.

Our work also contributes to the literature on optimal capital income taxation in life-cycle economies. The early literature by Pestieau (1974) and Atkinson and Sandmo (1980) studies optimal taxation with two-period lived households in deterministic general equilibrium models. In extensions to multi-period, deterministic models, Erosa and Gervais (2001, 2002) and Garriga (2017) emphasize that capital

\footnotetext{
${ }^{6}$ In related work, Chien and Wen (2017) develop a tractable Aiyagari-Bewley-Huggett model with preference rather than productivity shocks to address the impact of precautionary saving, through the general equilibrium interest rate, on the fraction of households at the borrowing constraint. Such effects are absent in our work with two period lived ex-ante identical households because borrowing constraints would never be binding in equilibrium.

${ }^{7}$ Heathcote, Storesletten, and Violante (2017) also develop an analytically tractable model with idiosyncratic income risk. They focus on characterizing the optimal progressivity of labor income taxation in a model with infinitely lived households, endogenous labor supply but without capital, rather than on capital income taxes in OLG models with capital, as we do.

${ }^{8}$ In a similar setting Hagedorn et al. (2015) obtain comparable results but argue for a significantly lower level of the capital income tax rate.

${ }^{9}$ These papers extend the work by Domeij and Heathcote (2004) analyzing the welfare consequences of abolishing capital income taxes in a Aiyagari-Bewley-Huggett economy taking into account the transition.
} 
income taxes will only be zero under strong assumptions on preferences, or if labor income tax rates are permitted to depend on household age. ${ }^{10}$ Building on these insights, Conesa et al. (2009) develop an overlapping generations model with uninsurable idiosyncratic labor income risk, and argue that their main finding of strongly positive optimal capital income taxes is driven by the life-cycle structure of th model and the absence of age-dependent labor income taxes. The general equilibrium price effects on the optimal Ramsey policy in general, and of precautionary savings on prices in particular, are not addressed in this body of work.

Finally, our analysis connects to the literature on optimal capital taxation in the Mirrleesian tradition. In models with idiosyncratic risk, the optimal Mirrleesian insurance arrangement calls for a positive capital income tax, see, e.g., Farhi and Werning (2012). Note that the concept of constrained efficiency differs between the literature on exogenously incomplete markets in general equilibrium (as in Davila et al. (2012) and Park (2017)) and the Mirrleesian literature. In the Mirrleesian tradition, constrained efficiency refers to incentive-compatibility constraints that arise from the asymmetry of information between the planner and agents. Constrained efficiency in our context instead refers to the constraint that the planner by assumption cannot directly overcome the frictions implied by missing markets. Thus, the planner can neither redistribute inter-generationally nor intra-generationally. In our two-period set-up with exogenous labor supply and labor income risk in the second period only, the absence of intra-generational redistribution across individuals with different income realizations would also emerge in a Mirrleesian analysis income is private information and the Mirrleesian planner designs incentive compatible allocations. If the Mirrleesian planner is also restricted not to redistribute inter-generationally, the optimal Ramsey allocation coincides with a Mirrleesian optimum, and our results can also be interpreted as optimal taxes in the New Dynamic Public Finance tradition.

The next section 2 presents our model and Section 3 characterizes the competitive equilibrium. Section 4 lays out the solution to the Ramsey problem and presents the analytical solution for logarithmic utility. Section 5 discusses the efficiency properties of the Ramsey equilibrium and gives conditions under which implementing the longrun optimal policy induces a Pareto improving transition. Section 6 presents the generalization of our results to Epstein-Zin-Weil utility and Section 7 concludes.

\footnotetext{
${ }^{10}$ Similar findings are obtained by Peterman (2016) in a quantitative human capital model with a learning by doing mechanism.
} 


\section{Model}

Time is discrete and extends from $t=0$ to $t=\infty$. In each period a new generation is born that lives for two periods. Thus at any point in time there is a young and an old generation. We normalize household size to 1 for each age cohort. In addition there is an initial old generation that has one remaining year of life.

\subsection{Household Preferences and Endowments}

\subsubsection{Endowments}

Each household has one unit of time in both periods, supplied inelastically to the market. Labor productivity when young is equal to $(1-\kappa)$, and, as in Harenberg and Ludwig (2015), in the second period labor productivity is given by $\kappa \eta_{t+1}$, where $\kappa \in[0,1)$ is a parameter that captures relative labor income of the old, and $\eta_{t+1}$ is an idiosyncratic labor productivity shock. We assume that the cdf of $\eta_{t+1}$ is given by $\Psi\left(\eta_{t+1}\right)$ in every period and denote the corresponding pdf by $\psi\left(\eta_{t+1}\right)$. We assume that $\Psi$ is both the population distribution of $\eta_{t+1}$ as well as the cdf of the productivity shock for any given individual (that is, we assume a Law of Large Numbers, LLN henceforth). Whenever there is no scope for confusion we suppress the time subscript of the productivity shock $\eta_{t+1}$. We make the following

Assumption 1. The shock $\eta_{t+1}$ takes positive values $\Psi$-almost surely and

$$
\int \eta_{t+1} d \Psi=1
$$

Each member of the initial old generation is additionally endowed with assets equal to $a_{0}$, equal to the initial capital stock $k_{0}$ in the economy. The asset endowment is independent of the household's realization of the shock $\eta$.

\subsubsection{Preferences}

A household of generation $t \geq 0$ has preferences over consumption allocations $c_{t}^{y}, c_{t+1}^{o}\left(\eta_{t+1}\right)$ given by

$$
V_{t}=u\left(c_{t}^{y}\right)+\beta \int u\left(c_{t+1}^{o}\left(\eta_{t+1}\right)\right) d \Psi .
$$


Lifetime utility of the initial old generation is determined as

$$
V_{-1}=\int u\left(c_{0}^{o}\left(\eta_{0}\right)\right) d \Psi
$$

In order to obtain the sharpest analytical results in the first part of the paper we will assume logarithmic utility:

Assumption 2. The utility function $u$ is logarithmic, $u(c)=\log (c)$.

We will generalize our results to a general Epstein-Zin-Weil (Epstein and Zin 1989; Epstein and Zin 1991; Weil 1989) utility function, which nests constant relative risk aversion (CRRA) preferences, in Section 6 of the paper.

\subsection{Technology}

The representative firm operates the Cobb-Douglas production technology:

$$
F\left(K_{t}, L_{t}\right)=K_{t}^{\alpha}\left(L_{t}\right)^{1-\alpha}
$$

Furthermore we assume that capital fully depreciates between two (30 year) periods.

\subsection{Government}

The government levies a potentially time varying capital tax $\tau_{t}$ on capital, and rebates the proceeds in a lump-sum fashion to all members of the current old generation as a transfer $T_{t}$. We assume the government has the following social welfare function

$$
S W F=\sum_{t=-1}^{\infty} \omega_{t} V_{t}
$$

where $\left\{\omega_{t}\right\}_{t=-1}^{\infty}$ are the Pareto weights on different generations and satisfy $\omega_{t} \geq 0$. Since lifetime utilities of each generation will be bounded, so will be the social welfare function as long as $\sum_{t=-1}^{\infty} \omega_{t}<\infty$. We will also consider the case $\omega_{t}=1$ for all $t$, in which case we will take the social welfare function to be defined as

$$
S W F=\lim _{T \rightarrow \infty} \frac{\sum_{t=-1}^{T} V_{t}}{T},
$$

which is equivalent to maximizing steady state welfare. 


\subsection{Competitive Equilibrium}

\subsubsection{Household Budget Set and Optimization Problem}

The budget constraints in both periods read as

$$
\begin{aligned}
c_{t}^{y}+a_{t+1} & =(1-\kappa) w_{t} \\
c_{t+1}^{o} & =a_{t+1} R_{t+1}\left(1-\tau_{t+1}\right)+\kappa \eta_{t+1} w_{t+1}+T_{t+1},
\end{aligned}
$$

where $w_{t}, w_{t+1}$ are the aggregate wages in period $t$ and $t+1, R_{t+1}=1+r_{t+1}$ is the gross interest rate between period $t$ and $t+1$, and $T_{t+1}$ are lump-sum transfers to the old generation, and $\eta_{t+1}$ is the age- 2 period- $t+1$ idiosyncratic shock to wages. $^{11}$

\subsubsection{Firm Optimization}

From the firms first order conditions we get

$$
\begin{aligned}
& R_{t}=\alpha k_{t}^{\alpha-1} \\
& w_{t}=(1-\alpha) k_{t}^{\alpha}
\end{aligned}
$$

where

$$
k_{t}=\frac{K_{t}}{L_{t}}=\frac{K_{t}}{1-\kappa+\kappa \int \eta_{t} d \Psi}=K_{t}
$$

is the capital-labor ratio. Since $L_{t}=1$, we henceforth do not need to distinguish between the aggregate capital stock $K_{t}$ and the capital-labor ratio.

\subsubsection{Equilibrium Definition}

Definition 1. Given initial condition $a_{0}=k_{0}$ an allocation is a sequence $\left\{c_{t}^{y}, c_{t}^{o}\left(\eta_{t}\right), L_{t}, a_{t+1}, k_{t+1}\right\}_{t=0}^{\infty}$.

Definition 2. Given the initial condition $a_{0}=k_{0}$ and a sequence of tax policies

\footnotetext{
${ }^{11}$ Notice that instead of working with a tax on capital $\tau_{t}$, one could work, completely equivalently, with a (standard) capital income tax $\tau_{t}^{k}$ given by

$$
1+r_{t}\left(1-\tau_{t}^{k}\right)=\left(1+r_{t}\right)\left(1-\tau_{t}\right)
$$

and thus

$$
\tau_{t}^{k}=1-\frac{R_{t}\left(1-\tau_{t}\right)-1}{R_{t}-1}
$$

ignoring the knife-edge case $R_{t}=1$.
} 
$\boldsymbol{\tau}=\left\{\tau_{t}\right\}_{t=0}^{\infty}$, a competitive equilibrium is an allocation $\left\{c_{t}^{y}, c_{t}^{o}, L_{t}, a_{t+1}, k_{t+1}\right\}_{t=0}^{\infty}$, prices $\left\{R_{t}, w_{t}\right\}_{t=0}^{\infty}$ and transfers $\left\{T_{t}\right\}_{t=0}^{\infty}$ such that

1. given prices $\left\{R_{t}, w_{t}\right\}_{t=0}^{\infty}$ and policies $\left\{\tau_{t}, T_{t}\right\}_{t=0}^{\infty}$ for each $t \geq 0,\left(c_{t}^{y}, c_{t+1}^{o}\left(\eta_{t+1}\right), a_{t+1}\right)$ maximizes (1) subject to (2) and (3) (for each realization of $\eta_{t+1}$ );

2. consumption $c_{0}^{o}\left(\eta_{0}\right)$ of the initial old satisfies (3) (for each realization of $\eta_{0}$ ):

$$
c_{0}^{o}=a_{0} R_{0}\left(1-\tau_{0}\right)+\kappa \eta_{0} w_{0}+T_{0}
$$

3. prices satisfy equations (4) and (5);

4. the government budget constraint is satisfied in every period: for all $t \geq 0$

$$
T_{t}=\tau_{t} R_{t} k_{t}
$$

5. markets clear

$$
\begin{aligned}
L_{t} & =L=1 \\
a_{t+1} & =k_{t+1} \\
c_{t}^{y}+\int c_{t}^{o}\left(\eta_{t}\right) d \Psi+k_{t+1} & =k_{t}^{\alpha} .
\end{aligned}
$$

Denote by $S W F(\boldsymbol{\tau})$ social welfare associated with an equilibrium for given tax policy $\boldsymbol{\tau}$. As we will show below, for a given tax policy $\boldsymbol{\tau}$ the associated competitive equilibrium in our economy exists and is unique and thus the function $S W F(\boldsymbol{\tau})$ is well-defined as long as $\tau_{t} \in(-\infty, 1)$ for all $t$.

Definition 3. Given the initial condition $a_{0}=k_{0}$, a Ramsey equilibrium is a sequence of tax policies $\hat{\boldsymbol{\tau}}=\left\{\hat{\tau}_{t}\right\}_{t=0}^{\infty}$ and equilibrium allocations, prices and transfers associated with $\hat{\boldsymbol{\tau}}$ (in the sense of the previous definition) such that

$$
\hat{\boldsymbol{\tau}} \in \arg \max _{\boldsymbol{\tau}} S W F(\boldsymbol{\tau}) .
$$




\section{Analysis of Equilibrium for a Given Tax Policy}

\subsection{Partial Equilibrium}

We first analyze the household problem for given prices and policies. We proceed under the assumption that a unique solution characterized by the Euler equation exists, and then make sufficient parametric assumptions to insure that this is indeed the case.

The optimal asset choice $a_{t+1}$ satisfies

$$
1=\beta\left(1-\tau_{t+1}\right) \int \frac{R_{t+1}\left[u^{\prime}\left(a_{t+1} R_{t+1}\left(1-\tau_{t+1}\right)+\kappa \eta_{t+1} w_{t+1}+T_{t+1}\right)\right]}{u^{\prime}\left((1-\kappa) w_{t}-a_{t+1}\right)} d \Psi\left(\eta_{t+1}\right) .
$$

Defining the saving rate as

$$
s_{t}=\frac{a_{t+1}}{(1-\kappa) w_{t}}
$$

we can rewrite the above equation as

$$
1=\beta\left(1-\tau_{t+1}\right) \int \frac{R_{t+1}\left[u^{\prime}\left(s_{t} R_{t+1}\left(1-\tau_{t+1}\right)(1-\kappa) w_{t}+\kappa \eta_{t+1} w_{t+1}+T_{t+1}\right)\right]}{u^{\prime}\left[(1-\kappa) w_{t}\left(1-s_{t}\right)\right]} d \Psi\left(\eta_{t+1}\right)
$$

which defines the solution

$$
s_{t}=s_{t}\left(w_{t}, w_{t+1}, R_{t+1}, \tau_{t+1}, T_{t+1} ; \beta, \kappa, \Psi\right)
$$

Note by assumption 1 that consumption in the second period is positive $\Psi$-almost surely. Without further assumptions on the fundamentals we cannot make analytical progress. Therefore now invoke assumption 2 that the utility function is logarithmic. Then the Euler equation becomes:

$$
1=\beta\left(1-\tau_{t+1}\right) \int \frac{1-s_{t}}{s_{t}\left(1-\tau_{t+1}\right)+\frac{\kappa w_{t+1}}{(1-\kappa) w_{t} R_{t+1}} \eta_{t+1}+\frac{T_{t+1}}{(1-\kappa) w_{t} R_{t+1}}} d \Psi\left(\eta_{t+1}\right)
$$

Equation (7) implicitly defines the optimal partial equilibrium saving rate $s_{t}=$ $s\left(w_{t}, w_{t+1}, R_{t+1}, \tau_{t+1}, T_{t+1} ; \beta, \kappa \Psi\right)$. 


\subsection{General Equilibrium}

Now we exploit the remaining equilibrium conditions. In equilibrium factor prices and transfers are given by

$$
\begin{aligned}
w_{t} & =(1-\alpha) k_{t}^{\alpha} \\
w_{t+1} & =(1-\alpha) k_{t+1}^{\alpha} \\
R_{t+1} & =\alpha k_{t+1}^{\alpha-1} \\
T_{t+1} & =\tau_{t+1} R_{t+1} k_{t+1}
\end{aligned}
$$

From the definition of the saving rate $s_{t}=\frac{a_{t+1}}{(1-\kappa) w_{t}}$ and market clearing in the asset market, which implies $a_{t+1}=k_{t+1}$, we find that

$$
k_{t+1}=a_{t+1}=(1-\kappa) s_{t} w_{t}
$$

and thus

$$
k_{t+1}=s_{t}(1-\kappa)(1-\alpha) k_{t}^{\alpha}
$$

In general, for a given sequence of capital taxes $\left\{\tau_{t}\right\}_{t=0}^{\infty}$ the competitive equilibrium is a sequence of capital stocks $\left\{k_{t+1}\right\}_{t=0}^{\infty}$ that solves, for a given initial condition $k_{0}$, the first order difference equation (7) when factor prices have been substituted

$$
\begin{aligned}
1 & =\alpha \beta\left(1-\tau_{t+1}\right) k_{t+1}^{\alpha-1} \int\left(\frac{\left[\kappa \eta_{t+1}(1-\alpha)+\alpha\right] k_{t+1}^{\alpha}}{(1-\kappa)(1-\alpha) k_{t}^{\alpha}-k_{t+1}}\right)^{-1} d \Psi\left(\eta_{t+1}\right) \\
& =\alpha \beta\left(1-\tau_{t+1}\right)\left(\frac{(1-\kappa)(1-\alpha) k_{t}^{\alpha}-k_{t+1}}{k_{t+1}}\right) \Gamma,
\end{aligned}
$$

where the constant

$$
\Gamma=\int\left(\kappa \eta_{t+1}(1-\alpha)+\alpha\right)^{-1} d \Psi\left(\eta_{t+1}\right)=\Gamma(\alpha, \kappa ; \Psi)
$$

fully captures the impact of idiosyncratic income risk on the equilibrium dynamics of the capital stock.

Equation (13) implicitly defines the function $k_{t+1}=\Omega\left(k_{t}, \tau_{t+1}\right)$. Alternatively, and often more conveniently, instead of expressing the solution as $k_{t+1}=\Omega\left(k_{t}, \tau_{t+1}\right)$, we 
can also express it in terms of the saving rate as

$$
s_{t}=\frac{k_{t+1}}{(1-\alpha)(1-\kappa) k_{t}^{\alpha}}=\frac{\Omega\left(k_{t}, \tau_{t+1}\right)}{(1-\alpha)(1-\kappa) k_{t}^{\alpha}}=\Lambda\left(k_{t}, \tau_{t+1}\right)
$$

where the function $s_{t}=\Lambda\left(k_{t}, \tau_{t+1}\right)$ solves (using the definition of the saving rate in equation (13)):

$$
1=\alpha \beta\left(1-\tau_{t+1}\right)\left(\frac{1-s_{t}}{s_{t}}\right) \Gamma
$$

\subsection{Characterization of the Saving Rate}

Evidently, equation (16) has a closed form solution for the saving rate $s_{t}$ in general equilibrium, and we can give a complete analytical characterization of its comparative statics properties.

Proposition 1. Suppose assumptions 1 and 2 are satisfied. Then for all $k_{t}>0$ and all $\tau_{t+1} \in(-\infty, 1]$ the unique saving rate $s_{t}=\Lambda\left(k_{t}, \tau_{t+1} ; \Gamma\right)$ is given by

$$
s_{t}=\frac{1}{1+\left[\left(1-\tau_{t+1}\right) \alpha \beta \Gamma(\alpha, \kappa ; \Psi)\right]^{-1}},
$$

which is strictly increasing in $\Gamma$, strictly decreasing in $\tau_{t+1}$ and independent of the beginning of the period capital stock.

The next corollary assures that any desired saving rate $s_{t} \in(0,1]$ can be implemented as part of a competitive equilibrium by appropriate choice of the capital tax rate $\tau_{t+1}$. This corollary is crucial for our approach of solving the optimal Ramsey tax problem, since we can cast that problem directly in terms of the government choosing saving rates rather than tax rates.

Corollary 1. For each saving rate $s_{t} \in(0,1]$ there exists a unique tax rate $\tau_{t+1} \in$ $(-\infty, 1)$ that implements that saving rate $s_{t}$ as part of a competitive equilibrium.

Finally we want to determine the influence of income risk on the saving rate in general equilibrium. From proposition 1 we know that the saving rate depends on income risk $\eta$ exclusively through the constant $\Gamma$. Furthermore, $\Gamma$ is a strictly convex function of income risk $\eta$, and thus by Jensen's inequality we have the following:

Observation 1. Assume that $\alpha \in(0,1)$ and $\kappa>0$. Then 
1. The constant $\Gamma(\alpha, \kappa ; \Psi)$ is strictly increasing in the amount of income risk, in the sense that if the distribution $\tilde{\Psi}$ over $\eta$ is a mean-preserving spread of $\Psi$, then $\Gamma(\alpha, \kappa ; \Psi)<\Gamma(\alpha, \kappa ; \tilde{\Psi})$.

2. Define the degenerate distribution at $\eta \equiv 1$ as $\bar{\Psi}$, then for any nondegenerate $\Psi$

$$
1<\bar{\Gamma}:=\Gamma(\alpha, \kappa ; \bar{\Psi})<\Gamma(\alpha, \kappa ; \Psi)
$$

We can immediately deduce the following:

Corollary 2. The equilibrium saving rate is strictly increasing in the amount of income risk.

The proof of this result follows directly from the fact that $s_{t}=\Lambda\left(k_{t}, \tau_{t+1} ; \Gamma\right)$ is strictly increasing in $\Gamma$ and $\Gamma$ is strictly increasing in the amount of income risk. Equipped with this full characterization of the competitive equilibrium for a given sequence of tax policies $\left\{\tau_{t+1}\right\}_{t=0}^{\infty}$ we now turn to the analysis of optimal fiscal policy.

\section{The Ramsey Problem}

The objective of the government is to maximize social welfare $W\left(k_{0}\right)=\sum_{t=-1}^{\infty} \omega_{t} V_{t}$ by choice of capital taxes $\left\{\tau_{t+1}\right\}_{t=0}^{\infty}$ where $V_{t}$ is the lifetime utility of generation $t$ in the competitive equilibrium associated with the sequence $\left\{\tau_{t+1}\right\}_{t=0}^{\infty}$. We start with general preferences and later again invoke assumption 2 that the utility function is logarithmic. Making use of corollary 1 we can substitute out taxes to write lifetime utility in terms of the saving rate $s_{t}$ yielding

$V\left(k_{t}, s_{t}\right)=u\left(\left(1-s_{t}\right)(1-\kappa)(1-\alpha) k_{t}^{\alpha}\right)+\beta \int u\left(\kappa \eta_{t+1} w\left(s_{t}\right)+R\left(s_{t}\right) s_{t}(1-\kappa)(1-\alpha) k_{t}^{\alpha}\right) d \Psi\left(\eta_{t+1}\right)$,

where

$$
\begin{aligned}
w\left(s_{t}\right) & =(1-\alpha)\left[k_{t+1}\left(s_{t}\right)\right]^{\alpha} \\
R\left(s_{t}\right) & =\alpha\left[k_{t+1}\left(s_{t}\right)\right]^{\alpha-1} \\
k_{t+1}\left(s_{t}\right) & =s_{t}(1-\kappa)(1-\alpha) k_{t}^{\alpha} .
\end{aligned}
$$


We could of course substitute factor prices in the lifetime utility function, but for the purpose of better interpretation of the results we refrain from doing so at this moment.

Finally, remaining lifetime utility of the initial old generation is given by (with factor prices already substituted out)

$$
V_{-1}=V\left(k_{0}, \tau_{0}\right)=\int u\left(\left[\alpha+\kappa \eta_{0}(1-\alpha)\right] k_{0}^{\alpha}\right) d \Psi\left(\eta_{0}\right)=V\left(k_{0}\right)
$$

Note that $\tau_{0}$ is irrelevant for welfare of the initial old generation (and all future generations) and can be set arbitrarily. This is due to the fact that $\tau_{0}$ is nondistortionary, is lump-sum rebated and (most crucially) that the government is assumed to have a period-by-period budget balance. In fact, expression (22) shows that with the set of policies we consider lifetime utility of the initial old cannot be affected at all, which is useful since we therefore do not need to include it in the social welfare function.

By corollary 1 the Ramsey government can implement any sequence of savings rates $\left\{s_{t}\right\}_{t=0}^{\infty}$ as a competitive equilibrium and thus can choose private savings rates directly. We therefore can restate the problem the Ramsey government solves as

$$
W\left(k_{0}\right)=\max _{\left\{s_{t}\right\}_{t=0}^{\infty}} \sum_{t=0}^{\infty} \omega_{t} V\left(k_{t}, s_{t}\right)
$$

subject to (19)-(21).

In the remainder of this section we now fully characterize the solution to the Ramsey problem. We can do so for arbitrary social welfare weights $\left\{\omega_{t}\right\}_{t=0}^{\infty}$ using the sequential formulation of the problem, as Appendix B shows. In the main text we exploit the recursive formulation of the problem, which requires a stationarity assumption on the social welfare weights (Assumption 3 below), but allows us to arrive at the solution rather immediately.

\subsection{Recursive Formulation and Characterization of the Ram- sey Problem}

The Ramsey problem lends itself to a recursive formulation, under the following assumption on the social welfare weights: 
Assumption 3. The social welfare weights satisfy, for all $t \geq 0, \omega_{t}>0$ and

$$
\frac{\omega_{t+1}}{\omega_{t}}=\theta \in(0,1)
$$

Under this assumption, the recursive formulation of the problem reads as

$$
\begin{aligned}
W(k)= & \max _{s \in[0,1)} u\left((1-s)(1-\kappa)(1-\alpha) k^{\alpha}\right) \\
& +\beta \int u\left(\kappa \eta w(s)+R(s) s(1-\kappa)(1-\alpha) k^{\alpha}\right) d \Psi(\eta)+\theta W\left(k^{\prime}(s)\right) \\
& \text { s.t. } \\
k^{\prime}(s)= & s(1-\kappa)(1-\alpha) k^{\alpha} \\
R(s)= & \alpha\left[k^{\prime}(s)\right]^{\alpha-1} \\
w(s)= & (1-\alpha)\left[k^{\prime}(s)\right]^{\alpha}
\end{aligned}
$$

This perhaps unusual way of writing the problem clarifies the three effects the Ramsey government considers when choosing the saving rate $s$ in the current period. ${ }^{12}$ First, there is the direct effect of reduced consumption when young and increased consumption when old, henceforth denoted by $P E(s)$. Second, there is the indirect, general equilibrium effect on the current generation of changed wages and rates of return when old, which we denote as $G E(s)$. And third, there is the impact on future generations from a changed capital stock induced by a change in the current saving rate, denoted by $F G(s)$.

Taking first order conditions yields

$$
\begin{aligned}
0= & (1-\kappa)(1-\alpha) k^{\alpha}\left[-u^{\prime}\left(c^{y}\right)+R(s) \beta \int u^{\prime}\left(c^{o}(\eta)\right) d \Psi(\eta)\right] \\
& +\beta \int u^{\prime}\left(c^{o}(\eta)\right)\left[\kappa \eta w^{\prime}(s)+(1-\kappa)(1-\alpha) k^{\alpha} R^{\prime}(s) s\right] d \Psi(\eta) \\
& +\theta W^{\prime}\left(k^{\prime}(s)\right) \frac{d k^{\prime}(s)}{d s} \\
= & P E(s)+G E(s)+F G(s)
\end{aligned}
$$

We make the following observations:

\footnotetext{
${ }^{12}$ Or equivalently, when choosing the tax rate $\tau^{\prime}$ that then induces private households to choose the saving rate $s$.
} 
1. Denote by $s^{C E}$ the saving rate households would choose in the competitive equilibrium with zero capital taxes. Then $P E\left(s^{C E}\right)=0$.

2. In Appendix A we show that the general equilibrium effect can be written as

$$
G E(s)=(1-\alpha) \alpha\left[(1-\kappa)(1-\alpha) k^{\alpha}\right]^{\alpha}[s]^{\alpha-1} \beta \int u^{\prime}\left(c^{o}(\eta)\right)[\kappa \eta-1] d \Psi(\eta)
$$

and thus the sign of the general equilibrium benefit of an extra unit of savings for the current generation is determined by the term

$$
\int u^{\prime}\left(c^{o}(\eta)\right)[\kappa \eta-1] d \Psi(\eta)=\int u^{\prime}\left(\kappa \eta w(s)+R(s) s(1-\kappa)(1-\alpha) k^{\alpha}\right)[\kappa \eta-1] d \Psi(\eta)
$$

If $\kappa=0$, then the old do not have labor income, and thus the impact of higher savings and consequently a larger capital stock is unambiguously negative, due to a lower return on saving when old. If, on the other hand, $\kappa$ is large, wages when old are important for this generation which calls, ceteris paribus, for a larger saving rate. Note that the magnitude of a change in factor prices induced by a change in saving rates is purely determined from the production side of the economy. The utility value to the household and thus to the Ramsey government of these factor price movements, however, depends on the utility function since it determines the size of the covariance between $u^{\prime}\left(c^{o}(\eta)\right)$ and $\eta$ (which is negative). If households are risk-neutral (or there is no risk), then the sign of $G E(s)$ is given by $\kappa-1$ which is negative, leading to a reduced incentive to save due to general equilibrium effects, and an associated extra incentive to tax capital income. With risk the sign of $G E(s)$ is determined by the sign of

$$
\begin{aligned}
E\left[u^{\prime}\left(c^{o}(\eta)\right)(\kappa \eta-1)\right] & =(\kappa-1) E\left[u^{\prime}\left(c^{o}(\eta)\right)\right]+\operatorname{Cov}\left[u^{\prime}\left(c^{o}(\eta)\right),(\kappa \eta-1)\right] \\
& <(\kappa-1) E\left[u^{\prime}\left(c^{o}(\eta)\right)\right]<0
\end{aligned}
$$

and thus there is an extra disincentive to save from the general equilibrium effect: higher wages exacerbate idiosyncratic income and thus consumption risk and thus it is optimal for the social planner to reduce labor income risk by reducing savings incentives, other things equal.

3. The effect of a higher saving rate today on future generations through a higher 
capital stock from tomorrow on, $k^{\prime}(s)$, is encoded in the term

$$
F G(s)=\theta W^{\prime}\left(k^{\prime}(s)\right) \frac{d k^{\prime}(s)}{d s}=(1-\kappa)(1-\alpha) k^{\alpha} \theta W^{\prime}\left(k^{\prime}(s)\right)>0
$$

and depends on the relative social welfare weights of future generations $\theta=\frac{\omega_{t+\tau}}{\omega_{t}}$.

Figure 1 plots the terms $P E(s), G E(s), F G(s)$ as well as their sum against the saving rate $s$ for a parametric example, and fixing a current (or initial) capital stock $k{ }^{13}$ We observe that, as expected, $F G(s)$ is always positive (the marginal benefit from a higher saving rate on future generations through a higher capital stock is always positive). Also, as argued in item 2 above, $G E(s)$ is always negative, and thus calls for a lower saving rate and higher capital income tax rate. Finally, the $P E(s)$ line shows where the competitive equilibrium saving rate absent government policies is located (at the intersection between $P E(s)$ and the zero line). The sum $P E(s)+G E(s)+F G(s)$ displays the optimal Ramsey saving rate $s$ (intersection with the zero line). In this example the $F G$ effect dominates the $G E$ effect and the saving rate $s^{*}$ chosen by the Ramsey government exceeds that emerging in the unregulated competitive equilibrium $s^{C E}$. Of course this is not a general result; for example, if $\theta=0$ and future generations are not valued at all, one would obtain $s^{*}<s^{C E}$.

\subsection{Explicit Solution of the Ramsey Tax Problem}

We now provide a complete analytical characterization of the Ramsey optimal policy problem under the assumption 2 that utility is logarithmic. As in the standard neoclassical growth model, the recursive version of the Ramsey problem with log-utility has a unique closed-form solution, which can be obtained by the method of undetermined coefficients. To this end, guess that the value function takes the following log-linear form:

$$
W(k)=\Theta_{0}+\Theta_{1} \log (k) .
$$

\footnotetext{
${ }^{13}$ We will show below that for the logarithmic case the Ramsey saving rate is independent of the current capital stock, and since we display an example with $\sigma=1$ in the plot, the dependence of $s$ on $k$ is actually moot here.
} 
Figure 1: Decomposition of Optimal Saving Rate Determination

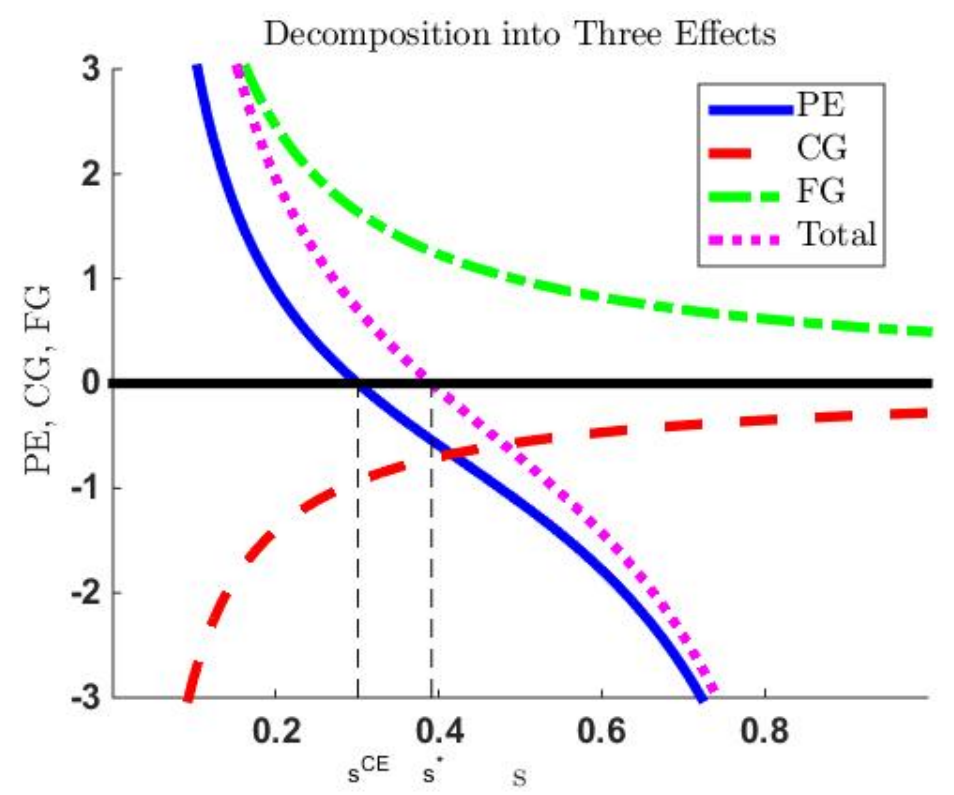

Notes: Decomposition of Ramsey planner's first-order condition into $P E(s), G E(s)$, and $F G(s)$. The intersection with the zero line gives the optimal saving rate $s^{*}$.

Using this guess and equations (25)-(27) rewrite the Bellman equation (24) as:

$$
\begin{aligned}
W(k)= & \Theta_{0}+\Theta_{1} \log (k) \\
= & \max _{s \in[0,1]}\left\{\log \left((1-s)(1-\kappa)(1-\alpha) k^{\alpha}\right)\right. \\
& \left.+\beta \int \log \left(\kappa \eta w(s)+R(s) s(1-\kappa)(1-\alpha) k^{\alpha}\right) d \Psi(\eta)+\theta W\left(k^{\prime}\right)\right\} \\
= & \log ((1-\kappa)(1-\alpha))+\alpha \beta \log ((1-\kappa)(1-\alpha)) \\
& +\int \log (\kappa \eta(1-\alpha)+\alpha) d \Psi(\eta)+\theta \Theta_{0}+\theta \Theta_{1} \log [(1-\kappa)(1-\alpha)] \\
& +\left[\alpha+\alpha^{2} \beta+\alpha \theta \Theta_{1}\right] \log (k)+\max _{s \in[0,1]}\left\{\log (1-s)+\left(\alpha \beta+\theta \Theta_{1}\right) \log (s)\right\} .
\end{aligned}
$$

For the Bellman equation to hold, the coefficient $\Theta_{1}$ has to satisfy

$$
\Theta_{1}=\alpha+\alpha^{2} \beta+\alpha \theta \Theta_{1}
$$


or

$$
\Theta_{1}=\frac{\alpha(1+\alpha \beta)}{(1-\alpha \theta)}
$$

We also immediately recognize that the optimal saving rate chosen by the Ramsey planner is independent of the capital stock $k$ and determined by the first order condition

$$
\frac{1}{1-s}=\frac{\alpha \beta+\theta \Theta_{1}}{s}
$$

and thus

$$
s^{*}=\frac{\alpha \beta+\theta \Theta_{1}}{1+\alpha \beta+\theta \Theta_{1}}=\frac{\alpha(\beta+\theta)}{1+\alpha \beta} .
$$

Plugging in $s^{*}$ and $\Theta_{1}$ into the Bellman equation (28) yields a linear equation in the constant $\Theta_{0}$ whose solution completes the full analytical characterization of the Ramsey optimal taxation problem, summarized in the following

Proposition 2. Suppose assumptions 1, 2 and 3 are satisfied. Then the solution of the Ramsey problem is characterized by a constant saving rate

$$
s_{t}=s^{*}=\frac{\alpha(\beta+\theta)}{1+\alpha \beta}
$$

and a sequence of capital stocks that satisfy

$$
k_{t+1}=s^{*}(1-\kappa)(1-\alpha) k_{t}^{\alpha}
$$

with initial condition $k_{0}$. The associated value function is given by

$$
W(k)=\Theta_{0}+\frac{\alpha(1+\alpha \beta)}{(1-\alpha \theta)} \log (k)
$$

with derivative

$$
W^{\prime}(k)=\frac{\alpha(1+\alpha \beta)}{(1-\alpha \theta) k} .
$$

The Ramsey allocation is implemented with constant capital taxes $\tau=\tau(\beta, \theta, \kappa, \alpha ; \Psi)$ satisfying

$$
1-\tau=\frac{(\theta+\beta)}{(1-\alpha \theta) \beta \Gamma(\alpha, \kappa ; \Psi)},
$$

where $\Gamma$ is a positive constant that is defined in equation (14) and just depends on 
parameters. ${ }^{14}$

Corollary 3. The optimal saving rates are independent of the extent of income risk in the economy and strictly increasing in the social discount factor $\theta$ and the individual discount factor $\beta$.

Corollary 4. The optimal capital tax rates are strictly increasing in the extent of income risk (as measured by $\Gamma$ ), strictly decreasing in $\theta$, strictly increasing in $\beta$ and strictly decreasing in the labor income share $\kappa$ of the old.

It is noteworthy that not only is the optimal saving rate constant and does not depend on the level of the capital stock, but it also is independent of the extent of income risk $\eta$. This is true despite the fact that for a given tax policy higher income risk induces a higher individually optimal saving rate, as shown in section 3.3. The Ramsey government finds it optimal to exactly offset this effect with a capital tax that is increasing in the amount of income risk, cancelling out exactly the partial equilibrium incentive to save more as income risk increases.

One advantage of the complete characterization of the recursive problem, relative to the sequential formulation in Appendix $\mathrm{B}$, is that we can now give a clean decomposition of the three forces determining the optimal Ramsey saving rate. We now find that

$$
\begin{aligned}
P E(s) & =\frac{-1}{(1-s)}+\frac{\alpha \beta}{s} \Gamma(\alpha, \kappa ; \Psi) \\
G E(s) & =\frac{\alpha \beta}{s}[1-\Gamma(\alpha, \kappa ; \Psi)] \\
F G(s) & =\frac{\theta \alpha(1+\alpha \beta)}{(1-\alpha \theta) s}
\end{aligned}
$$

where we note that that

$$
\Gamma(\alpha, \kappa ; \Psi)>\frac{1}{\kappa(1-\alpha)+\alpha} \geq 1
$$

\footnotetext{
${ }^{14}$ Appendix B shows, using the sequential formulation of the problem, that for arbitrary welfare weights the optimal saving rate is still independent of the capital stock and given by

$$
s_{t}=\frac{1}{1+\left(\alpha \beta+\alpha(1+\alpha \beta) \sum_{j=1}^{\infty} \frac{\omega_{t+j}}{\omega_{t}} \alpha^{j-1}\right)^{-1}}
$$

The saving rate in the proposition is a special case under the assumption $\frac{\omega_{t+1}}{\omega_{t}}=\theta$ for all $t$.
} 
and where the first inequality is strict as long as $\Psi$ is nondegenerate and $\kappa>0$, and the second inequality is strict as long as $\kappa<1$. Thus $[1-\Gamma(\alpha, \kappa ; \Psi)] \leq 0$, with strict inequality if $\kappa<1$. We find that

$$
\begin{aligned}
& P E(s) \gtreqless 0, P E^{\prime}(s)<0 \\
& G E(s)<0, G E^{\prime}(s)>0 \\
& F G(s)>0, F G^{\prime}(s)<0 .
\end{aligned}
$$

Recall that the saving rate $s^{C E}$ in the competitive equilibrium with zero taxes satisfies $P E\left(s^{C E}\right)=0$. This implies that, starting from zero taxes, the only reason to tax capital is the general equilibrium effect which unambiguously pushes the desired saving rate down and the tax rate up (i.e. makes it positive). Against this works the future generations effect (whose size is controlled by $\theta$ ) and calls unambiguously for a higher saving rate and thus a lower (i.e. negative) tax rate.

Also note that

$$
\begin{aligned}
P E(s)+G E(s) & =\frac{-1}{(1-s)}+\frac{\alpha \beta}{s} \Gamma(\alpha, \kappa ; \Psi)+\frac{\alpha \beta}{s}[1-\Gamma(\alpha, \kappa ; \Psi)] \\
& =\frac{-1}{(1-s)}+\frac{\alpha \beta}{s}
\end{aligned}
$$

and thus the partial equilibrium incentive to save more when income risk rises is exactly cancelled out by the general equilibrium effect on factor prices. Thus the simple solution with log-utility of the Ramsey problem masks the presence of a partial equilibrium and a general equilibrium effect that turn out to exactly cancel each other out.

\subsection{Discussion of Optimal Tax Rates}

In this section we use the sharp characterization of optimal Ramsey saving rates and capital taxes from equation (30) to discuss further properties of the optimal Ramsey capital tax rates. The following proposition, which follows immediately from inspection of (30), gives conditions under which the optimal Ramsey capital tax is positive, and, in contrast, conditions under which capital is subsidized. For the next proposition, recall that for $\theta=0$ only the utility of the first generation receives weight in the social welfare function, whereas $\theta=1$ amounts to the Ramsey government 
maximizing steady state welfare.

Proposition 3. There is a threshold social discount factor $\bar{\theta}$ such that for all $\theta \geq \bar{\theta}$ capital is subsidized in every period whereas for all $\theta<\bar{\theta}$ it is taxed in every period. This threshold is explicitly given as

$$
\bar{\theta}=\frac{(\Gamma-1) \beta}{1+\alpha \beta \Gamma}>0
$$

Corollary 5. If $\bar{\theta} \geq 1$, then capital is taxed even when the Ramsey government maximizes steady state welfare. If $\bar{\theta}<1$ then the government should subsidize capital when the Ramsey government maximizes steady state welfare. If the government maximizes welfare of only the initial generation $(\theta=0)$ it should unambiguously tax capital.

Note that these results also apply to the model without income risk. In that case, which provides a useful benchmark to interpret the general findings, note that the optimal Ramsey capital tax from equation (30) is given by

$$
\tau=1-\frac{(\theta / \beta+1)(1-(1-\kappa)(1-\alpha))}{(1-\alpha \theta)}
$$

If $\theta=0$ and the Ramsey government only values the first generation (as effectively, in the simple model of Krusell et al. (2012)), the future generations term $F G(s)$ is absent, and the optimal capital tax is given by

$$
\tau=(1-\kappa)(1-\alpha)
$$

Thus capital is taxed at a strictly positive rate (recall that $\kappa \in[0,1)$ ). Since taxes with income risk are higher than without, the capital tax rate $\tau$ is strictly positive for any degenerate distribution of the income shock if $\theta=0$.

At the other extreme, suppose that $\theta=1$. Then

$$
\tau=1-\frac{(1 / \beta+1)(1-(1-\kappa)(1-\alpha))}{(1-\alpha)}
$$

and we show in appendix C.3 that in this case $\tau<0$ if and only if the competitive equilibrium without taxes is dynamically efficient (i.e. has an interest rate $R>1$, or equivalently, a capital stock below the golden rule capital stock $k^{G R}$ ). 
This suggests the possibility that without income risk the competitive economy is dynamically efficient and the government optimally subsidizes capital in the steady state, but with sufficiently large income risk the result reverses and the Ramsey government finds it optimal to tax capital in the steady state. The following proposition, again proved in appendix C.3, shows that this is indeed the case.

Proposition 4. Let $\theta=1$ such that the Ramsey government maximizes steady state welfare, and denote by $s^{*}$ the associated optimal saving rate. Furthermore denote by $s_{0}(\eta)$ the steady state equilibrium saving rate in the absence of government policy and by $s^{G R}$ the golden rule saving rate that maximizes steady state aggregate consumption. Finally assume that $\beta<[(1-\alpha) \bar{\Gamma}-1]^{-1}$.

1. Let income risk be large: $\Gamma>\frac{1}{\beta[(1-\alpha)-1 / \bar{\Gamma}]}$. Then the steady state competitive equilibrium is dynamically inefficient, $s^{G R}<s_{0}(\eta)$, and $s^{*}<s_{0}(\eta)$, and the optimal capital tax rate has $\tau>0$.

2. Let income risk be intermediate:

$$
\Gamma \in\left(\frac{1+\beta}{(1-\alpha) \beta}, \frac{1}{[(1-\alpha)-1 / \bar{\Gamma}] \beta}\right)
$$

Then the steady state competitive equilibrium is dynamically efficient, $s^{*}<$ $s_{0}(\eta)<s^{G R}$, but optimal capital taxes are nevertheless positive.

3. Let income risk be small:

$$
\Gamma \in\left[\bar{\Gamma}, \frac{1+\beta}{(1-\alpha) \beta}\right)
$$

Then the steady state competitive equilibrium is dynamically efficient, $s_{0}(\eta)<$ $s^{G R}$, and $s_{0}(\eta)<s^{*}$, and optimal capital taxes are negative.

Note that if condition $\beta<[(1-\alpha) \bar{\Gamma}-1]^{-1}$ is violated, then the steady state competitive equilibrium is dynamically inefficient and the optimal capital tax rate is positive for all degrees of income risk. The interesting result is case 2: in the presence of income risk the Ramsey government maximizing steady state welfare might want to tax capital even though this reduces aggregate consumption (since the equilibrium capital stock is not inefficiently high) because of the GE effect: a lower capital stock shifts away income from risky labor income to non-risky capital income, 
and for moderate income risk this effect dominates the future generations effect as parametrized by $\theta$. Note that the bounds in the previous proposition can of course be directly defined in terms of the variance of the idiosyncratic income shock $\eta$, to a second order approximation of the integral defining $\Gamma$ (see Appendix E.2).

\subsection{Implications for Dynamics of the Capital Stock and Cap- ital Income Taxes}

The discussion in the previous section concerned the optimal, time-invariant saving rate. The saving rate, together with the law of motion for the capital stock

$$
k_{t+1}=s_{t}(1-\kappa)(1-\alpha) k_{t}^{\alpha}=\frac{\alpha(\theta+\beta)(1-\kappa)(1-\alpha)}{1+\alpha \beta} k_{t}^{\alpha}
$$

and the initial condition $k_{0}$ determine the entire time path for the capital stock. That sequence $\left\{k_{t}\right\}_{t=1}^{\infty}$ is independent of the amount of income risk and converges monotonically to the steady state

$$
k^{*}=\left[\frac{\alpha(\theta+\beta)(1-\kappa)(1-\alpha)}{1+\alpha \beta}\right]^{\frac{1}{1-\alpha}},
$$

either from above if $k_{0}>k^{*}$ or from below, if $k_{0}<k^{*}$. Again, the optimal tax policy that implements this allocation depends on the extent of income risk, as shown above.

With this sharp analytical characterization of the optimal sequence of capital, we can now also make precise the relation between the capital taxes $\tau_{t}$ studied thus far, and the implied optimal capital income taxes $\tau_{t}^{k}$. These are related by the equation

$$
1+\left(R_{t}-1\right)\left(1-\tau_{t}^{k}\right)=R_{t}\left(1-\tau_{t}\right)
$$

and thus

$$
\tau_{t}^{k}=\frac{R_{t}}{R_{t}-1} \tau_{t}
$$

where the gross return is given by $R_{t}=\alpha\left(k_{t}\right)^{\alpha-1}$. As long as $R_{t}>1$ for all $t$, capital taxes and capital income taxes have the same sign, and the two instruments are equivalent. A sufficient condition for this is

Assumption 4. The initial capital stock satisfies $k_{0}<\alpha^{\frac{1}{1-\alpha}}$ and the model parameters 
satisfy

$$
\frac{1+\alpha \beta}{(\theta+\beta)(1-\kappa)(1-\alpha)}>1
$$

This assumption assures that net returns are strictly positive at all times in the Ramsey equilibrium, since $R_{0}=\alpha\left(k_{0}\right)^{\alpha-1}>1$ and $R^{*}=\alpha\left(k^{*}\right)^{\alpha-1}>1$, (and because the sequence of $R_{t}$ along the transition is monotone) and thus the Ramsey allocation can be supported by capital income taxes of the same sign as the original wealth taxes. Under assumption 4 therefore all interpretations and qualitative results extend without change to capital income taxes. If instead assumption 4 is not satisfied, and (ignoring the knife edge case $R_{t}=1$ ) thus for some $t$ we have $R_{t}<1$ as part of the Ramsey allocation, then, since capital income is negative (the net return $R_{t}-1<0$ ), the capital tax $\tau_{t}$ and associated capital income tax $\tau_{t}^{k}$ are of opposite signs.

\section{$5 \quad$ Efficiency Properties of the Ramsey Equilibrium}

In this section we discuss the welfare properties of the Ramsey equilibrium characterized thus far. By construction, the Ramsey allocation is the best allocation, given the weights in the social welfare function, that a government that needs to respect equilibrium behavior of households and is restricted to proportional taxes on capital can implement. In this section we establish three main results. First, defining constrained efficient allocations as those chosen by a social planner that cannot directly transfer consumption across households of different ages and with different idiosyncratic shocks (as in Davila et al. (2012)), we show that the Ramsey equilibrium is constrained efficient in this precise sense. Second, we relate our results to the dynamic public finance literature by showing that the Mirrleesian optimum coincides with the Ramsey optimum if we restrict the Mirrleesian planner not to redistribute inter-generationally. And third, we prove that if the optimal Ramsey saving rate $s^{*}(\theta=1)$ that maximizes steady state welfare is smaller than $s_{0}(\eta)$, the steady state saving rate in the competitive equilibrium without government, then implementing $s^{*}(\theta=1)$ through positive capital taxes yields a Pareto-improving transition from the initial steady state equilibrium without government policy towards the steady state associated with $s^{*}(\theta=1)$. This is true even if $s_{0}(\eta)<s^{G R}$ and thus the steady state equilibrium capital stock is smaller than the golden rule capital stock. 


\subsection{Constrained Efficiency of Ramsey Equilibria}

Not surprisingly, the Ramsey government cannot, in general, implement Pareto efficient allocations. ${ }^{15}$ Can the government at least achieve constrained efficient allocations with the set of instruments it has? A constrained efficient allocation is an allocation of capital and consumption that maximizes social welfare subject to the constraint that the allocation does not permit transfers across currently old households with different $\eta$ realizations. Define the set of allocations that are feasible for the constrained planner as

$$
\begin{aligned}
c_{t}^{y}+\int c_{t}^{o}\left(\eta_{t}\right) d \Psi+k_{t+1} & =k_{t}^{\alpha} \\
c_{t}^{o}\left(\eta_{t}\right) & =k_{t} M P K\left(k_{t}\right)+\kappa \eta_{t} M P L\left(k_{t}\right) .
\end{aligned}
$$

The first constraint is simply the resource constraint. The second constraint has extra bite as it restricts transfers across different $\eta$ households: old age consumption is required to equal capital income plus an $\eta$ household's share of labor income, where the returns to capital and labor are equal to the factors' relative productivities. The constrained planner might find it optimal, however, to manipulate factor prices by choosing a different sequence of capital stocks, relative to that of a competitive equilibrium (without or with tax policy). Note that these constraints also imply that

$$
\begin{aligned}
\int c_{t}^{o}\left(\eta_{t}\right) d \Psi & =k_{t} \operatorname{MPK}\left(k_{t}\right)+\kappa M P L\left(k_{t}\right) \\
c_{t}^{y} & =(1-\kappa) M P L\left(k_{t}\right)-k_{t+1}
\end{aligned}
$$

so that no intergenerational transfers are permitted either, relative to the competitive equilibrium. A constrained efficient allocation is one that maximizes

$$
S W F=\sum_{t=-1}^{\infty} \omega_{t} V_{t}
$$

subject to (32) and (33).

The social planner may want to manipulate the capital stock so as to change relative factor prices, relative to the competitive equilibrium without taxes. The question is whether the simple tax policy we consider is sufficient to offset the precautionary

\footnotetext{
${ }^{15}$ See Appendix C for a complete characterization of Pareto efficient allocations.
} 
savings externality on factor prices, and implement the constrained efficient allocation. The answer is yes, as the following proposition (proved in appendix C.2) shows.

Proposition 5. The Ramsey allocation is constrained-efficient.

\subsection{Relation to Mirrleesian Approach}

Consider a Mirrleesian planner who chooses optimal allocations under the constraint that $\eta$-shocks are private information of households. Assume that this Mirrleesian planner additionally is not permitted to issue intergenerational transfers, i.e., impose the constraints $(34,35)$. The Mirrleesian planner would want to implement transfers across $\hat{\eta}$-types (where $\hat{\eta}$ denotes the productivity reports of households), and provide insurance against low $\hat{\eta}$ realizations. The resource constraint and assumed absence of intergenerational transfers implies that these transfers have to net out to zero in every period. However, under any such transfer scheme, all high- $\eta$ households would have an incentive to report low $\hat{\eta}$ and therefore any transfer scheme across $\hat{\eta}$-types would not be incentive compatible. Furthermore the Mirrleesian planner has no other means to incentivize truthful reporting (e.g. by making future consumption or labor supply contingent on the $\hat{\eta}$ reports). Thus, transfers across $\hat{\eta}$-households are infeasible and the constraint (33) would result as a consequence of incentive compatibility in the Mirrleesian problem. The Mirrleesian planner would therefore implement the constrained efficient allocation in the sense of the previous subsection 5.1, which coincides with the Ramsey optimum as we had shown there.

\subsection{Pareto-Improving Tax Transitions}

In this section we show that under certain conditions, starting from the steady state competitive equilibrium without taxes as initial condition, switching to the Ramsey optimal savings and tax policy that maximizes steady state welfare yields a Pareto improvement, that is, all generations, including those along the transition, are better off. This is true, again under certain parametric restrictions, even if the original competitive steady state equilibrium is dynamically efficient in the sense of satisfying $k_{0}<k^{G R}$ (and thus $R_{0}>1$ ), where $k^{G R}$ is the golden rule capital stock maximizing steady state aggregate consumption (see Appendix C). 
Proposition 6. Let $s_{0}(\eta)$ denote the saving rate in a steady state competitive equilibrium with zero taxes. Assume that $s_{0}(\eta)>s^{*}$. Then a government policy that sets $\tau_{t}=\tau^{*}>0$ leads to a Pareto improving transition from the initial steady state with capital $k_{0}(\eta)$ towards the new steady state associated with tax policy $\tau^{*}$.

We provide the proof of this proposition in appendix C.4. The proof shows that all generations benefit from the government implementing a saving rate that is lower than the initial competitive equilibrium rate despite the fact that it lowers the capital stock, thus aggregate production, wages and consumption along the transition. The key step is to argue that this adverse effect of a lower capital stock is most severe in the long run (the new steady state), and to show that by choice of $s^{*}$ the government insures that even generations in the new steady state benefit, in terms of lifetime utility, from the higher tax rate and associated lower saving rate. Note that this argument is independent of the specific form of the utility function and thus holds for arbitrary Epstein-Zin-Weil utility, although the conditions on fundamentals that guarantee that the equilibrium saving rate $s_{0}(\eta)$ exceeds the optimal Ramsey steady state saving rate $s^{*}$ evidently does depend on the specific form of the utility function.

Note that from proposition 4 the assumption $s_{0}(\eta)>s^{*}$ is satisfied if and only if income risk is sufficiently large, in the sense that $\Gamma>\frac{1+\beta}{(1-\alpha) \beta}$. The result in the previous proposition is of course not surprising if $s_{0}(\eta)$ is larger than the golden rule implementing saving rate $s^{S G}$ and the initial steady state competitive equilibrium is dynamically inefficient to start with. However, for intermediate risk, i.e. for

$$
\Gamma \in\left(\frac{1+\beta}{(1-\alpha) \beta}, \frac{1}{[(1-\alpha)-1 / \bar{\Gamma}] \beta}\right)
$$

the proposition shows that $s^{*}<s_{0}(\eta)<s^{G R}$, and thus the steady state equilibrium is dynamically efficient yet setting $\tau^{*}>0$ implements a Pareto-improving transition.

Finally, it is important to note that the converse of proposition 6 is not true: even if $s_{0}(\eta)<s^{*}$, implementing the Ramsey optimal (for $\theta=1$ ) savings subsidy $\tau^{*}<0$ and associated higher saving rate $s^{*}$ does not lead to a Pareto improving transition. We demonstrate this in Appendix C.5 by showing that the generation born into the first period of this hypothetical policy-induced transition will lose from this policy innovation. In fact, not only is implementing $\tau^{*}<0$ not Pareto improving if $s_{0}(\eta)<s^{*}$, any policy reform that induces a saving rate in period 1 above the 
competitive saving rate with zero taxes, $s_{0}(\eta)$, will not result in a Pareto improvement (since it will make the first generation strictly worse off).

\section{General Intertemporal Elasticity of Substitution $\rho$ and Risk Aversion $\sigma$}

In this section we extend our results to a more general utility function with intertemporal elasticity of substitution $\rho$ and risk aversion $\sigma$, as in Epstein and Zin (1989, 1991) and Weil (1989). While most of this analysis focusses on steady states, we establish that our closed form results for the transition go through unchanged for an IES $\rho=1$. All details of formal derivations are relegated to Appendix D.

We now consider a utility function of the form

$$
V_{t}=\frac{\left(c_{t}^{y}\right)^{1-\frac{1}{\rho}}-1}{1-\frac{1}{\rho}}+\beta \frac{\left\{\left[\int c_{t+1}^{o}\left(\eta_{t+1}\right)^{1-\sigma} d \Psi\right]^{\frac{1}{1-\sigma}}\right\}^{1-\frac{1}{\rho}}-1}{1-\frac{1}{\rho}}
$$

The parameter $\rho$ measures the IES and the parameter $\sigma$ governs risk aversion. ${ }^{16}$ If $\sigma=\frac{1}{\rho}$ then the utility function takes the standard CRRA form, and as the IES $\rho \rightarrow 1$,

\footnotetext{
${ }^{16}$ This specification of Epstein-Zin-Weil preferences is often used in the literature, e.g., in Bommier et al. (2017). Note that $V_{t}$ is ordinally equivalent to the more commonly used specification

$$
\tilde{V}_{t}=\left\{(1-\tilde{\beta})\left(c_{t}^{y}\right)^{1-\frac{i_{1}}{\rho}}+\tilde{\beta}\left[\int c_{t+1}^{o}\left(\eta_{t+1}\right)^{1-\sigma} d \Psi\right]^{\frac{1-\frac{1}{\rho}}{1-\sigma}}\right\}^{\frac{1}{1-\frac{1}{\rho}}}
$$

since one is a monotone transformation of the other:

$$
V_{t}=\frac{\tilde{V}_{t}^{1-\frac{1}{\rho}}}{(1-\tilde{\beta})\left(1-\frac{1}{\rho}\right)}-\frac{(1+\beta)}{1-\frac{1}{\rho}}
$$

where $\beta=\frac{\tilde{\beta}}{1-\tilde{\beta}}$. However, since the Ramsey problem is stated in terms of the weighted sum of cardinal utilities, a monotone transformation of the utility function will in general alter the Ramsey problem. When focusing on a steady state analysis, this concern does not arise, since the same saving rate (and associated tax rate) maximizes steady state $V$ and its monotone transformation $\tilde{V}$.
} 
the utility function becomes ${ }^{17}$

$$
V_{t}=\ln \left(c_{t}^{y}\right)+\frac{\beta}{1-\sigma} \ln \left(\int c_{t+1}^{o}\left(\eta_{t+1}\right)^{1-\sigma} d \Psi\right) .
$$

As in section 4, equation (18) we can write lifetime utility of a generation born in period $t$, in general equilibrium, as a function of the beginning of the period capital stock $k_{t}$ and the saving rate $s_{t}$ chosen by the Ramsey government and implemented by the appropriate choice of the capital tax $\tau_{t+1}$. In addition, in the steady state the saving rate and the associated capital stock are related by:

$$
k=((1-\kappa)(1-\alpha) s)^{\frac{1}{1-\alpha}}
$$

In Appendix D we show that the objective function of the Ramsey government boils down to maximizing, by choice of the steady state saving rate, steady state lifetime utility, which is given (for $\rho \neq 1$ ) by

$$
V(s)=\tilde{\phi}\left((1-s)^{\left(1-\frac{1}{\rho}\right)}+\beta \tilde{\zeta} \tilde{\Gamma}_{2}\right) s^{\frac{\alpha\left(1-\frac{1}{\rho}\right)}{1-\alpha}},
$$

where $\tilde{\phi}$ and $\tilde{\zeta}>0$ and $\tilde{\Gamma}>0$ are constants that depend on parameter values. We find that the optimal steady state saving rate is defined implicitly as

$$
s^{*}=\frac{\alpha}{1-\alpha}\left[\left(1-s^{*}\right)+\beta \tilde{\zeta} \tilde{\Gamma}_{2}\left(1-s^{*}\right)^{\frac{1}{\rho}}\right] .
$$

Inspection of equation (37) (see Appendix D) we obtain

Proposition 7. Suppose that $\theta=1$ and thus the Ramsey government maximizes steady state welfare. There exists a unique optimal Ramsey saving rate $s^{*} \in(0,1)$ solving equation (37). This saving rate can be implemented with a capital tax rate $\tau^{*}$ determined by the competitive equilibrium Euler equation:

$$
1=\left(1-\tau^{*}\right) \alpha \beta((1-\kappa)(1-\alpha))^{\left(\frac{1}{\rho}-1\right)} \frac{\left(1-s^{*}\right)^{\frac{1}{\rho}}}{s^{*}} \tilde{\Gamma} .
$$

Note that all comparative statics results, especially those with respect to an increase in income risk, can be deduced from an analysis of equations $(37,38)$. Income

\footnotetext{
${ }^{17}$ Tallarini (2000) shows that this coincides with risk-sensitive utility of Hansen and Sargent (1995).
} 
risk affects the optimal Ramsey savings rate $s^{*}$ and associated implementing tax rate $\tau^{*}$ only through the constants $\tilde{\Gamma}, \tilde{\Gamma}_{2}$ which are given as:

$$
\begin{aligned}
\tilde{\Gamma} & =c e(\eta)^{\left(\sigma-\frac{1}{\rho}\right)} \Gamma \\
\tilde{\Gamma}_{2} & =c e(\eta)^{\left(1-\frac{1}{\rho}\right)}
\end{aligned}
$$

where we had defined $\Gamma$ above for the log-case, which is now given by:

$$
\Gamma=\int\left(\kappa \eta_{t+1}(1-\alpha)+\alpha\right)^{-\sigma} d \Psi\left(\eta_{t+1}\right)
$$

and where the certainty equivalent of $\eta$ is defined as, for $\sigma \neq 1$

$$
c e(\eta)=\left\{\begin{array}{lc}
{\left[\int(\alpha+(1-\alpha) \kappa \eta)^{1-\sigma} d \Psi(\eta)\right]^{\frac{1}{1-\sigma}}} & \text { for } \sigma=1 \\
\exp \left(\int \ln (\alpha+(1-\alpha) \kappa \eta) d \Psi(\eta)\right) & \text { otherwise }
\end{array}\right.
$$

In appendix E.1 we prove the following result relating the extent of income risk to the constants $\tilde{\Gamma}, \tilde{\Gamma}_{2}$ which are in turn crucial for the comparative statics results we will provide in section 6.2 .

Lemma 1. An increase in income risk (again in the sense of a mean-preserving spread of $\eta)$, unambiguously reduces ce $(\eta)$, increases $\tilde{\Gamma}_{2}$ if and only if $\rho<1$ and increases $\tilde{\Gamma}$ if $\rho<1$, or $\rho>1$ and $\sigma<1 / \rho$.

Note that the condition that characterizes the relation between income risk and $\tilde{\Gamma}_{2}$ is necessary and sufficient whereas the two alternative conditions that characterize the relation between income risk and $\tilde{\Gamma}$ are only sufficient.

\subsection{Unit Elasticity of Substitution $\rho=1$}

Recognizing that for an IES of $\rho=1$ we have $\tilde{\zeta}=\tilde{\Gamma}_{2}=1$, direct calculations yield:

Proposition 8. Suppose that the IES $\rho=1$. Then the solution of the Ramsey problem is identical to that of the log-utility case analyzed in section 4. That is, the optimal, constant saving rate is given by

$$
s=\frac{\alpha(\beta+\theta)}{1+\alpha \beta}
$$


The optimal tax rate $\tau$ that implements this saving rate as a competitive equilibrium is given by

$$
1=(1-\tau)\left(\frac{1-s}{s}\right) \alpha \beta \tilde{\Gamma}
$$

and thus is strictly increasing in income risk measured by $\tilde{\Gamma}$.

Note that the optimal Ramsey saving rate does neither depend on income risk nor on risk aversion, but that the optimal capital tax rate $\tau$ implementing this saving rate is increasing in income risk, and does depend on risk aversion through the constant $\tilde{\Gamma}=\frac{\int(\kappa \eta(1-\alpha)+\alpha)^{-\sigma} d \Psi(\eta)}{\int(\kappa(1-\alpha) \eta+\alpha)^{1-\sigma} d \Psi(\eta)}$ since $\sigma$ controls the degree of precautionary saving in the competitive equilibrium that needs to be offset with capital taxes.

Also note that although here we state this result for steady states only, Appendix D.2 shows that the entire analysis of section 4 with log-utility (including the dynamic programming formulation and the analysis of the transition path) goes through completely unchanged (by only replacing $\Gamma$ by $\tilde{\Gamma}$ ) for general Epstein-Zin-Weil utility as long as the IES is unity, $\rho=1$.

\subsection{The Impact of Risk on the Optimal Saving and Tax Rate: Disentangling Risk Aversion and IES: $\frac{1}{\sigma} \neq \rho \neq 1$}

In the previous section we demonstrated that an IES of 1 is sufficient (and, as turns out, necessary) for the result that the optimal Ramsey saving rate can be solved in closed form, is constant over time and independent of the extent of income risk. In this section we investigate how income risk impacts the optimal Ramsey saving rate and implementing capital tax rate when we allow for general IES and risk aversion $(\rho, \sigma)$ where the standard CRRA case is nested for $\rho=1 / \sigma$.

From equation (37) we immediately observe that the optimal steady state saving rate $s$ is strictly increasing in the constant $\tilde{\Gamma}_{2}$ that fully summarizes the impact of income risk. The response of $s$ to income risk then immediately follows from the impact of an increase in income risk on $\tilde{\Gamma}_{2}$ stated in Lemma 1 . Thus we have

Proposition 9. An increase in income risk, that is, a mean-preserving spread in the distribution of $\eta$, increases the optimal steady state Ramsey saving rate $s^{*}$ if and only if $\rho<1$ and decreases it if and only if $\rho>1$.

Thus the direction of the change in $s$ with respect to income risk is exclusively determined by the IES $\rho$, with the log-case acting as a natural watershed. Of course 
how strongly the saving rate responds to an increase in income risk is also controlled by risk aversion through the term $\tilde{\Gamma}_{2}$.

What is the intuition for this result? Suppose the economy is in the steady state associated with a given extent of income risk and the optimal Ramsey tax policy, and now consider an increase in income risk. The Ramsey government can neutralize the response of private households' savings behavior, by appropriate adjustment of the tax rate on capital to implement the new optimal saving rate. ${ }^{18}$ The question is then how the saving rate desired by the Ramsey government itself changes. Households (and thus the Ramsey government) obtain utility from safe consumption when young and risky consumption when old, and the desire for smoothing utility from safe consumption when young and the certainty equivalent of consumption when old is determined by the IES $\rho$. As risk increases, the certainty equivalent of old-age consumption declines, for a given consumption allocation. Old age consumption is now a less effective way to generate utility, and whether the Ramsey government wants to prop up old-age consumption (by increasing the saving rate) or reduce it (by lowering the saving rate) depends on how much households value a smooth life cycle utility profile. In the log-case the two forces exactly balance out and the Ramsey saving rate does not respond to income risk at all. In contrast, if households strongly desire a smooth path of (the certainty equivalence of) consumption, then the Ramsey government compensates for the loss of old-age certainty equivalent consumption induced by larger income risk by saving at a higher rate. Thus $s$ increases with income risk if the IES $\rho$ is small. The reverse is true for a high IES.

Finally, we can also determine the impact of income risk on optimal steady state capital taxes. From equation (38) the optimal Ramsey tax rate is given by

$$
1=\left(1-\tau^{*}\right) \alpha \beta((1-\kappa)(1-\alpha))^{\left(\frac{1}{\rho}-1\right)} \frac{\left(1-s^{*}\right)^{\frac{1}{\rho}}}{s^{*}} \tilde{\Gamma}
$$

We observe that income risk affects the optimal tax rate in two ways. First, for a given target saving rate $s^{*}$, the direct impact of income risk depends on how $\tilde{\Gamma}$ (and thus the private saving rate) responds to an increase in risk. Second, a change in

\footnotetext{
${ }^{18}$ We saw this explicitly in the decomposition of the first order condition of the Ramsey government in section 4.2 , where the risk term $\Gamma$ from the competitive equilibrium optimality condition dropped out because the government chooses, through taxes and the associated changes in factor prices, to exactly offset the impact of higher risk on private household savings decisions. In the logic of that section, an increase in $\Gamma$ increases $P E(s)$ but reduces $G E(s)$ by precisely the same factor.
} 
income risk changes the optimal saving rate $s^{*}$ through $\tilde{\Gamma}_{2}$, as characterized in the previous proposition. The next proposition, proved in section D.4 of the appendix, gives sufficient conditions on the IES and risk aversion $(\rho, \sigma)$ under which the optimal capital tax rate $\tau^{*}$ is increasing in income risk, and a necessary condition required for the tax rate to be decreasing in income risk. The proof of the first proposition exploits the fact that using equation (37) we can rewrite equation (43) as:

$$
1=\left(1-\tau^{*}\right)\left(1-\frac{\alpha}{s^{*}}\right) \frac{\tilde{\Gamma}}{\tilde{\Gamma}_{2}} .
$$

Proposition 10. If $\rho \leq 1$, then an increase in income risk increases the optimal tax rate on capital. Similarly, if $\rho>1$ and $\sigma \leq 1 / \rho$, then an increase in income risk increases the optimal tax rate on capital.

Proposition 11. If $\rho>1$ and $\sigma>1 / \rho$ then an increase in income risk might lead to a strict reduction in the optimal tax rate on capital. A necessary condition for this to happen is that the private saving rate in competitive equilibrium for given tax rate $\tau \in(-\infty, 1)$ is strictly decreasing in income risk.

The intuition for this last proposition is that, if $\rho>\max \{1,1 / \sigma\}$, then private households might decrease their saving rate too much in general equilibrium in response to an increase in income risk since they do no internalize the impact of the decline of the saving rate on the capital stock and thus on wages of future generations. For the capital tax to decrease in income risk this future generations effect has to be sufficiently strong. To see this formally, we first derive in Appendix D.5 the decomposition of the first-order condition for the optimal saving rate into the terms $P E(s), G E(s)$ and $F G(s)$, as for $\log$ utility in Section 4.1. In Appendix D.6 we use this decomposition to decompose the tax rate equation (44) as

$$
1=\underbrace{\left(1-\tau^{*}\right) \frac{\tilde{\Gamma}}{\tilde{\Gamma}_{2}}}_{\text {from } P E(s)+G E(s)}-\underbrace{\left(1-\tau^{*}\right) \frac{\alpha}{s^{*}} \frac{\tilde{\Gamma}}{\tilde{\Gamma}_{2}}}_{\text {from } F G(s)} .
$$

Since $\frac{\tilde{\Gamma}}{\tilde{\Gamma}_{2}}$ is unambiguously increasing in income risk, the optimal capital tax rate $\tau^{*}$ can only decrease in income risk when the last term, the future generations effect, is quantitatively potent; note that this effect calls for a tax rate that decreases with income risk since $s^{*}$ is decreasing in risk for $\rho>1$. 
In the next section we characterize the optimal solution of the Ramsey tax problem numerically outside the steady state. We use the results to demonstrate that there are indeed robust regions of the preference parameter space in which the optimal sequence of tax rates in the Ramsey equilibrium is indeed strictly decreasing in the extent of income risk, uniformly over time, confirming that our last theoretical statement does not characterize the empty set of Epstein-Zin-Weil utility functions.

\subsection{Numerical Exploration of Optimal Ramsey Tax Transi- tions for General IES $\rho \neq 1$ and Risk Aversion $\sigma$}

In the previous subsection we provided a theoretical characterization of the optimal Ramsey policy under the assumption that the government maximized steady state utility, i.e. $\theta=1$. Since no analytical results are available outside the steady state unless we assume an IES $\rho=1$, in this section we solve for the optimal Ramsey tax transition numerically. We take as initial condition the steady state capital stock in the competitive equilibrium without taxes and characterize the sequences of saving rates, capital stocks, capital tax rates as well as the lifetime utility consequences from the transition for various generations, relative to the steady state without taxes.

To implement the simulations we need to choose parameters. To exploit the dynamic programming solution of the Ramsey problem with a social discount factor $\theta<1$, but to retain the steady state results as useful benchmark for comparison, we choose $\theta=0.9$. The main focus of this section is to characterize how the extent of income risk affects the optimal Ramsey tax transition, and how households' preferences towards that risk (as measured by $\sigma$ ) and their willingness to inter-temporally substitute (as measured by $\rho$ ) shape this transition. In the main text we focus on a parameter constellation for which changes in income risk have a potentially nonmonotonic impact on the optimal tax rate in steady state. Recall that this requires large $\sigma$ and $\rho$, together with the restriction that $\sigma>1 / \rho$. Thus, here we choose $\rho=20$ and $\sigma=50$; in Appendix $\mathrm{F}$ we also present quantitative results for lower, more commonly used values of both parameters. To vary the degree of idiosyncratic income risk we assume that $\eta$ is distributed log-normally and consider four levels of risk: $\sigma_{\eta} \in\{0,0.25,1,2\}$, and by adjusting $\mu_{\eta}$ such that $E(\eta)=1$ for all risk parameterizations. ${ }^{19}$ Note that the purpose of the simulations is to illustrate qualitative

\footnotetext{
${ }^{19}$ We approximate the distribution with $n=21$ Gaussian quadrature nodes. Other parameters
} 
properties of the Ramsey solution when analytical results are not available, rather than making firm quantitative statements.

Figure 2: Policy Functions for $\rho=20, \sigma=50$ and Log Utility $(\sigma=\rho=1)$

(a) $s^{*}(k)$

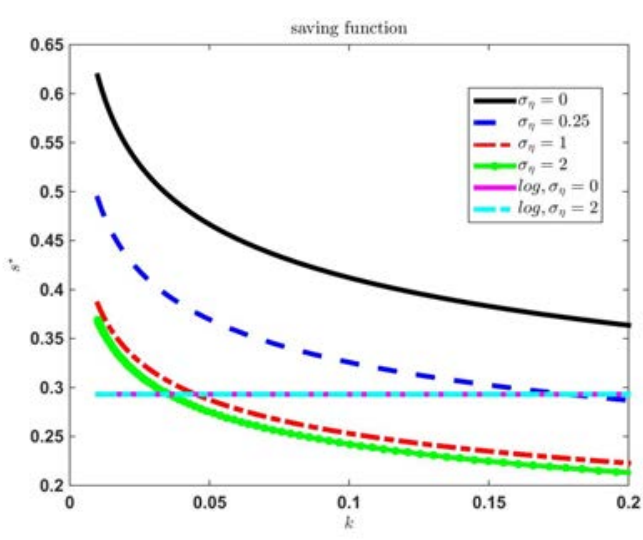

(b) $k^{\prime^{*}}(k)$

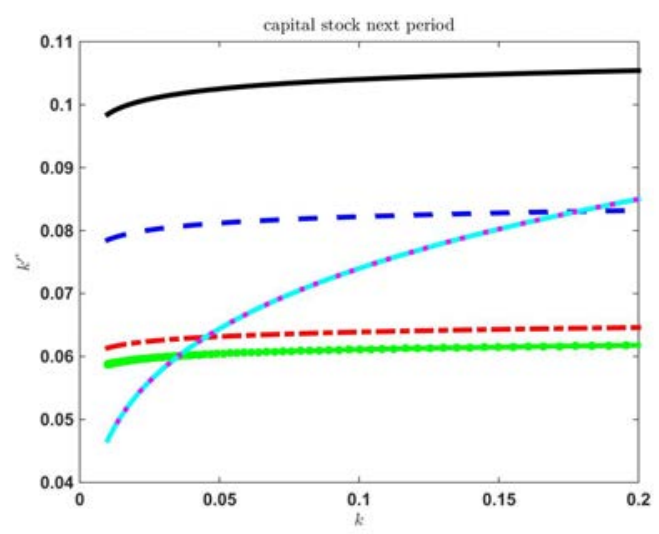

Notes: Optimal saving rate and next period capital stock as function of current $k$; for $\rho=20, \sigma=50$ as well as for logarithmic utility $(\rho=\sigma=1)$.

Figure 2 plots the optimal Ramsey saving rate (Panel (a)) and the implied capital stock carried into the next period (Panel (b)) against the capital stock today, for various degrees of income risk (and $\rho=20, \sigma=50$ ). The figure also displays the policy functions for logarithmic utility $(\rho=\sigma=1)$ for $\sigma_{\eta}^{2} \in\{0,2\}$ and confirms that for $\rho=1$ the optimal saving rate is independent of income risk and of the current capital stock. Relative to this benchmark, and consistent with our steady state findings in proposition 9, for an IES $\rho>1$ the saving policy function is decreasing in income risk. Thus, as shown theoretically in the steady state with a high IES the Ramsey government optimally shifts consumption towards the first period of individuals' lives when income risk rises. Panel (a) also shows that the saving rate is a decreasing function of the current capital stock if $\rho>1$ since an increase in the capital stock raises wages and thus labor income risk when old, thereby leading to a reduction in the saving rate when households are very willing to intertemporally substitute consumption. As a consequence, the optimal capital stock tomorrow is less elastic to capital today with a high IES, relative to the log-case, as shown in Panel (b).

include $\alpha=0.2, \beta=0.8$ and $\kappa=0.5$. This choice of $\alpha$ and $\kappa$ implies that the golden rule saving rate in this economy is $s^{G R}=0.5$. 
Table 1: Saving Rates in Competitive Equilibrium and Optimal Long-Run Saving \& Capital Income Tax Rates: EZW-Preferences with $\rho=20, \sigma=50$

\begin{tabular}{lccc}
\hline \hline & $s_{0}(\eta)$ & $s_{\infty}^{*}$ & $\tau_{\infty}^{k^{*}}$ \\
\hline$\sigma_{\eta}=0$ & 0.38 & 0.41 & -0.13 \\
$\sigma_{\eta}=0.25$ & 0.48 & 0.34 & 0.52 \\
$\sigma_{\eta}=1$ & 0.44 & 0.28 & 0.60 \\
$\sigma_{\eta}=2$ & 0.42 & 0.27 & 0.56 \\
\hline Log Utility & $(\rho=\sigma=1)$ & \\
\hline$\sigma_{\eta}=0$ & 0.21 & 0.29 & -0.88 \\
$\sigma_{\eta}=2$ & 0.36 & 0.29 & 0.39 \\
\hline \hline
\end{tabular}

Notes: Saving rates in the initial competitive equilibrium, $s_{0}(\eta)$, and optimal long-run saving, $s_{\infty}^{*}$, and capital income tax rates $\tau_{\infty}^{k^{*}}$ for $\alpha=0.2, \beta=0.8, \kappa=0.5, \quad \sigma_{\eta} \in\{0,0.25,1,2\}, \quad \theta=0.9$ and $\rho=20, \sigma=50$ as well as for logarithmic utility $(\sigma=\rho=1)$.

From an initial capital stock $k_{0}$, assumed to be the steady state capital stock absent tax policy, we now determine the optimal time sequence of saving rates, capital, and capital tax rates starting from period $t=1$. Thus, the Ramsey government determines the optimal sequence of saving rates from period 1 onwards, and implements them with capital income taxes from period 2 onwards. For the various parameterizations, the initial competitive equilibrium saving rate, $s_{0}(\eta)$, the optimal saving rate in the long-run, $s_{\infty}^{*}$, and the optimal long-run capital income tax rate, $\tau_{\infty}^{k^{*}}$ are shown in Table $1 .{ }^{20}$ We observe that for our parameterization with a high IES the steady state competitive equilibrium saving rate $s_{0}(\eta)$ is inverse U-shaped in income risk, initially increasing but eventually declining in $\sigma_{\eta}$ when income risk exceeds some threshold. ${ }^{21}$

In proposition 11 we showed that when the Ramsey government maximizes steady state utility $(\theta=1)$, a necessary condition for optimal capital taxes to decline with income risk is that the competitive equilibrium saving rate absent taxes falls with income risk. This result is also apparent in Table 1 in that $s_{0}(\eta)$ starts to decline with income risk after $\sigma_{\eta}$ exceeds 0.32 , and the optimal long-run Ramsey tax rate also eventually decreases with income risk, but not until after $\sigma_{\eta}$ surpasses 1 . Finally, notice that only in the deterministic economy with $\sigma_{\eta}=0$, the competitive equilibrium

\footnotetext{
${ }^{20}$ Notice that all economies considered here are dynamically efficient in that the saving rate $s_{0}(\eta)$ is always less than the golden rule saving rate of $s^{G R}=0.5$ Consequently gross real rates of return are always positive, and taxes on capital, and on capital income have the same sign.

${ }^{21}$ For our parameterization the threshold is at $\bar{\sigma}_{\eta} \approx 0.32$.
} 
saving rate is lower than the long-run optimum saving rate; in all other economies it is higher, and optimal taxes on capital income are positive in these cases. ${ }^{22}$

Figure 3: Policy Transition for $\rho=20, \sigma=50$ and Log Utility $(\sigma=\rho=1)$

(a) $s_{t}$

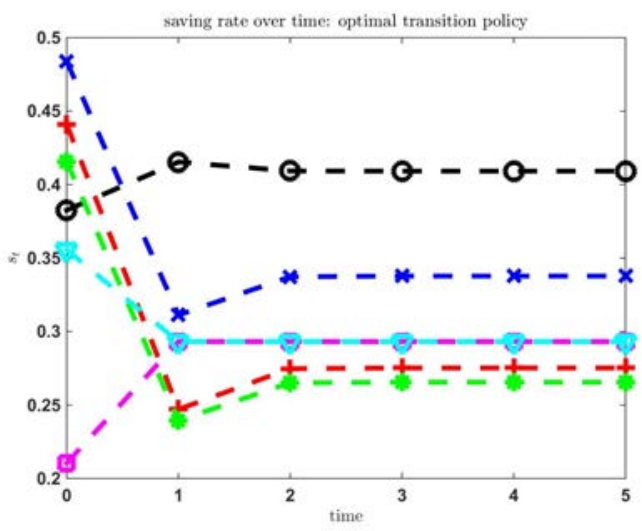

(c) $\tau_{t}^{k}$

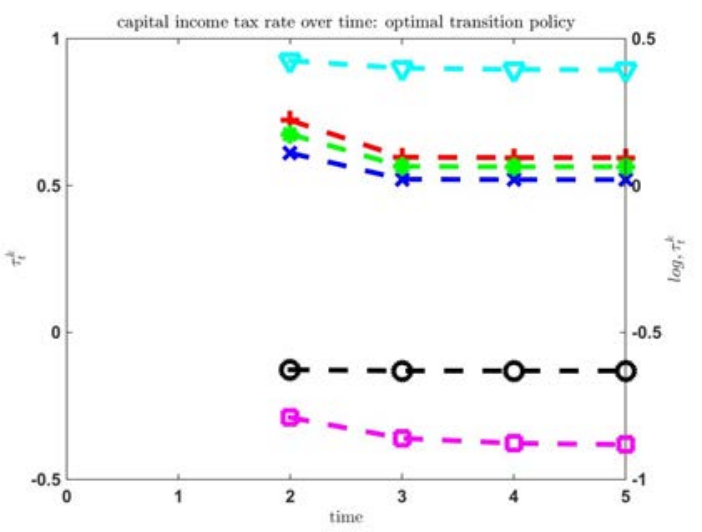

(b) $k_{t}$

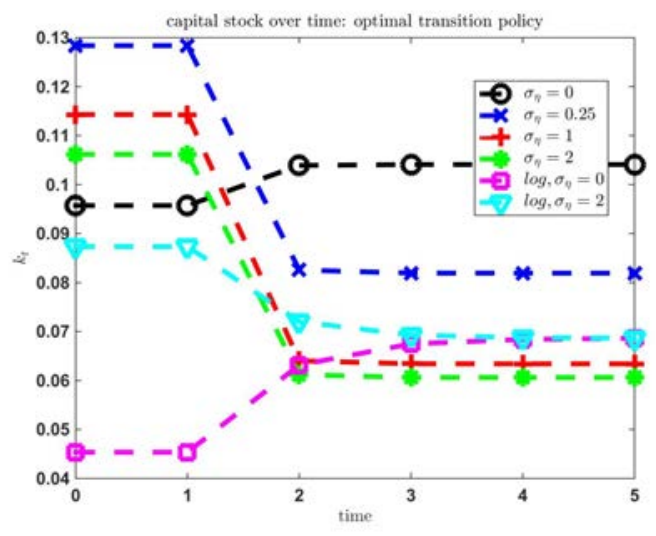

(d) $\Delta v_{t}$

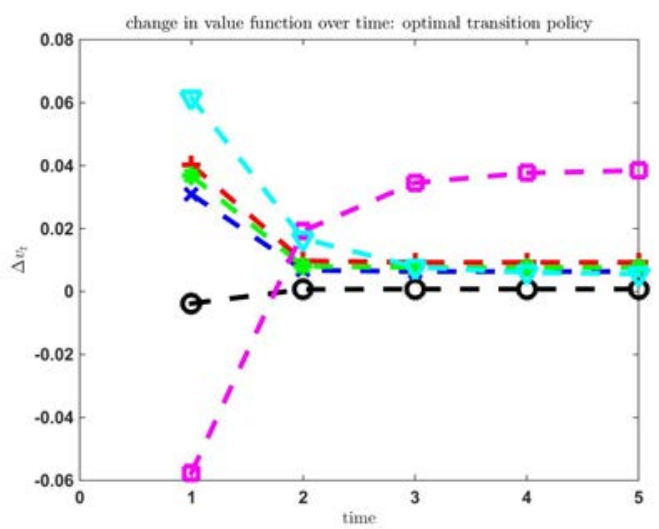

Notes: Initial and optimal saving rate, capital stock, optimal capital income tax rate and changes in lifetime utility in transition for for $\alpha=0.2, \beta=0.8, \kappa=0.5, \quad \sigma_{\eta} \in\{0,0.25,1,2\}, \quad \theta=0.9$ and $\rho=20, \sigma=50$ as well as for logarithmic utility $(\rho=\sigma=1)$.

Figure 3 shows, in panels (a) and (b), the optimal dynamic Ramsey equilibrium allocation $\left\{s_{t}, k_{t}\right\}$ and associated tax policy $\left\{\tau_{t+1}\right\}$, see panel (c), both for log-utility and high risk aversion and high IES $\rho=20, \sigma=50$. Recall that, for each parameter-

\footnotetext{
${ }^{22}$ As comparison, Table 1 also reports results for $\log$ utility for $\sigma_{\eta}^{2} \in\{0,1\}$. For $\sigma_{\eta}^{2}=0$ the optimal long-run saving rate exceeds the saving rate in the initial competitive equilibrium, whereas for $\sigma_{\eta}^{2}=2$ it is lower, corresponding to cases 3 and 2 of proposition 4, respectively. Consistent with corollary 4 , the long-run optimal capital income tax rate $\tau_{\infty}^{*}$ is increasing in risk.
} 
ization, the initial condition is the steady state capital stock absent capital income taxes. From panels (a) and (c) we observe that the optimal policy in the presence of income risk $\left(\sigma_{\eta}^{2}>0\right)$ is to implement a lower saving rate (through a positive capital income $\left.\operatorname{tax}^{23}\right)$ in the initial period of the transition than would emerge in the unregulated competitive equilibrium, but also relative to the long-run optimum, i.e., $s_{1}^{*}<s_{\infty}^{*}$. With this policy the Ramsey government brings down the capital stock quite strongly in the initial period (see panel (b)). Also note that for all periods $t$ along the transition, optimal capital income taxes are inverse u-shaped in income risk, showing that the long-run results of table 1 extend to the entire transition path.

Finally, panel (d) of the figure shows the difference in lifetime utility of a generation born in period $t$ of the optimal tax transition, relative to living in the unregulated steady state equilibrium. It illustrates that for all economies with $\sigma_{\eta} \geq 0.25$ the optimal Ramsey tax transition constitutes a Pareto improvement relative to the competitive equilibrium without taxes. Hence our analytical results on Pareto improving tax transitions from maximizing steady state utility $(\theta=1)$ from section 5.3 carries over to these calibrated example economies.

The illustrative quantitative findings in this section were derived under an arguably fairly extreme preference parametrization $(\sigma=50, \rho=20)$, which permitted the possibility that optimal tax rates are (eventually) decreasing in the amount of income risk. Appendix F shows that the main conclusions in this section (apart from this inverse U-shape in income risk) are robust to more common values of risk aversion and of the IES (e.g., the CRRA specification with $\sigma=2$ and $\rho=0.5$ ). For these parameterizations the optimal tax rate is monotonically increasing in income risk, and tends to be negative unless income risk is sufficiently large. If income risk is sufficiently large, a tax reform from the status quo of no capital taxation to the optimal Ramsey policy with positive capital income taxes again constitutes a Pareto improvement. ${ }^{24}$

\footnotetext{
${ }^{23}$ Left $\mathrm{y}$-axis of Panel (c): $\rho=20, \sigma=50$ case. Right $\mathrm{y}$-axis: Log-utility, $\rho=\sigma=1$.

${ }^{24}$ We also consider $\sigma=2$ and $\rho=20$ to show that the non-monotonicity of the tax rate with respect to income risk disappears when we lower risk aversion.
} 


\section{Conclusion}

In this paper we have analyzed optimal capital taxes in a canonical OLG model with idiosyncratic labor income risk. The problem permits a full analytical characterization of the Ramsey allocation and associated tax policy along the transition to a steady state in case the intertemporal elasticity of substitution is unity. The optimal aggregate saving rate is independent of idiosyncratic income risk, and is implemented by a tax rate that is increasing in income risk (unless both the IES and risk aversion are large), and positive if and only if income risk is sufficiently large.

By showing that the Ramsey government can implement constrained efficient allocations through a proportional tax on capital we confirm that capital income taxation, in the context of our model, is the appropriate fiscal tool to deal with the externality on equilibrium factor prices induced by private precautionary savings behavior against uninsurable idiosyncratic income risk. However, we also demonstrate that capital should not necessarily be taxed, and should be subsidized when the government cares strongly about future generations. Judiciously chosen assumptions permit us to make these points in a fully analytically tractable and transparent manner. The next, and complementary step in this area of research would be, in our view, to investigate numerically, whether in richer life cycle models with idiosyncratic income risk

and thus heterogeneity in income and wealth within generations the optimal Ramsey tax policy is well approximated by the simple linear and time-constant tax on capital that we have shown theoretically to be optimal in our simple OLG economy.

\section{References}

Açikgöz, O. (2015). Transitional Dynamics and Long-Run Optimal Taxation under Incomplete Markets. Working Paper.

Aiyagari, S. R. (1994). Uninsured Idiosyncratic Risk and Aggregate Saving. Quarterly Journal of Economics 109, 659-684.

Aiyagari, S. R. (1995). Optimal Capital Income Taxation with Incomplete Markets, Borrowing Constraints, and Constant Discounting. Journal of Political Economy 103, 1158-1175.

Atkinson, A. B. and A. Sandmo (1980). Welfare Implications of the Taxation of Savings. The Economic Journal 90, 529-549. 
Bewley, T. F. (1986). Stationary Monetary Equilibrium with a Continuum of Independently Fluctuating Consumers. In W. Hildenbrand and A. Mas-Colell (Eds.), Contributions to Mathematical Economics in Honor of Gerard Debreu, pp. 79-102. Amsterdam: North-Holland.

Bommier, A., D. Harenberg, and F. Le Grand (2017). Recursive Preferences, the Value of Life, and Household Finance. Working Paper.

Chamley, C. (1986). Optimal Taxation of Capital Income in General Equilibrium with Infinite Lives. Econometrica 54, 607-622.

Chamley, C. (2001). Capital Income Taxation, Wealth Distribution and Borrowing Constraints. Journal of Public Economics 79, 55-69.

Chen, Y., Y. Chien, and C. Yang (2017). Aiyagari Meets Ramsey: Optimal Capital Taxation with Incomplete Markets. Working Paper.

Chien, Y. and Y. Wen (2017). Optimal Ramsey Capital Income Taxation - A Reappraisal. Federal Reserve Bank of St. Louis Working Paper 2017-024C.

Conesa, J.-C., S. Kitao, and D. Krueger (2009). Taxing Capital? Not a Bad Idea After All! American Economic Review 99, 25-48.

Davila, J., J. H. Hong, P. Krusell, and J. V. Rios-Rull (2012). Constrained efficiency in the neoclassical growth model with uninsurable idiosyncratic shocks. Econometrica 80(6), 2431-2467.

Diamond, P. A. (1965). National Debt in a Neoclassical Growth Model. American Economic Review 55(Vol. 55, No. 5, Part 1 (Dec., 1965)), 1126-1150.

Diamond, P. A. (1967). The Role of a Stock Market in a General Equilibrium Model with Technological Uncertainty Author. American Economic Review 57(4), 759-776.

Domeij, D. and J. Heathcote (2004). On the Distributional Effects of Reducing Capital Taxes. Internation Economic Review 45(2), 523-554.

Dyrda, S. and M. Pedroni (2016). Optimal Fiscal Policy in a Model with Uninsurable Idiosyncratic Shocks. Working Paper.

Epstein, L. G. and S. E. Zin (1989). Substitution, Risk Aversion, and the Temporal Behavior of Consumption and Asset Returns: A Theoretical Framework. 57(4), 937-969. 
Epstein, L. G. L. and S. Zin (1991). Substitution, Risk Aversion, and the Temporal Behavior of Consumption and Asset Returns: An Empirical Analysis. Journal of Political Economy 99(4), 263-286.

Erosa, A. and M. Gervais (2001). Optimal Taxation in Infinitely-Lived Agent and Overlapping Generations Models: A Review. Federal Reserve Bank of Richmond Economic Quarterly 87(2), 23-44.

Erosa, A. and M. Gervais (2002). Optimal Taxation in Life-Cycle Economies. Journal of Economic Theory 105, 338-369.

Evans, D. (2014). Optimal Taxation with Persistent Idiosyncratic Investment Risk. Working Paper.

Farhi, E. and I. Werning (2012). Capital Taxation: Quantitative Explorations of the Inverse Euler Equation. Journal of Political Economy 120(3), 398-445.

Garriga, C. (2017). Optimal Fiscal Policy in Overlapping Generations Models. Public Finance Review (DOI: 10.1177/1091142117735601).

Geanakoplos, J. D. and H. M. Polemarchakis (1986). Existence, Regularity, and Constrained Suboptimality of Competitive Allocations when the Asset Market is Incomplete. In W. P. Heller, R. M. Starr, and D. A. Starrett (Eds.), Uncertainty, Information and Communication: Essays in Honor of Kenneth J. Arrow, Chapter 3, pp. 65-96. Cambridge University Press.

Gottardi, P., A. Kajii, and T. Nakajima (2015). Optimal Taxation and Debt with Uninsurable Risks to Human Capital Accumulation. American Economic Review 105(11), 3443-3470.

Hagedorn, M., H. Holter, and Y. Wang (2015). The Optimum Quantity of Capital and Debt. Working Paper.

Hansen, L. P. and T. J. Sargent (1995). Discounted Linear Exponential Quadratic Gaussian Control. IEEE Transactions on Automatic Control 40(5), 968-971.

Harenberg, D. and A. Ludwig (2015). Social Security in an Analytically Tractable Overlapping Generations Model with Aggregate and Idiosyncratic Risk. International Tax and Public Finance 22(4), 579-603.

Heathcote, J., K. Storesletten, and G. L. Violante (2017). Optimal Tax Progressivity: An Analytical Framework. Quarterley Journal of Economics (doi:10.1093/qje/qjx018), 1693-1754. 
Huggett, M. (1993). The Risk-Free Rate in Heterogeneous-Agent IncompleteInsurance Economies. Journal of Economic Dynamics and Control 17, 953-969.

Judd, K. (1985). Redistributive Taxation in a Perfect Foresight Model. Journal of Public Economics 28, 59-84.

Krebs, T. (2003). Human Capital Risk and Economic Growth. Quarterly Journal of Economics 118, 709-745.

İmrohoroğlu, A. (1989). Cost of Business Cycles with Indivisibilities and Liquidity Constraints. Journal of Political Economy 97(6), 1364-1383.

Panousi, V. (2015). Capital Taxation with Entrepreneurial Risk. accepted for publication in: Journal of Monetary Economics.

Panousi, V. and C. Reis (2015). Optimal Taxation with Idiosyncratic Investment Risk. Working Paper.

Panousi, V. and C. Reis (2017). A Unified Framework for Optimal Taxation with Undiversiable Risk. Working Paper.

Park, Y. (2017). Constrained Efficiency in a Risky Human Capital Model. American Economic Journal: Macroeconomics (Forthcoming).

Pestieau, P. (1974). Optimal Taxation and Discount Rate for Public Investment in a Growth Setting. Journal of Public Economics 3, 217-235.

Peterman, W. B. (2016). The Effect of Endogenous Human Capital Accumulation on Optimal Taxation. Review of Economic Dynamics 21, 46-71.

Pigou, A. C. (1920). The Economics of Welfare. London: Macmillan.

Ramsey, F. (1927). A Contribution to the Theory of Taxation. Economic Journal 3\%, 47-61.

Tallarini, T. D. J. (2000). Risk-Sensitive Real Business Cycles. Journal of Monetary Economics 45(3), 507-532.

Weil, P. (1989). The Equity Premium Puzzle and the Risk-Free Rate Puzzle. Journal of Monetary Economics 24(3), 401-421. 


\section{A Details of the General Ramsey Problem}

From equations (26) and (27) we find that

$$
\begin{aligned}
& w^{\prime}(s)=(1-\alpha) \alpha\left[k^{\prime}(s)\right]^{\alpha-1} \frac{d k^{\prime}(s)}{d s}=(1-\alpha) \alpha\left[(1-\kappa)(1-\alpha) k^{\alpha}\right]^{\alpha}[s]^{\alpha-1} \\
& R^{\prime}(s)=\alpha(\alpha-1)\left[k^{\prime}(s)\right]^{\alpha-2} \frac{d k^{\prime}(s)}{d s}=\alpha(\alpha-1)\left[(1-\kappa)(1-\alpha) k^{\alpha}\right]^{\alpha-1}[s]^{\alpha-2}
\end{aligned}
$$

and thus

$$
\begin{aligned}
(1-\kappa)(1-\alpha) k^{\alpha} R^{\prime}(s) s & =\alpha(\alpha-1)\left[(1-\kappa)(1-\alpha) k^{\alpha}\right]^{\alpha}[s]^{\alpha-1} \\
\kappa \eta w^{\prime}(s)+(1-\kappa)(1-\alpha) k^{\alpha} R^{\prime}(s) s & =(1-\alpha) \alpha\left[(1-\kappa)(1-\alpha) k^{\alpha}\right]^{\alpha}[s]^{\alpha-1}[\kappa \eta-1]
\end{aligned}
$$

which leads to the equation in the main text:

$$
G E(s)=(1-\alpha) \alpha\left[(1-\kappa)(1-\alpha) k^{\alpha}\right]^{\alpha}[s]^{\alpha-1} \beta \int u^{\prime}\left(c^{o}(\eta)\right)[\kappa \eta-1] d \Psi(\eta)
$$

\section{B Derivation for Log-Utility}

In this section we provide a full solution to the Ramsey optimal taxation problem for the case of logarithmic utility in its sequential formulation, for an arbitrary set of social welfare weights. We first recognize from the aggregate law of motion that

$$
\begin{aligned}
\log \left(k_{t+1}\right) & =\log (1-\alpha)+\log (1-\kappa)+\alpha \log \left(k_{t}\right)+\log \left(s_{t}\right) \\
& =\varkappa+\log \left(s_{t}\right)+\alpha\left[\alpha \log \left(k_{t-1}\right)+\log \left(s_{t-1}\right)\right] \\
& =\varkappa+\sum_{\tau=0}^{t} \alpha^{\tau} \log \left(s_{t-\tau}\right)+\alpha^{t+1} \log \left(k_{0}\right) \\
& =\varkappa_{t+1}+\sum_{\tau=0}^{t} \alpha^{\tau} \log \left(s_{t-\tau}\right)
\end{aligned}
$$


or

$$
\log \left(k_{t}\right)=\varkappa_{t}+\sum_{\tau=0}^{t-1} \alpha^{\tau} \log \left(s_{t-1-\tau}\right)=\varkappa_{t}+\sum_{\tau=1}^{t} \alpha^{\tau-1} \log \left(s_{t-\tau}\right)
$$

Therefore the objective of the Ramsey is given by (suppressing maximization-irrelevant constants)

$$
\begin{aligned}
\sum_{t=0}^{\infty} \omega_{t} V\left(k_{t}, s_{t}\right) & =\sum_{t=0}^{\infty} \omega_{t}\left[\log \left(1-s_{t}\right)+\alpha \beta \log \left(s_{t}\right)+\alpha(1+\alpha \beta) \log \left(k_{t}\right)\right] \\
& =\chi+\sum_{t=0}^{\infty} \omega_{t}\left[\log \left(1-s_{t}\right)+\alpha \beta \log \left(s_{t}\right)+\alpha(1+\alpha \beta) \sum_{\tau=1}^{\infty} \alpha^{\tau-1} \log \left(s_{t-\tau}\right)\right] \\
& =\chi+\sum_{t=0}^{\infty}\left[\omega_{t} \log \left(1-s_{t}\right)+\log \left(s_{t}\right)\left(\alpha \beta \omega_{t}+\alpha(1+\alpha \beta) \sum_{\tau=t+1}^{\infty} \omega_{\tau} \alpha^{\tau-(t+1)}\right)\right]
\end{aligned}
$$

and thus the social welfare function can be expressed purely in terms of saving rates as

$S W F\left(\left\{s_{t}\right\}_{t=0}^{\infty}\right)=\chi+\sum_{t=0}^{\infty} \omega_{t}\left[\log \left(1-s_{t}\right)+\log \left(s_{t}\right)\left(\alpha \beta+\alpha(1+\alpha \beta) \sum_{j=1}^{\infty} \frac{\omega_{t+j}}{\omega_{t}} \alpha^{j-1}\right)\right]$,

where $\chi$ is a constant that depends positively on the initial capital stock $k_{0}$, but is again irrelevant for maximization.

Taking first order conditions with respect to $s_{t}$ and setting it to zero delivers the optimal saving rate

$$
s_{t}=\frac{1}{1+\left(\alpha \beta+\alpha(1+\alpha \beta) \sum_{j=1}^{\infty} \frac{\omega_{t+j}}{\omega_{t}} \alpha^{j-1}\right)^{-1}} .
$$

\section{Characterization of (Unconstrained) Efficient Al- locations}

\section{C.1 Characterization of Pareto Efficient Allocations}

In this section we derive the solution to the unconstrained social planner problem and study whether the Ramsey government implements Pareto efficient allocations. The obvious answer is no, since an unconstrained social planner would provide full 
insurance against idiosyncratic $\eta$ shocks, which, given the market structure, is ruled out in any competitive equilibrium. We again invoke assumption 2 of logarithmic utility. The planner maximizes social welfare

$$
\omega_{-1} \int \log \left(c_{0}^{o}\left(\eta_{0}\right)\right) d \Psi\left(\eta_{0}\right)+\sum_{t=0}^{\infty} \omega_{t}\left[\log \left(c_{t}^{y}\right)+\beta \int \log \left(c_{t+1}^{o}\left(\eta_{t+1}\right)\right) d \Psi\left(\eta_{t+1}\right)\right]
$$

subject just to the sequence of resource constraints

$$
c_{t}^{y}+\int c_{t}^{o}\left(\eta_{t}\right) d \Psi\left(\eta_{t}\right)+k_{t+1}=k_{t}^{\alpha}
$$

As before, we restrict attention to geometrically declining welfare weights such that $\omega_{t+1} / \omega_{t}=\theta \leq 1$.

Trivially, the social planner provides full insurance against idiosyncratic income risk so that $c_{t}^{o}(\eta)=c_{t}^{o}$ for all $\eta$ and all $t$. Thus the problem simplifies to

$$
\begin{aligned}
& \max _{\left\{c_{t}^{y}, c_{t}^{o}, k_{t+1}\right\}} \omega_{-1} \log \left(c_{0}^{o}\right)+\sum_{t=0}^{\infty} \omega_{t}\left[\log \left(c_{t}^{y}\right)+\beta \log \left(c_{t+1}^{o}\right)\right] \\
& \text { s.t. } \\
& c_{t}^{y}+c_{t}^{o}+k_{t+1}=k_{t}^{\alpha}
\end{aligned}
$$

with $k_{0}>0$ given. The first order conditions are given by

$$
\begin{aligned}
\frac{\omega_{t}}{c_{t}^{y}} & =\lambda_{t} \\
\frac{\beta \omega_{t-1}}{c_{t}^{o}} & =\lambda_{t} \\
\lambda_{t} & =\lambda_{t+1} \alpha k_{t+1}^{\alpha-1} \\
c_{t}^{y}+c_{t}^{o}+k_{t+1} & =k_{t}^{\alpha}
\end{aligned}
$$

Thus the optimal allocation of consumption across the two generations at a given point of time is given by

$$
\frac{c_{t}^{o}}{c_{t}^{y}}=\frac{\beta \omega_{t-1}}{\omega_{t}}=\frac{\beta}{\theta}
$$


and thus from the resource constraint

$$
\begin{aligned}
c_{t}^{y} & =\frac{\theta}{\theta+\beta}\left(k_{t}^{\alpha}-k_{t+1}\right) \\
c_{t}^{o} & =\frac{\beta}{\theta+\beta}\left(k_{t}^{\alpha}-k_{t+1}\right) .
\end{aligned}
$$

Define, similarly to the Ramsey problem, the saving rate of the social planner as

$$
s_{t}=\frac{k_{t+1}}{(1-\kappa)(1-\alpha) k_{t}^{\alpha}}
$$

or

$$
(1-\kappa)(1-\alpha) s_{t}=\frac{k_{t+1}}{k_{t}^{\alpha}} .
$$

Then from the first order conditions we get

$$
\begin{aligned}
\frac{1}{c_{t}^{y}} & =\frac{\beta}{c_{t+1}^{o}} \alpha k_{t+1}^{\alpha-1} \\
\frac{k_{t+1}}{\left(k_{t}^{\alpha}-k_{t+1}\right)} & =\frac{\alpha \theta k_{t+1}^{\alpha}}{\left(k_{t+1}^{\alpha}-k_{t+2}\right)} \\
\left(1-(1-\kappa)(1-\alpha) s_{t+1}\right) & =\alpha \theta\left(\frac{1}{(1-\kappa)(1-\alpha) s_{t}}-1\right) .
\end{aligned}
$$

As in the neoclassical growth model we can show that the only solution to the first order difference equation that does not eventually violate the non-negativity constraint of consumption and does not violate the TVC is the constant saving rate $s$ solving

$$
(1-(1-\kappa)(1-\alpha) s)=\alpha \theta\left(\frac{1}{(1-\kappa)(1-\alpha) s}-1\right)
$$

Define $\tilde{s}=(1-\kappa)(1-\alpha) s$ then we have

$$
1-\tilde{s}=\alpha \theta\left(\frac{1}{\tilde{s}}-1\right)
$$

with solutions $\tilde{s}=1$ and $\tilde{s}=\alpha \theta$ and thus

$$
s^{S P}=\frac{\alpha \theta}{(1-\kappa)(1-\alpha)} .
$$

The optimal sequence of capital stocks, starting from initial capital stock $k_{0}$, is there- 
fore given by

$$
\begin{aligned}
k_{t+1} & =(1-\kappa)(1-\alpha) s_{t} k_{t}^{\alpha} \\
& =\alpha \theta k_{t}^{\alpha} .
\end{aligned}
$$

Since

$$
k_{t}^{\alpha}-k_{t+1}=(1-\alpha \theta) k_{t}^{\alpha}
$$

we immediately have

Proposition 12. The solution to the social planner problem, for any $k_{0}>0$, is given by a constant saving rate

$$
s^{S P}=\frac{k_{t+1}}{(1-\kappa)(1-\alpha) k_{t}^{\alpha}}=\frac{\alpha \theta}{(1-\kappa)(1-\alpha)}
$$

and associated sequence of capital stocks

$$
k_{t+1}=\alpha \theta k_{t}^{\alpha}
$$

and consumption levels

$$
\begin{aligned}
c_{t}^{y} & =\frac{\theta(1-\alpha \theta) k_{t}^{\alpha}}{\theta+\beta} \\
c_{t}^{o} & =\frac{\beta(1-\alpha \theta) k_{t}^{\alpha}}{\theta+\beta}
\end{aligned}
$$

Corollary 6. If $\theta=1$ (associated with a steady state analysis), then the social planner chooses the golden rule saving rate

$$
s^{S P}=s^{G R}=\frac{\alpha}{(1-\kappa)(1-\alpha)}
$$

and the capital stock converges, in the long run, to

$$
k^{G R}=\alpha^{\frac{1}{1-\alpha}}
$$

which satisfies

$$
\alpha\left[k^{G R}\right]^{\alpha-1}=1
$$


and associated consumption levels

$$
\begin{aligned}
c^{y} & =\frac{(1-\alpha)}{1+\beta} \alpha^{\frac{\alpha}{1-\alpha}} \\
c_{t}^{o} & =\frac{\beta(1-\alpha)}{1+\beta} \alpha^{\frac{\alpha}{1-\alpha}}
\end{aligned}
$$

Thus the social planner chooses the golden rule capital stock $k^{G R}$ that maximizes net output $y^{G R}=\left(k^{G R}\right)^{\alpha}-k^{G R}$ and splits it efficiently between $c^{y}$ and $c^{o}$ according to the rule $c^{o}=\beta c^{y}$.

The next corollary states an obvious result:

Corollary 7. The Ramsey equilibrium is not Pareto efficient because it does not provide full consumption insurance against idiosyncratic income risk.

Of course this result is fully expected and not noteworthy at all, since the Ramsey government has no powers to affect or offset the market incompleteness inherent in our model. What is more remarkable is that even though the optimal Ramsey saving rate is independent of income risk (and the same as in a model where income risk is absent), it is in general different from the saving rate optimally chosen by the social planner (who fully insures the idiosyncratic income risk). This result is summarized in the next

Corollary 8. For a fixed social discount factor $\theta \in[0,1]$, the optimal Ramsey saving rate equals the saving rate chosen by the social planner if and only if the following knife edge condition is satisfied:

$$
(1-\kappa)=\frac{\theta(1+\alpha \beta)}{(1-\alpha)(\beta+\theta)}
$$

Note that the Ramsey government can surely implement the saving rate desired by the social planner through an appropriate choice of taxes, but unless the condition above is satisfied, it is suboptimal to do so. The reason is that the Ramsey government has no instruments to transfer resources across generations and thus forcing the planner saving rate onto households (by appropriate choice of the capital tax rate) results in an equilibrium allocation of consumption across the young and the old that is typically suboptimal. ${ }^{25}$

\footnotetext{
${ }^{25}$ Finally note that if one were to treat the social discount factor $\theta$ as a free parameter, then one
} 


\section{C.2 Proof of Constrained Efficiency of Ramsey Allocation}

Proof. Define the saving rate of the constrained planner as

$$
s_{t}=\frac{k_{t+1}}{(1-\kappa) M P L\left(k_{t}\right)}=\frac{k_{t+1}}{(1-\alpha)(1-\kappa) k_{t}^{\alpha}}
$$

and thus the law of motion for the effective capital stock for the constrained planner is

$$
k_{t+1}=s_{t}(1-\alpha)(1-\kappa) k_{t}^{\alpha}
$$

as in the Ramsey problem. Furthermore, from the constraints on the constrained planner

$$
\begin{aligned}
c_{t}^{y} & =(1-\kappa) M P L\left(k_{t}\right)-k_{t+1}=\left(1-s_{t}\right)(1-\kappa)(1-\alpha) k_{t}^{\alpha} \\
c_{t+1}^{o}\left(\eta_{t+1}\right) & =k_{t+1} \operatorname{MPK}\left(k_{t+1}\right)+\kappa \eta_{t+1} M P L\left(k_{t+1}\right) \\
& =\alpha k_{t+1}^{\alpha}+\kappa \eta_{t+1}(1-\alpha) k_{t+1}^{\alpha} \\
& =\left[\alpha+\kappa \eta_{t+1}(1-\alpha)\right] k_{t+1}^{\alpha} \\
& =\left[\alpha+\kappa \eta_{t+1}(1-\alpha)\right]\left[s_{t}(1-\alpha)(1-\kappa) k_{t}^{\alpha}\right]^{\alpha}
\end{aligned}
$$

and thus consumption levels are the same as in the Ramsey equilibrium. Thus the solution, in terms of saving rates, of the constrained planner problem is identical to that of the Ramsey equilibrium.

\section{C.3 Dynamic Inefficiency of the Competitive Equilibrium and Positive Capital Taxation}

In this section we provide the details of the steady state analysis of the Ramsey problem and its connection with the dynamic efficiency of the steady state equilibrium absent government policy. First, recall that the golden rule capital stock, saving rate concludes that the Ramsey optimal saving rate is efficient, in that it is identical to the choice of the social planner with a different social discount rate $\theta^{S P}$

$$
\theta^{S P}=\frac{(\beta+\theta)(1-\kappa)(1-\alpha)}{1+\alpha \beta} .
$$


and associated gross real interest rate are given by (see proposition 6)

$$
\begin{aligned}
k^{G R} & =\alpha^{\frac{1}{1-\alpha}} \\
s^{G R} & =\frac{\alpha}{(1-\kappa)(1-\alpha)} \\
R^{G R} & =1
\end{aligned}
$$

Second, we note that the steady state gross interest rate is given by

$$
R=\alpha k^{\alpha-1}
$$

and from the law of motion of capital (equation (12)) we have

$$
k=s(1-\kappa)(1-\alpha) k^{\alpha}
$$

and thus

$$
R=\frac{\alpha}{s(1-\kappa)(1-\alpha)} .
$$

The steady state saving rate in turn is given by (see equation (17))

$$
s_{\tau}(\eta)=\frac{1}{1+[(1-\tau) \alpha \beta \Gamma]^{-1}}=\frac{(1-\tau) \alpha \beta \Gamma}{1+(1-\tau) \alpha \beta \Gamma}
$$

Thus we have a steady state relation between the real interest rate and the tax rate determined by

$$
R=\frac{\frac{1}{(1-\tau) \beta \Gamma}+\alpha}{(1-\kappa)(1-\alpha)}=R(\tau ; \Gamma)
$$

and thus a higher tax rate reduces the saving rate, thus the capital stock and thus increases the real interest rate. Furthermore, for a given $\tau$, the steady state interest rate is decreasing in the amount of income risk (unless $\beta=0$ ). Therefore the steady state interest rate in the absence of government policy is given by

$$
R(\tau=0 ; \Gamma)=\frac{\frac{1}{\beta \Gamma}+\alpha}{(1-\kappa)(1-\alpha)}
$$

and thus the steady state competitive equilibrium without taxes is dynamically inefficient, i.e.

$$
R(\tau=0 ; \Gamma)<1
$$


if and only if

$$
\frac{\frac{1}{\beta \Gamma}+\alpha}{(1-\kappa)(1-\alpha)}<1
$$

or if and only if

$$
\begin{aligned}
\frac{1}{[(1-\kappa)(1-\alpha)-\alpha] \Gamma} & <\beta \\
\Theta_{1}(\Gamma) & :=\frac{1}{(1-\alpha) \Gamma-\Gamma / \bar{\Gamma}}<\beta
\end{aligned}
$$

where $\bar{\Gamma} \leq \Gamma$, with equality if $\eta$ is degenerate at $\eta=1$, and thus there is no income risk.

The optimal Ramsey steady state (i.e., $\theta=1$ ) saving and tax rates (see equations (29) and (30)) are given by

$$
\begin{aligned}
s^{*} & =\frac{\alpha(1+\beta)}{1+\alpha \beta} \\
1-\tau & =\frac{1+\beta}{(1-\alpha) \beta \Gamma}
\end{aligned}
$$

and thus the optimal Ramsey tax rate is positive, $\tau>0$, if and only if

$$
\frac{(1+\beta)}{(1-\alpha) \beta \Gamma}<1
$$

or if and only if

$$
\Theta_{2}:=\frac{1}{(1-\alpha) \Gamma-1}<\beta
$$

Since

$$
\Theta_{2}(\Gamma)=\frac{1}{(1-\alpha) \Gamma-1} \leq \frac{1}{(1-\alpha) \Gamma-\Gamma / \bar{\Gamma}}=\Theta_{1}(\Gamma)
$$

with equality if and only if $\eta$ is degenerate at $\eta=1$, we conclude that if the competitive equilibrium absent taxes is dynamically inefficient, the optimal Ramsey steady state capital tax rate is positive. The reverse is not true, however. 
Comparing saving rates we have

$$
\begin{aligned}
s^{*} & =\frac{\alpha(1+\beta)}{1+\alpha \beta} \\
s_{0}(\eta) & =\frac{1}{1+[\alpha \beta \Gamma]^{-1}} \\
s^{G R} & =\frac{\alpha}{(1-\kappa)(1-\alpha)}
\end{aligned}
$$

and thus $s_{0}(\eta)>s^{G R}$ if and only if

$$
\beta>\frac{1}{[(1-\kappa)(1-\alpha)-\alpha] \Gamma}
$$

and thus if and only if the steady state equilibrium is dynamically inefficient. Furthermore $s^{*}<s_{0}(\eta)$ if and only if $\Theta_{2}(\Gamma)<\beta$ and thus if and only if $\tau>0$.

Stating inequalities (50) and (51) in terms of $\Gamma$ gives proposition 4 in the main text. Furthermore, here we collect the relationship between dynamic inefficiency and a positive Ramsey steady state capital tax rate in the following

Proposition 13. Let $\theta=1$. If the steady state competitive equilibrium is dynamically inefficient, then the optimal Ramsey tax rate $\tau$ is positive. If in addition $\eta$ is degenerate at $\eta=1$, then the reverse is true as well: $\tau>0$ only if the steady state competitive equilibrium is dynamically inefficient.

\section{C.4 Proof of Pareto-Improving Tax-Induced Transition}

Proof of Proposition 6. The capital stock evolves according to the law of motion

$$
k_{t+1}=s(1-\kappa)(1-\alpha) k_{t}^{\alpha}
$$

Therefore if the Ramsey government implements $s^{*}$ through positive capital taxes in the first period of the transition this will lead to a falling capital stock along the transition. Recall from (1) that utility of a generation born in period $t$ is given by

$$
V_{t}=\ln \left(c_{t}^{y}\right)+\beta \int \ln \left(c_{t+1}^{o}\left(\eta_{t+1}\right)\right) d \Psi
$$


Now, suppose that the policy is implemented (as a surprise) in period 1 where $k_{1}=k_{0}$. The initial old are unaffected by and thus indifferent to the tax reform. Now we need to characterize the utility consequences for all generations born along the transition. Denoting by $s_{0}=s_{0}(\eta)$ the equilibrium saving rate in the initial steady state, we have

$\Delta V_{t}=V_{t}\left(s^{*}\right)-V_{t}\left(s_{0}\right)=\ln \left(c_{t}^{y}\left(s^{*}\right)\right)-\ln \left(c_{t}^{y}\left(s_{0}\right)\right)+\beta \int\left(\ln \left(c_{t+1}^{o}\left(s^{*}\right)\right)-\ln \left(c_{t+1}^{o}\left(s_{0}\right)\right)\right) d \Psi$.

where the consumption allocations can be written as

$$
\begin{aligned}
c_{t}^{y}\left(s_{t}\right) & =\left(1-s_{t}\right)(1-\kappa)(1-\alpha) k_{t}^{\alpha} \\
c_{t+1}^{o}\left(\eta_{t+1} ; s_{t}\right) & =s_{t}(1-\kappa)(1-\alpha) k_{t}^{\alpha} \alpha k_{t+1}^{\alpha-1}+\kappa \eta_{t+1}(1-\alpha) k_{t+1}^{\alpha} \\
& =\left[\alpha+\kappa \eta_{t+1}(1-\alpha)\right] k_{t+1}^{\alpha}
\end{aligned}
$$

Thus

$$
\Delta V_{t}=\underbrace{\ln \left(1-s^{*}\right)-\ln \left(1-s_{0}\right)}_{=\Lambda_{1}>0}+\underbrace{\alpha\left(\ln \left(k_{t}\left(s^{*}\right)\right)-\ln \left(k_{0}\right)\right)+\alpha \beta\left(\ln \left(k_{t+1}\left(s^{*}\right)\right)-\ln \left(k_{0}\right)\right)}_{=\Lambda_{2, t}<0}
$$

Term $\Lambda_{1}$ is positive because $s^{*}<s_{0}$, and constant in $t$. Term $\Lambda_{2, t}$ is negative for all generations $t$ because $k_{t}\left(s^{*}\right) \leq k_{0}$ for all $t$ and because $k_{t+1}\left(s^{*}\right)<k_{0}$ for all $t$. Furthermore $\Lambda_{2, t}$ monotonically declines and converges from above to its minimum for $t \rightarrow \infty$ when the economy reaches the optimal steady state capital allocation where

$$
\lim _{t \rightarrow \infty} \Lambda_{2, t}=\alpha(1+\beta)\left(\ln \left(k^{*}\right)-\ln \left(k_{0}\right)\right) .
$$

But because $s^{*}$ maximizes steady state utility and $s_{0} \neq s^{*}$, we know that

$$
\lim _{t \rightarrow \infty} \Delta V_{t}=\Lambda_{1}+\lim _{t \rightarrow \infty} \Lambda_{2, t}>0 .
$$

It then follows that

$$
\Delta V_{t} \geq \lim _{\tau \rightarrow \infty} \Delta V_{\tau}>0
$$

and thus all transition generations strictly benefit from the tax reform. 


\section{C.5 Savings Subsidy Does Not Induce Pareto Improvement}

In this section we show that even if $s_{0}(\eta)<s^{*}$, implementing the Ramsey optimal (for $\theta=1$ ) savings subsidy $\tau^{*}<0$ and associated higher saving rate $s^{*}$ does not lead to a Pareto improving transition.

Exploiting the fact that in the first period of the transition the capital stock $k_{1}=k_{0}$ is predetermined, and the capital stock in period 2 satisfies

$$
k_{2}=s(1-\alpha)(1-\kappa) k_{0}^{\alpha}
$$

for any saving rate implemented by a given tax policy. Thus we can calculate lifetime utility of the first transition generation, as a function of an implemented saving rate $s$, as

$$
\begin{aligned}
V_{1}(s) & =\ln \left((1-s)(1-\kappa)(1-\alpha) k_{0}^{\alpha}\right)+\beta \int \ln \left(\alpha+\kappa \eta_{2}(1-\alpha)\right)\left(s(1-\alpha)(1-\kappa) k_{0}^{\alpha}\right)^{\alpha} d \Psi(\eta) \\
& =\ln (1-s)+\beta \alpha \ln (s)+\ln \left((1-\kappa)(1-\alpha) k_{0}^{\alpha}\right) \\
& +\beta \int \ln \left(\alpha+\kappa \eta_{2}(1-\alpha)\right)\left((1-\alpha)(1-\kappa) k_{0}^{\alpha}\right)^{\alpha} d \Psi(\eta)
\end{aligned}
$$

and thus

$$
\begin{aligned}
V_{1}^{\prime}(s) & =-\frac{1}{1-s}+\frac{\alpha \beta}{s} \\
V_{1}^{\prime \prime}(s) & =-\frac{1}{(1-s)^{2}}-\frac{\alpha \beta}{s^{2}}<0
\end{aligned}
$$

and thus $V_{1}(s)$ is strictly concave in $s$. Therefore, if $V_{1}^{\prime}\left(s=s_{0}(\eta)\right) \leq 0$, then $V(s=$ $\left.s_{0}(\eta)\right)>V(s)$ for all $s>s_{0}(\eta)$. We have

$$
\begin{aligned}
V_{1}^{\prime}(s= & \left.s_{0}(\eta)\right)=-\frac{1}{1-s_{0}(\eta)}+\alpha \beta \frac{1}{s_{0}(\eta)} \leq 0 \\
& \Leftrightarrow \quad s_{0}(\eta) \geq \frac{\alpha \beta}{1+\alpha \beta}
\end{aligned}
$$

which is satisfied, exploiting expression (17) for the optimal competitive equilibrium saving rate (with zero taxes).

Thus not only is implementing $\tau^{*}<0$ not Pareto improving if $s_{0}(\eta)<s^{*}$, but in fact any policy reform that induces a saving rate in period 1 above the competitive 
saving rate with zero taxes, $s_{0}(\eta)$, will not result in a Pareto improvement (since it will make the first generation strictly worse off).

\section{Analysis of General Epstein-Zin Utility}

Now consider general Epstein-Zin preferences, applied to our two period OLG model. Households have preferences over deterministic consumption when young, $c_{t}^{y}$, and the (deterministic) certainty equivalent over utility from consumption tomorrow, $\int c_{t+1}^{o}\left(\eta_{t+1}\right)^{1-\sigma} d \Psi$. We assume that these preferences are represented by the lifetime utility function

$$
V_{t}=\frac{\left(c_{t}^{y}\right)^{1-\frac{1}{\rho}}-1}{1-\frac{1}{\rho}}+\beta \frac{\left\{\left[\int c_{t+1}^{o}\left(\eta_{t+1}\right)^{1-\sigma} d \Psi\right]^{\frac{1}{1-\sigma}}\right\}^{1-\frac{1}{\rho}}-1}{1-\frac{1}{\rho}}
$$

Note that in the limit, as the IES $\rho \rightarrow 1$, the utility function becomes

$$
V_{t}=\ln \left(c_{t}^{y}\right)+\frac{\beta}{1-\sigma} \ln \left(\int c_{t+1}^{o}\left(\eta_{t+1}\right)^{1-\sigma} d \Psi\right)
$$

and as $\rho \rightarrow \infty$, we have

$$
V_{t}=c_{t}^{y}+\beta\left[\int c_{t+1}^{o}\left(\eta_{t+1}\right)^{1-\sigma} d \Psi\right]^{\frac{1}{1-\sigma}}
$$

Finally, if in addition $\sigma \rightarrow \infty$, then

$$
V_{t}=c_{t}^{y}+\beta \inf _{\eta_{t+1}}\left\{c_{t+1}^{o}\left(\eta_{t+1}\right)\right\}
$$

and indifference curves are linear in the time dimension and Leontieff in the state dimension, where only the worst $\eta$ state gets weight. ${ }^{26}$

We should point out that often in the literature Epstein-Zin preferences of the

\footnotetext{
${ }^{26}$ In this case we need to insure that $\inf _{\eta_{t+1}} c_{t+1}^{o}\left(\eta_{t+1}\right) \geq 0$ under any distribution of risk we consider (including those obtained by mean-preserving spreads of the original distribution). Evidently, if $\eta_{t+1}$ is drawn from compact support then the inf can be replaced by the min .
} 
form

$$
\tilde{V}_{t}=\left\{(1-\tilde{\beta})\left(c_{t}^{y}\right)^{1-\frac{i_{1}}{\rho}}+\tilde{\beta}\left[\int c_{t+1}^{o}\left(\eta_{t+1}\right)^{1-\sigma} d \Psi\right]^{\frac{1-\frac{1}{\rho}}{1-\sigma}}\right\}^{\frac{1}{1-\frac{1}{\rho}}}
$$

are used. When it comes to ordinal rankings of allocations, we can take monotonic transformations of (53) without changing preference rankings. Thus for all ordinal purposes the formulations in (52) and (53) are equivalent since

$$
V_{t}=\frac{\tilde{V}_{t}^{1-\frac{1}{\rho}}}{(1-\tilde{\beta})\left(1-\frac{1}{\rho}\right)}-\frac{(1+\beta)}{1-\frac{1}{\rho}}
$$

where $\beta=\frac{\tilde{\beta}}{1-\tilde{\beta}}$.

However, also note that, in contrast to any analyses that only require ordinal rankings (such as studying competitive equilibrium for a given tax system), when moving from utility form $V_{t}$ to $\tilde{V}_{t}$ we are changing the Ramsey problem, since this problem is based on cardinal weighted lifetime utilities. It is therefore not innocuous whether we choose (53) or (52) when formulating the Ramsey optimal tax problem. ${ }^{27}$ If, however, we restrict attention to a steady state analysis, then this last concern does not emerge, since the first order condition characterizing the optimal Ramsey steady state saving rate is identical under any monotone transformation of steady state lifetime lifetime utility (as effectively the only generation that is relevant for the maximization is the long-run, steady state generation).

\section{D.1 Competitive Equilibrium for Given Tax Policy}

Household maximization delivers

$$
\begin{aligned}
\left(c_{t}^{y}\right)^{-\frac{1}{\rho}} & =\beta\left(1-\tau_{t+1}\right) R_{t+1}\left[\int c_{t+1}^{o}\left(\hat{\eta}_{t+1}\right)^{1-\sigma} d \Psi\right]^{\frac{1-\frac{1}{\rho}}{1-\sigma}-1} \int c_{t+1}^{o}\left(\eta_{t+1}\right)^{-\sigma} d \Psi\left(\eta_{t+1}\right) \\
1 & =\beta\left(1-\tau_{t+1}\right) R_{t+1}\left[\int\left(\frac{c_{t+1}^{o}\left(\eta_{t+1}\right)}{c_{t}^{y}}\right)^{1-\sigma} d \Psi\left(\eta_{t+1}\right)\right]^{\frac{\sigma-\frac{1}{\rho}}{1-\sigma}} \int\left(\frac{c_{t+1}^{o}\left(\eta_{t+1}\right)}{c_{t}^{y}}\right)^{-\sigma} d \Psi\left(\eta_{t+1}\right) .
\end{aligned}
$$

\footnotetext{
${ }^{27}$ For both formulations the household is not indifferent to the resolution of income risk as long as $\sigma \neq \frac{1}{\rho}$.
} 
Now, we need to work out the ratio

$$
\begin{aligned}
\frac{c_{t+1}^{o}\left(\eta_{t+1}\right)}{c_{t}^{y}} & =\frac{s_{t} R_{t+1}\left(1-\tau_{t+1}\right)(1-\kappa) w_{t}+\kappa \eta_{t+1} w_{t+1}+T_{t+1}}{(1-\kappa) w_{t}\left(1-s_{t}\right)} \\
& =\left[\alpha+(1-\alpha) \kappa \eta_{t+1}\right] \frac{s_{t}}{1-s_{t}} k_{t+1}^{\alpha-1}
\end{aligned}
$$

and thus

$$
\begin{aligned}
& 1=\beta\left(1-\tau_{t+1}\right) R_{t+1}\left[\int\left(\frac{c_{t+1}^{o}\left(\eta_{t+1}\right)}{c_{t}^{y}}\right)^{1-\sigma} d \Psi\left(\eta_{t+1}\right)\right]^{\frac{\sigma-\frac{1}{\rho}}{1-\sigma}} \int\left(\frac{c_{t+1}^{o}\left(\eta_{t+1}\right)}{c_{t}^{y}}\right)^{-\sigma} d \Psi\left(\eta_{t+1}\right) \\
& 1=\beta\left(1-\tau_{t+1}\right) R_{t+1}\left(\frac{s_{t} k_{t+1}^{\alpha-1}}{1-s_{t}}\right)^{-\frac{1}{\rho}} \tilde{\Gamma} \\
& 1=\alpha \beta\left(1-\tau_{t+1}\right)\left(k_{t+1}^{\alpha-1}\right)^{\left(1-\frac{1}{\rho}\right)}\left(\frac{s_{t}}{1-s_{t}}\right)^{-\frac{1}{\rho}} \tilde{\Gamma} \\
& 1=\alpha \beta\left(1-\tau_{t+1}\right)\left(s_{t}(1-\kappa)(1-\alpha) k_{t}^{\alpha}\right)^{(\alpha-1)\left(1-\frac{1}{\rho}\right)}\left(\frac{s_{t}}{1-s_{t}}\right)^{-\frac{1}{\rho}} \tilde{\Gamma} \\
& 1=\alpha \beta\left(1-\tau_{t+1}\right)\left(s_{t}(1-\kappa)(1-\alpha) k_{t}^{\alpha}\right)^{(\alpha-1)\left(1-\frac{1}{\rho}\right)}\left(\frac{s_{t}}{1-s_{t}}\right)^{-\frac{1}{\rho}} \tilde{\Gamma} \\
& 1=\alpha \beta((1-\kappa)(1-\alpha))^{(\alpha-1)\left(1-\frac{1}{\rho}\right)}\left(1-\tau_{t+1}\right) k_{t}^{\alpha(\alpha-1)\left(1-\frac{1}{\rho}\right)} s_{t}^{(\alpha-1)\left(1-\frac{1}{\rho}\right)}\left(\frac{1-s_{t}}{s_{t}}\right)^{\frac{1}{\rho}} \tilde{\Gamma} .
\end{aligned}
$$

In the main text we are mainly concerned with characterizing the Ramsey steady state saving and associated tax rate. In steady state the Euler equation reads as

$$
1=\alpha \beta((1-\kappa)(1-\alpha))^{(\alpha-1)\left(1-\frac{1}{\rho}\right)}(1-\tau) k^{\alpha(\alpha-1)\left(1-\frac{1}{\rho}\right)} s^{(\alpha-1)\left(1-\frac{1}{\rho}\right)}\left(\frac{1-s}{s}\right)^{\frac{1}{\rho}} \tilde{\Gamma}
$$

where

$$
k=[(1-\kappa)(1-\alpha) s]^{\frac{1}{1-\alpha}}
$$

is the steady state capital stock. Inserting the steady state capital stock into the Euler equation delivers

$$
1=(1-\tau) \alpha \beta((1-\kappa)(1-\alpha))^{\left(\frac{1}{\rho}-1\right)} s^{\left(\frac{1}{\rho}-1\right)}\left(\frac{1-s}{s}\right)^{\frac{1}{\rho}} \tilde{\Gamma}
$$


Or

$$
1=(1-\tau) \alpha \beta((1-\kappa)(1-\alpha))^{\left(\frac{1}{\rho}-1\right)} \frac{(1-s)^{\frac{1}{\rho}}}{s} \tilde{\Gamma}
$$

where

$$
\begin{aligned}
\tilde{\Gamma} & =\frac{\int(\alpha+(1-\alpha) \kappa \eta)^{-\sigma} d \Psi(\eta)}{\left[\int(\alpha+(1-\alpha) \kappa \eta)^{1-\sigma} d \Psi(\eta)\right]^{\frac{1}{\rho}-\sigma}}=c e(\eta)^{\left(\sigma-\frac{1}{\rho}\right)} \Gamma . \\
\Gamma & =\int(\alpha+(1-\alpha) \kappa \eta)^{-\sigma} d \Psi(\eta)
\end{aligned}
$$

and where the certainty equivalent of $\eta$ is defined as, for $\sigma \neq 1$

$$
c e(\eta)=\left[\int(\alpha+(1-\alpha) \kappa \eta)^{1-\sigma} d \Psi(\eta)\right]^{\frac{1}{1-\sigma}}
$$

and for $\sigma=1$

$$
c e(\eta)=\exp \left(\int \ln (\alpha+(1-\alpha) \kappa \eta) d \Psi(\eta)\right) .
$$

Note that this result is precisely the generalization of the log-case where $\rho=\sigma=1$, and where the Euler equation was given as

$$
\begin{aligned}
1 & =(1-\tau) \alpha \beta\left(\frac{1-s}{s}\right) \Gamma \\
\Gamma & =\int(\kappa \eta(1-\alpha)+\alpha)^{-1} d \Psi(\eta)
\end{aligned}
$$

Thus our previous analysis for log-utility is just a special case. Also note that if $\rho=1$ but $\sigma \neq 1$, then the steady state Euler equation is given by

$$
1=(1-\tau) \alpha \beta\left(\frac{1-s}{s}\right)^{\frac{1}{\rho}} \tilde{\Gamma}
$$

but

$$
\tilde{\Gamma}=\frac{\int(\alpha+(1-\alpha) \kappa \eta)^{-\sigma} d \Psi(\eta)}{\left[\int(\alpha+(1-\alpha) \kappa \eta)^{1-\sigma} d \Psi(\eta)\right]} \neq \int(\kappa \eta(1-\alpha)+\alpha)^{-1} d \Psi(\eta)=\Gamma_{\sigma=1}
$$




\section{D.1.1 Precautionary Savings Behavior in the Competitive Equilibrium}

In order to aid with the interpretation of the optimal Ramsey tax rate it is useful to establish conditions under which, for a fixed tax rate constant, the saving rate in a competitive general equilibrium is increasing in income risk.

Proposition 14. If $\tilde{\Gamma}$ is strictly increasing in income risk, then for any given tax rate $\tau \in(-\infty, 1)$ the steady state saving rate $s^{C E}(\tau)$ in competitive equilibrium is strictly increasing in income risk. If $\tilde{\Gamma}$ is strictly decreasing in income risk, then so is $s^{C E}(\tau)$. Proof. Rewrite equation (55) as

$$
f(s)=(1-\tau) \alpha \beta((1-\kappa)(1-\alpha))^{\left(\frac{1}{\rho}-1\right)} \frac{(1-s)^{\frac{1}{\rho}}}{s}-\frac{1}{\tilde{\Gamma}} .
$$

Then a saving rate $s^{C E}(\tau)$ that satisfies $f\left(s^{C E}(\tau)\right)=0$ is a steady state equilibrium saving rate. We readily observe that $f$ is continuous and strictly decreasing in $s$, with

$$
\begin{aligned}
\lim _{s \rightarrow 0} f(s) & =\infty \\
f(1) & =-\frac{1}{\tilde{\Gamma}}<0
\end{aligned}
$$

and thus for each $\tau \in(-\infty, 1)$ there is a unique $s=s^{C E}(\tau)$ that satisfies $f\left(s^{C E}(\tau)\right)=$ 0 . Inspection of $f$ immediately reveals that $s^{C E}(\tau)$ is strictly increasing in $\tilde{\Gamma}$, from which the comparative statics results immediately follow.

Corollary 9. For any given $\tau \in(-\infty, 1)$, the steady state saving rate $s^{C E}(\tau)$ increases in income risk if either $\rho \leq 1$, or $1<\rho<\frac{1}{\sigma}$.

Proof. Follows directly from the previous proposition and Lemma 1 characterizing the behavior of $\tilde{\Gamma}$ with respect to income risk.

Proposition 14 establishes a sufficient condition for the private saving rate to increase in income risk. But, for $\rho>\frac{1}{\sigma}>1$ it might be possible that the combination of individual precautionary savings behavior and general equilibrium factor price movements lead to the result that, for fixed government policy, the equilibrium saving rate is decreasing in income risk. ${ }^{28}$ We will show below that this in turn is a necessary condition for the optimal Ramsey tax rate to decrease in income risk.

\footnotetext{
${ }^{28}$ Also observe that a parameter constellation $1<\rho<\frac{1}{\sigma}$ pairs a high IES with a preference
} 


\section{D.2 Ramsey Problem for Unit IES}

Now suppose we use the formulation of lifetime utility in equation (52). Then it is straightforward to show that for $\rho=1$ the analysis of the Ramsey problem proceeds exactly as before,

$$
\begin{aligned}
W(k)= & \Theta_{0}+\Theta_{1} \log (k) \\
= & \max _{s \in[0,1]}\left\{\log \left((1-s)(1-\kappa)(1-\alpha) k^{\alpha}\right)\right. \\
& \left.+\frac{\beta}{1-\sigma} \log \int\left(\kappa \eta w(s)+R(s) s(1-\kappa)(1-\alpha) k^{\alpha}\right)^{1-\sigma} d \Psi(\eta)+\theta W\left(k^{\prime}\right)\right\} \\
= & \max _{s \in[0,1]}\left\{\log \left((1-s)(1-\kappa)(1-\alpha) k^{\alpha}\right)\right. \\
& \left.+\frac{\beta}{1-\sigma} \log \int\left([\kappa \eta(1-\alpha)+\alpha]\left[s(1-\kappa)(1-\alpha) k^{\alpha}\right]^{\alpha}\right)^{1-\sigma} d \Psi(\eta)+\theta W\left(s(1-\kappa)(1-\alpha) k^{\alpha}\right)\right\} \\
= & \alpha\left[1+\theta \Theta_{1}+\alpha \beta\right] \log (k)+\log [(1-\kappa)(1-\alpha)]+\theta \Theta_{0}+\theta \Theta_{1} \log ((1-\kappa)(1-\alpha)) \\
& +\beta \alpha \log [(1-\kappa)(1-\alpha)]+\frac{\beta \log \int[\kappa \eta(1-\alpha)+\alpha]^{1-\sigma} d \Psi(\eta)}{1-\sigma} \\
& +\max _{s \in[0,1]}\left\{\log (1-s)+\alpha \beta \log (s)+\theta \Theta_{1} \log (s)\right\}
\end{aligned}
$$

with an optimal saving rate as in the main text:

$$
s=\frac{\alpha(\beta+\theta)}{1+\alpha \beta} .
$$

These results clarify that the closed form solution, and the fact that the optimal saving rate is constant over time and independent of the level of capital, is driven by an $I E S=\rho=1$ (and obtained for arbitrary risk aversion), whereas the size of the capital tax needed to implement the optimal Ramsey allocation does depend on risk aversion $\sigma$, since this parameter determines the degree of precautionary saving in the competitive equilibrium that needs to be offset with capital taxes, see Section D.1.1.

for a late resolution of risk in a multi-period (more than two periods) model. Interestingly, the competitive equilibrium saving rate may therefore decrease in income risk precisely when we pair a high IES with a preference constellation for early resolution of risk. 


\section{D.3 Steady State Analysis for Arbitrary IES}

In the steady state we seek to maximize

$$
\begin{aligned}
V(s)= & \frac{\left(c_{t}^{y}\right)^{1-\frac{1}{\rho}}+\beta\left\{\left[\int c_{t+1}^{o}\left(\eta_{t+1}\right)^{1-\sigma} d \Psi\right]^{\frac{1}{1-\sigma}}\right\}^{1-\frac{1}{\rho}}}{1-\frac{1}{\rho}} \\
= & \frac{\left((1-\kappa)(1-s)(1-\alpha) k^{\alpha}\right)^{1-\frac{1}{\rho}}}{1-\frac{1}{\rho}} \\
& +\frac{\left.\beta\left[s(1-\kappa)(1-\alpha) k^{\alpha}\right]^{\alpha\left(1-\frac{1}{\rho}\right)}\left\{\left[\int\{\kappa \eta(1-\alpha)+\alpha]\right\}^{1-\sigma} d \Psi\right]^{\frac{1}{1-\sigma}}\right\}^{1-\frac{1}{\rho}}}{1-\frac{1}{\rho}} \\
= & \frac{((1-\kappa)(1-\alpha))^{1-\frac{1}{\rho}}}{1-\frac{1}{\rho}}(1-s)^{\left(1-\frac{1}{\rho}\right)} k^{\alpha\left(1-\frac{1}{\rho}\right)}+\frac{\beta[(1-\kappa)(1-\alpha)]^{\alpha\left(1-\frac{1}{\rho}\right)} \tilde{\Gamma}_{2}}{1-\frac{1}{\rho}} s^{\alpha\left(1-\frac{1}{\rho}\right)} k^{\alpha^{2}\left(1-\frac{1}{\rho}\right)}
\end{aligned}
$$

where

$$
\tilde{\Gamma}_{2}=\left[\int\{[\kappa \eta(1-\alpha)+\alpha]\}^{1-\sigma} d \Psi\right]^{\frac{1-\frac{1}{\rho}}{1-\sigma}}=\Gamma_{2}^{\frac{\sigma-\frac{1}{\rho}}{1-\sigma}} \Gamma_{2}
$$

Exploiting that

$$
k=((1-\kappa)(1-\alpha) s)^{\frac{1}{1-\alpha}}
$$

yields

$$
\begin{aligned}
V(s)= & \frac{((1-\kappa)(1-\alpha))^{1-\frac{1}{\rho}}}{1-\frac{1}{\rho}}(1-s)^{\left(1-\frac{1}{\rho}\right)}((1-\kappa)(1-\alpha) s)^{\frac{\alpha\left(1-\frac{1}{\rho}\right)}{1-\alpha}} \\
& +\frac{\beta[(1-\kappa)(1-\alpha)]^{\alpha\left(1-\frac{1}{\rho}\right)} \tilde{\Gamma}_{2}}{1-\frac{1}{\rho}}(s)^{\alpha\left(1-\frac{1}{\rho}\right)}((1-\kappa)(1-\alpha) s)^{\frac{\alpha^{2}\left(1-\frac{1}{\rho}\right)}{1-\alpha}} \\
= & \frac{((1-\kappa)(1-\alpha))^{\frac{1-\frac{1}{\rho}}{1-\alpha}}}{1-\frac{1}{\rho}}\left[(1-s)^{\left(1-\frac{1}{\rho}\right)}+\beta[(1-\kappa)(1-\alpha)]^{-\left(1-\frac{1}{\rho}\right)} \tilde{\Gamma}_{2}\right] s^{\frac{\alpha\left(1-\frac{1}{\rho}\right)}{1-\alpha}} \\
= & \tilde{\phi}\left((1-s)^{\left(1-\frac{1}{\rho}\right)}+\beta \tilde{\zeta} \tilde{\Gamma}_{2}\right) s^{\frac{\alpha\left(1-\frac{1}{\rho}\right)}{1-\alpha}}
\end{aligned}
$$


where

$$
\begin{aligned}
\tilde{\phi} & =\frac{((1-\kappa)(1-\alpha))^{\frac{1-\frac{1}{\rho}}{1-\alpha}}}{1-\frac{1}{\rho}} \\
\tilde{\zeta} & =\left(\frac{1}{(1-\kappa)(1-\alpha)}\right)^{\left(1-\frac{1}{\rho}\right)}>0 \\
\tilde{\Gamma}_{2} & =\left(\left[\int\{[\kappa \eta(1-\alpha)+\alpha]\}^{1-\sigma} d \Psi\right]^{\frac{1}{1-\sigma}}\right)^{1-\frac{1}{\rho}}>0
\end{aligned}
$$

as before. Thus the steady state analysis in the main text carries through to EpsteinZin utility almost entirely unchanged, but with the constant that maps earnings risk into the optimal saving rate now being affected both by risk aversion and the IES.

Hence, the optimal steady state saving rate is defined implicitly as

$$
\frac{s}{(1-s)^{\frac{1}{\rho}}}=\frac{\alpha}{1-\alpha}(1-s)^{\left(1-\frac{1}{\rho}\right)}+\beta \frac{\alpha}{1-\alpha} \tilde{\zeta} \tilde{\Gamma}_{2}
$$

and rewriting this equation yields

$$
L H S(s)=s=\frac{\alpha}{1-\alpha}\left[(1-s)+\beta \tilde{\zeta} \tilde{\Gamma}_{2}(1-s)^{\frac{1}{\rho}}\right]=R H S(s)
$$

We observe that the left hand side is linearly increasing in $s$, with $L H S(0)=0$ and $L H S(1)=1$ and the right hand side is strictly decreasing in $s$, with $R H S(0)>0$ and $R H S(1)=0$. Since both sides are continuous in $s$, from the intermediate value theorem it follows that there is a unique $s^{*} \in(0,1)$ solving the first order condition of the Ramsey problem (57). Since $R H S(s)$ is strictly increasing in $\tilde{\Gamma}_{2}$, the Ramsey saving rate is strictly increasing in $\tilde{\Gamma}_{2}$. The comparative statics of $s^{*}$ with respect to income risk in the main text then directly follow from the properties of $\tilde{\Gamma}_{2}$ stated in Lemma 1.

For future reference we rewrite equation (57) as

$$
\begin{aligned}
\frac{1-\alpha}{\alpha} & =\left[\frac{(1-s)}{s}+\beta \tilde{\zeta} \tilde{\Gamma}_{2} \frac{(1-s)^{\frac{1}{\rho}}}{s}\right] \text { or } \\
\frac{(1-s)^{\frac{1}{\rho}}}{s} & =\frac{\frac{1-\alpha}{\alpha}-\frac{(1-s)}{s}}{\beta \tilde{\zeta} \tilde{\Gamma}_{2}}=\frac{\frac{1}{\alpha}-\frac{1}{s}}{\beta \tilde{\zeta} \tilde{\Gamma}_{2}} .
\end{aligned}
$$




\section{D.4 Implementation}

The optimal steady state capital tax rate $\tau^{*}$ satisfies, as in equation (55)

$$
1=\left(1-\tau^{*}\right) \alpha \beta((1-\kappa)(1-\alpha))^{\left(\frac{1}{\rho}-1\right)} \frac{\left(1-s^{*}\right)^{\frac{1}{\rho}}}{s^{*}} \tilde{\Gamma}
$$

We observe that the optimal tax rate is strictly increasing in $\tilde{\Gamma}$ and strictly decreasing in the Ramsey saving rate $s^{*}$ that is to be implemented. Further, recall that the Ramsey saving rate $s^{*}$ itself satisfies the first order condition (58)

$$
\frac{\left(1-s^{*}\right)^{\frac{1}{\rho}}}{s^{*}}=\frac{\frac{1}{\alpha}-\frac{1}{s^{*}}}{\beta \tilde{\zeta} \tilde{\Gamma}_{2}}
$$

and is impacted by income risk through $\tilde{\Gamma}_{2}$. Plugging (60) into (59) and exploiting the definition of $\tilde{\zeta}$ yields

$$
1=\left(1-\tau^{*}\right)\left(1-\frac{\alpha}{s^{*}}\right) \frac{\tilde{\Gamma}}{\tilde{\Gamma}_{2}} .
$$

Lemma 1 establishes that $\frac{\tilde{\Gamma}}{\tilde{\Gamma}_{2}}$ is strictly increasing in income risk, and proposition 9 of the main text establishes that an increase in income risk increases $s^{*}$ if and only if $\rho<1$ and decreases it if and only if $\rho>1$. To sign the overall impact of income risk on the capital tax rate it is therefore useful to consider the following cases:

\section{D.4.1 Case $\rho \leq 1$}

This case gives clean results. From equation (61), since $\frac{\tilde{\Gamma}}{\tilde{\Gamma}_{2}}$ is strictly increasing in income risk, and since $s^{*}$ is increasing in income risk for $\rho \leq 1$, strictly so if $\rho<1$, then $\tau^{*}$ is strictly increasing in risk.

\section{D.4.2 Case $\rho>1$ and $\sigma \leq 1 / \rho$}

In this case $\tilde{\Gamma}$ is strictly increasing in risk (Lemma 1 ) and $s^{*}$ is strictly decreasing in risk (see Proposition 9) It then directly follows from equation (59) that $\tau^{*}$ is strictly increasing in income risk as well. 


\section{D.4.3 Case $\rho>1$ and $\sigma>1 / \rho$}

Since $\rho>1$, the Ramsey saving rate $s^{*}$ is strictly decreasing in income risk (which by itself calls for a tax rate that is strictly increasing in income risk)., by equation (59). However, now the direct impact of income risk on taxes through the term $\tilde{\Gamma}$ might call for lower taxes since $\tilde{\Gamma}$ might now be decreasing in income risk. If $\tilde{\Gamma}$ is weakly increasing in income risk, then so is $\tau^{*}$. Thus a necessary condition for $\tau^{*}$ to decrease with income risk is for $\tilde{\Gamma}$ to be strictly decreasing with income risk. This in turn is a necessary and sufficient condition for the private saving rate in competitive equilibrium to decrease with income risk (see Proposition 14). Thus the Ramsey tax rate $\tau^{*}$ is strictly decreasing in income risk only if the private saving rate $s^{C E}(\tau)$ is strictly decreasing in income risk (for any given tax rate $\tau$ ). The corresponding if statement is not necessarily true, as the numerical illustrations in the main text show.

Finally, one might conjecture that, since $\rho>1$ and $\sigma>1 / \rho$ is required for the capital tax to decrease in income risk, that as long as both parameters are large enough the result will materialize. This conjecture turns out to be false, as an investigation of the most extreme case $\rho=\sigma=\infty$ shows. In this case lifetime utility is given by

$$
V_{t}=c_{t}^{y}+\beta \underline{c}_{t+1}^{o}
$$

where $\underline{c}_{t+1}^{o}$ is consumption in old age if the lowest possible labor productivity realization $\eta=\underline{\eta}_{t+1}$ materializes. In this case one can solve analytically for the optimal interior Ramsey saving and tax rate, and show that the optimal tax rate is the higher the lower is $\underline{\eta}_{t+1}$ and thus the higher is income risk. ${ }^{29}$ In fact, as our numerical results in the main text show, for the case $\rho>1$ and $\sigma>1 / \rho$ the Ramsey tax rate is an increasing function of income risk once $\rho$ and $\sigma$ become sufficiently large.

\footnotetext{
${ }^{29}$ In this case it is possible that the Ramsey government will want to implement a saving rate of $s=1$ since households have linear preferences over consumption when young and minimum (across $\eta$ ) consumption when old. As long as $\eta$ is sufficiently small, however, the Ramsey government prefers to implement an interior saving rate.
} 


\section{D.5 Decomposition into $P E(s), G E(s)$ and $F G(s)$}

Proposition 15. For $\theta=1, \sigma \neq \frac{1}{\rho}$, terms $P E(s), G E(s), F G(s)$ are given by

$$
\begin{aligned}
& P E(s)=-\frac{1}{1-s}\left(\frac{1-s}{s}\right)^{1-\frac{1}{\rho}} k(s)^{1-\frac{1}{\rho}}+\frac{\alpha \beta}{s} \tilde{\Gamma} k(s)^{\alpha\left(1-\frac{1}{\rho}\right)} \\
& G E(s)=\frac{\alpha \beta}{s} k(s)^{\alpha\left(1-\frac{1}{\rho}\right)}\left(\tilde{\Gamma}_{2}-\tilde{\Gamma}\right) \\
& F G(s)=\frac{\alpha}{s(1-\alpha)}\left(\frac{1-s}{s}\right)^{1-\frac{1}{\rho}} k(s)^{1-\frac{1}{\rho}}+\frac{\alpha^{2} \beta}{s(1-\alpha)} k(s)^{\alpha\left(1-\frac{1}{\rho}\right)} \tilde{\Gamma}_{2}
\end{aligned}
$$

where $k(s)=(s(1-\kappa)(1-\alpha))^{\frac{1}{1-\alpha}}$ is the steady state capital stock.

Therefore,

$$
P E(s)+G E(s)=-\frac{1}{1-s}\left(\frac{1-s}{s}\right)^{1-\frac{1}{\rho}} k(s)^{1-\frac{1}{\rho}}+\frac{\alpha \beta}{s} k(s)^{\alpha\left(1-\frac{1}{\rho}\right)} \tilde{\Gamma}_{2} .
$$

and

$$
P E(s)+G E(s)+F G(s)=\left(\frac{1-s}{s}\right)^{1-\frac{1}{\rho}} k(s)^{1-\frac{1}{\rho}}\left(\frac{\alpha}{s(1-\alpha)}-\frac{1}{1-s}\right)+\frac{1}{s} k(s)^{\alpha\left(1-\frac{1}{\rho}\right)} \frac{\alpha \beta}{(1-\alpha)} \tilde{\Gamma}_{2} .
$$

Thus, compared to the expressions for these three effects we derived in section 4.2, the partial equilibrium precautionary savings effect still cancels out with the general equilibrium effect ( $\tilde{\Gamma}$ cancels out when adding up $P E(s)$ and $G E(s)$ ). However, additionally risk enters through $\tilde{\Gamma}_{2}$. With $\rho<1$ an increase of risk increases $\tilde{\Gamma}_{2}$ thereby pushing up the desired saving rate of the Ramsey planner. The reason is that an increase of risk decreases the utility value of second period consumption of current generations (effect in $G E(s)$ ) and of all future generations (effect in $F G(s)$ ). With a low IES, it is optimal to compensate this with higher savings; vice versa for a high IES where the Ramsey planner rather prefers increased first-period consumption, respectively current generations consumption, over future consumption in response to an increase in risk. 
Proof of proposition 15. Calculating the respective terms yields

$$
\begin{aligned}
P E(s)= & (1-\kappa)(1-\alpha) k^{\alpha}\left[-\left((1-s)(1-\kappa)(1-\alpha) k^{\alpha}\right)^{-\frac{1}{\rho}}+\right. \\
& \left.\alpha k^{\prime}(s)^{\alpha-1} \beta\left(\int(\kappa \eta(1-\alpha)+\alpha)^{1-\sigma} d \Psi\right)^{\frac{\sigma-\frac{1}{\rho}}{1-\sigma}} k^{\prime}(s)^{\alpha\left(\sigma-\frac{1}{\rho}\right)} \int(\kappa \eta(1-\alpha)+\alpha)^{-\sigma} d \Psi k^{\prime}(s)^{-\alpha \sigma}\right] \\
= & \frac{1}{s}\left(-\left(\frac{1-s}{s}\right)^{-\frac{1}{\rho}} k^{\prime}(s)^{1-\frac{1}{\rho}}+\alpha \beta k^{\prime}(s)^{\alpha\left(1-\frac{1}{\rho}\right)} \Gamma_{2}^{\frac{\sigma-\frac{1}{\rho}}{1-\sigma}} \Gamma\right) \\
= & -\frac{1}{1-s}\left(\frac{1-s}{s}\right)^{1-\frac{1}{\rho}} k(s)^{1-\frac{1}{\rho}}+\frac{\alpha \beta}{s} \tilde{\Gamma} k(s)^{\alpha\left(1-\frac{1}{\rho}\right) .}
\end{aligned}
$$

and for

$$
\begin{aligned}
G E(s) & =\beta\left(\int c^{o}(\eta)^{1-\sigma} d \Psi\right)^{\frac{\sigma-\frac{1}{\rho}}{1-\sigma}} \int\left(c^{o}(\eta)^{-\sigma}\right)\left[\kappa \eta w^{\prime}(s)+(1-\kappa)(1-\alpha) k^{\alpha} R^{\prime}(s) s\right] d \Psi(\eta) \\
& =\beta \Gamma_{2}^{\frac{\sigma-\frac{1}{\rho}}{1-\sigma}} k^{\prime}(s)^{\alpha\left(\sigma-\frac{1}{\rho}\right)} \int(\kappa \eta(1-\alpha)+\alpha)^{-\sigma} k^{\prime}(s)^{-\alpha \sigma} \alpha(1-\alpha) s^{-1} \\
& \times\left[\kappa \eta k^{\prime}(s)^{\alpha}-(1-\kappa)(1-\alpha) k^{\alpha} k^{\prime}(s)^{\alpha-1} s\right] d \Psi \\
& =\frac{\alpha \beta}{s} k^{\prime}(s)^{\alpha\left(1-\frac{1}{\rho}\right)} \Gamma_{2}^{\frac{\sigma-\frac{1}{\rho}}{1-\sigma}} \int(\kappa \eta(1-\alpha)+\alpha)^{-\sigma}[\kappa \eta(1-\alpha)+\alpha-1] d \Psi \\
& =\frac{\alpha \beta}{s} k(s)^{\alpha\left(1-\frac{1}{\rho}\right)} \Gamma_{2}^{\frac{\sigma-\frac{1}{\rho}}{1-\sigma}}\left(\Gamma_{2}-\Gamma\right) \\
& =\frac{\alpha \beta}{s} k(s)^{\alpha\left(1-\frac{1}{\rho}\right)}\left(\tilde{\Gamma}_{2}-\tilde{\Gamma}\right) .
\end{aligned}
$$

When maximizing steady state utility, $F G(s)$ is equivalent to the derivative of the utility function with respect to the current period capital stock. Therefore:

$$
\begin{aligned}
F G(s) & =u_{c^{y}} c_{k(s)}^{y} k(s)_{s}+\beta\left(\int c^{o}(\eta)^{1-\sigma} d \Psi\right)^{\frac{\sigma-\frac{1}{\rho}}{1-\sigma}} \int\left(c^{o}(\eta)^{-\sigma}\right) c_{k^{\prime}(s)}^{o} k^{\prime}(s)_{k(s)} k(s)_{s} d \Psi, \\
u_{c^{y}} c_{k(s)}^{y} k(s)_{s} & =\left((1-s)(1-\kappa)(1-\alpha) k(s)^{\alpha}\right)^{-\frac{1}{\rho}}(1-s)(1-\kappa)(1-\alpha) \alpha k(s)^{\alpha-1}(1-\kappa) k(s)^{\alpha} \\
& =\frac{\alpha}{s(1-\alpha)}\left(\frac{1-s}{s}\right)^{1-\frac{1}{\rho}} k^{\prime}(s)^{1-\frac{1}{\rho}}
\end{aligned}
$$


with

$$
\left(\int c^{o}(\eta)^{1-\sigma} d \Psi\right)^{\frac{\sigma-\frac{1}{\rho}}{1-\sigma}}=\Gamma_{2}^{\frac{\sigma-\frac{1}{\rho}}{1-\sigma}} k^{\prime}(s)^{\alpha\left(\sigma-\frac{1}{\rho}\right)}
$$

and

$$
\begin{aligned}
& \beta \int c^{0-\sigma} c_{k^{\prime}(s)}^{o} k^{\prime}(s)_{k(s)} k(s)_{s} d \Psi= \\
& \beta \int(\kappa \eta(1-\alpha)+\alpha)^{-\sigma} k^{\prime}(s)^{-\alpha \sigma}(\kappa \eta(1-\alpha)+\alpha) d \Psi \alpha k^{\prime}(s)^{\alpha-1} k^{\prime}(s) \alpha(1-\kappa) k(s)^{\alpha-1} \\
& =\frac{\alpha^{2} \beta}{s(1-\alpha)} k^{\prime}(s)^{\alpha(1-\sigma)} \Gamma_{2} .
\end{aligned}
$$

Therefore:

$$
F G(s)=\frac{\alpha}{s(1-\alpha)}\left(\frac{1-s}{s}\right)^{1-\frac{1}{\rho}} k(s)^{1-\frac{1}{\rho}}+\frac{\alpha^{2} \beta}{s(1-\alpha)} k(s)^{\alpha\left(1-\frac{1}{\rho}\right)} \tilde{\Gamma}_{2} .
$$

\section{D.6 Decomposition of $\tau^{*}$}

Corollary 10. $\tau^{*}$ can only be decreasing in risk if the effect of $F G(s)$ is sufficiently strong.

Proof. We know that the FOC for $s^{*}$ follows from

$$
P E(s)+G E(s)+F G(s)=0
$$

Now set $F G(s)=0$. Rewrite from (63)

$$
P E(s)+G E(s)=0 \Leftrightarrow \frac{s}{(1-s)^{\frac{1}{\rho}}}=\alpha \beta \tilde{\zeta} \tilde{\Gamma}_{2}
$$

which uses $k(s)=(s(1-\kappa)(1-\alpha))^{\frac{1}{1-\alpha}}$ and $\tilde{\zeta}=((1-\alpha)(1-\kappa))^{\frac{1}{\rho}-1}$. Using the above in (59) gives

$$
1=\left(1-\tau^{*}\right) \frac{\tilde{\Gamma}}{\tilde{\Gamma}_{2}}
$$

and $\frac{\tilde{\Gamma}}{\tilde{\Gamma}_{2}}$ is unambiguously increasing in risk, see Appendix E.1. Using the above we 
can thus decompose equation (44) as

$$
1=\underbrace{\left(1-\tau^{*}\right) \frac{\tilde{\Gamma}}{\tilde{\Gamma}_{2}}}_{\text {from } P E(s)+G E(s)}-\underbrace{\left(1-\tau^{*}\right) \frac{\alpha}{s^{*}} \frac{\tilde{\Gamma}}{\tilde{\Gamma}_{2}}}_{\text {from } F G(s)} .
$$

\section{E Income Risk and $\Gamma, \Gamma_{2}, \tilde{\Gamma}, \tilde{\Gamma}_{2}$}

\section{E.1 General Case}

In this section we prove Lemma 1 in the main text through two separate Lemmas. For this, recall that the relevant expressions involving idiosyncratic income risk are given by:

$$
\begin{aligned}
\Gamma & =\int(\kappa \eta(1-\alpha)+\alpha)^{-\sigma} d \Psi(\eta) \\
\Gamma_{2} & =\int(\kappa \eta(1-\alpha)+\alpha)^{1-\sigma} d \Psi(\eta) \\
\tilde{\Gamma} & =\Gamma_{2}^{\frac{\sigma-\frac{1}{\rho}}{1-\sigma}} \Gamma=c e(\eta)^{\sigma-\frac{1}{\rho}} \Gamma \\
\tilde{\Gamma}_{2} & =\Gamma_{2}^{\frac{\sigma-\frac{1}{\rho}}{1-\sigma}} \Gamma_{2}=\Gamma_{2}^{\frac{1-\frac{1}{\rho}}{1-\sigma}}=c e(\eta)^{1-\frac{1}{\rho}} \\
\frac{\tilde{\Gamma}_{\tilde{\Gamma}}}{\tilde{\Gamma}_{2}} & =\frac{\Gamma^{2}}{\Gamma_{2}} \\
c e(\eta) & \equiv \begin{cases}{\left[\int(\alpha+(1-\alpha) \kappa \eta)^{1-\sigma} d \Psi(\eta)\right]^{\frac{1}{1-\sigma}}} & \text { for } \sigma \neq 1 \\
\exp \left[\int \ln (\alpha+(1-\alpha) \kappa \eta) d \Psi(\eta)\right] & \text { for } \sigma=1\end{cases}
\end{aligned}
$$

Furthermore, as in the main text we use the notion of a mean-preserving spread in the random variable $\eta$ when referring to an increase in risk, that is, formally, random variable $\eta$ is replaced by $\tilde{\eta}=\eta+\nu$, where $\nu$ is a random variable with zero mean and positive variance (and Assumption 1 applies to $\tilde{\eta}$ as well).

Lemma 2. The certainty equivalent ce $(\eta)$ is decreasing in $\eta$-risk.

Proof. If $\sigma>1$ (respectively $\sigma<1$ ), then $(\alpha+(1-\alpha) \kappa \eta)^{1-\sigma}$ is convex and downward sloping (respectively, concave and upward sloping) in $\eta$. The certainty equivalent of 
a convex and downward sloping (respectively, concave and upward sloping) function is decreasing in risk.

Lemma 3. The comparative statics of the other risk terms with respect to a meanpreserving spread in $\eta$ are given by:

1. $\Gamma$ is increasing in $\eta$-risk.

2. $\Gamma_{2}$ is increasing (respectively, decreasing) in $\eta$-risk if $\sigma>1$ (respectively $\sigma<1$ ).

3. $\tilde{\Gamma}_{2}$ is increasing (decreasing) in $\eta$-risk if $\rho<1(\rho>1)$.

4. For $\rho<1, \tilde{\Gamma}$ is increasing in $\eta$-risk. For $\rho>1$ we have the following case distinction:

(a) For $\frac{1}{\sigma}>\rho>1, \tilde{\Gamma}$ unambiguously increases in income risk.

(b) For $\rho>1, \rho>\frac{1}{\sigma}>0$, i.e., $\sigma<\infty$ the effect of $\eta$-risk on $\tilde{\Gamma}$ is ambiguous.

Proof. 1. $\Gamma$ is increasing in $\eta$-risk because $(\kappa \eta(1-\alpha)+\alpha)^{-\sigma}$ is a convex function in $\eta$ (with the degree of convexity increasing in $\sigma$ ).

2. $\Gamma_{2}$ is increasing (decreasing) in $\eta$-risk if $\sigma>1(\sigma<1)$ because $(\kappa \eta(1-\alpha)+\alpha)^{1-\sigma}$ is a convex (concave) function of $\eta$.

3. $\tilde{\Gamma}_{2}$ is increasing (decreasing) in $\eta$-risk if $\rho<1(\rho>1)$ because the certainty equivalent $c e(\eta)$ decreases in $\eta$-risk and because for $\rho<1(\rho>1)$ the exponent $1-\frac{1}{\rho}$ is negative (positive).

4. For $\rho<1, \tilde{\Gamma}$ is increasing in $\eta$-risk (sufficient condition). To see this, rewrite $\tilde{\Gamma}$ as

$$
\tilde{\Gamma}=\frac{\Gamma}{\Gamma_{2}^{-\frac{-(1-\sigma)+\left(1-\frac{1}{\rho}\right)}{1-\sigma}}}=\frac{\Gamma}{\Gamma_{2}^{1-\frac{1-\frac{1}{\rho}}{1-\sigma}}}=\frac{\Gamma}{\Gamma_{2}} \Gamma_{2}^{\frac{1-\frac{1}{\rho}}{1-\sigma}}=\frac{\Gamma}{\Gamma_{2}} c e(\eta)^{1-\frac{1}{\rho}}
$$

Notice that for $\sigma \leq 1, \frac{\Gamma}{\Gamma_{2}}$ is the ratio of the expectation of a strictly convex and a concave function. Hence, for $\sigma \leq 1$ the term $\frac{\Gamma}{\Gamma_{2}}$ is increasing in risk by Jensen's inequality. For $\sigma>1$ term $\frac{\Gamma}{\Gamma_{2}}$ is the ratio of the expectation of two convex functions with the convexity of the function in the numerator, 
$(\kappa \eta(1-\alpha)+\alpha)^{-\sigma}$, being stronger than in the denominator, $(\kappa \eta(1-\alpha)+\alpha)^{1-\sigma}$ as long as $\sigma<\infty$. Therefore, also for $1<\sigma<\infty$ term $\frac{\Gamma}{\Gamma_{2}}$ is increasing in risk. For $\sigma=\infty$ term $\frac{\Gamma}{\Gamma_{2}}$ is equal to 1 . Finally, since the certainty equivalent $c e(\eta)$ is decreasing in $\eta$-risk, term $c e(\eta)^{1-\frac{1}{\rho}}$ increases in $\eta$-risk if and only if $\rho<1$.

For $\rho>1$ we have the following case distinction:

(a) For $\frac{1}{\sigma}>\rho>1, \tilde{\Gamma}$ unambiguously increases in $\eta$-risk because $c e(\eta)$ decreases in $\eta$-risk and $\sigma-\frac{1}{\rho}<0$.

(b) For $\rho>1, \rho>\frac{1}{\sigma}>0$ the effect of $\eta$-risk on $\tilde{\Gamma}$ is ambiguous because $c e(\eta)$ is decreasing in $\eta$-risk and $\sigma-\frac{1}{\rho}>0$ so that $c e(\eta)^{\sigma-\frac{1}{\rho}}$ is decreasing in $\eta$ risk whereas $\Gamma$ is increasing in $\eta$-risk. Rewriting $\tilde{\Gamma}$ as in equation (65) does not resolve this ambiguity because therm $\frac{\Gamma}{\Gamma_{2}}$ is increasing in $\eta$-risk whereas $c e(\eta)^{1-\frac{1}{\rho}}$ is decreasing in $\eta$ risk because $1-\frac{1}{\rho}>0$.

\section{E.2 Expressing $\Gamma$-Intervals from Proposition 4 in Terms of Variances}

The bounds in proposition 4 can be defined in terms of the variances of the idiosyncratic income shock $\eta$, to a second-order approximation of the integral defining $\Gamma$. Notice that by a second-order Taylor series expansion around $\eta=1$ we can approximate $\Gamma$ as

$$
\Gamma(\alpha, \kappa, \sigma, \Psi) \approx \bar{\Gamma}+\frac{[\kappa(1-\alpha)]^{2}}{[\kappa(1-\alpha)+\alpha]^{3}} \sigma_{\eta}^{2} .
$$

From this it is straightforward to see that the interval for intermediate risk, see item 2 of proposition 4 , is equivalent to

$$
\sigma_{\eta}^{2} \in\left(\underline{\sigma_{\eta}^{2}}, \overline{\sigma_{\eta}^{2}}\right),
$$


where

$$
\begin{aligned}
& \underline{\sigma_{\eta}^{2}}=\frac{(\kappa(1-\alpha)+\alpha)^{3}}{(\kappa(1-\alpha))^{2}}\left(\frac{1+\beta}{(1-\alpha) \beta}-\bar{\Gamma}\right) \\
& \overline{\sigma_{\eta}^{2}}=\frac{(\kappa(1-\alpha)+\alpha)^{3}}{(\kappa(1-\alpha))^{2}}\left(\frac{1}{\left((1-\alpha)-\frac{1}{\bar{\Gamma}}\right) \beta}-\bar{\Gamma}\right)
\end{aligned}
$$

and $\overline{\sigma_{\eta}^{2}}>\sigma_{\eta}^{2}>0$ under the maintained assumption that $\beta<[(1-\alpha) \bar{\Gamma}-1]^{-1}$ so that all intervals defined in proposition 4 can be expressed in terms of variances and are non-empty. Also note that if the distribution $\Psi$ is log-normal and thus exclusively determined by its variance (given that the mean is pinned down by the maintained assumption $E(\eta)=1$ ), then no second order approximation is necessary in the above argument, but the mapping between the variance bounds and the $\Gamma$ bounds becomes algebraically much more involved.

\section{F Further Numerical Results}

In Section 6.3 we show results for an extreme parameter constellation by taking $\rho=20$ and $\sigma=50$ to illustrate hump shaped saving rates in the competitive equilibrium and hump shaped optimal capital income tax rates in the optimal policy. We here reduce the values of both parameters.

Results for a lower risk aversion of $\sigma=2$ (maintaining $\rho=20$ ) are shown in Figures $4-5$ and Table 2. Given the lower risk aversion, the optimal policy for the economy with $\sigma_{\eta}^{2}=0.25$ is now to implement a capital income subsidy. Also, while the competitive equilibrium saving rate continues to be slightly decreasing in risk, when $\sigma_{\eta}$ increases from 1 to 2 , the optimal tax rate is strictly increasing in risk because risk aversion is too low so that the future generations effect is not powerful enough to offset the increasing capital income tax.

Results for a lower risk aversion of $\sigma=2$ and a lower IES of $\rho=0.5$ are shown in Figures 6-7 and Table 3. As the motive for inter-temporal shifting is now less strong, policy functions for the optimal saving rate are increasing in risk and in the capital stock. With this calibration, the competitive equilibrium saving rate is only too high relative to the long-run optimum for the calibrations with a high risk of $\sigma_{\eta}^{2}=2$. Consequently, only this economy will experience capital income taxation along the transition. It also features a Pareto improvement from the tax reform. 
Figure 4: Policy Functions for $\rho=20, \sigma=2$ and Log Utility $(\sigma=\rho=1)$

(a) $s^{*}(k)$

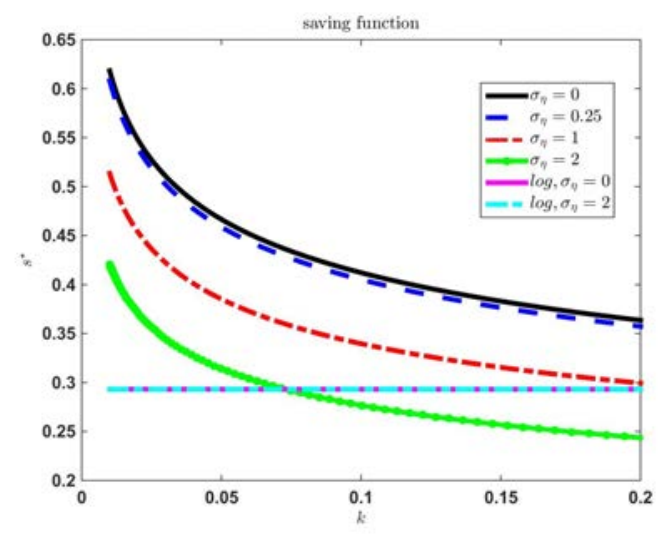

(b) $k^{\prime *}(k)$

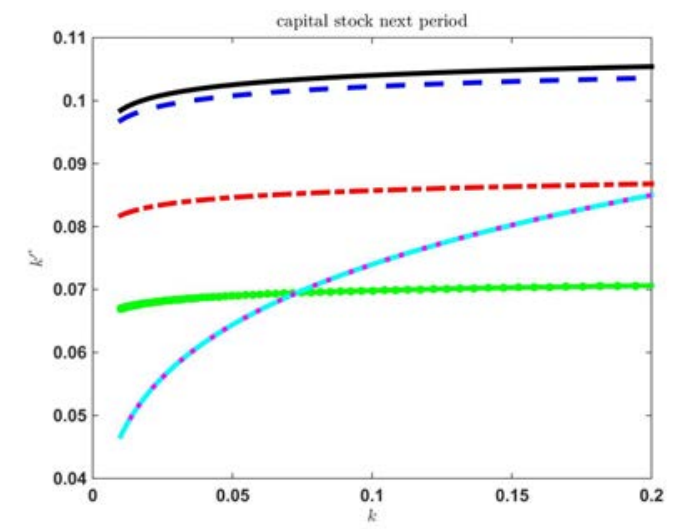

Notes: Policy function for optimal saving rate and next period capital stock for $\alpha=0.2, \beta=0.8$, $\kappa=0.5, \sigma_{\eta} \in\{0,0.25,1,2\}, \theta=0.9$ and $\rho=20, \sigma=2$ as well as for logarithmic utility $(\rho=\sigma=1)$.

Table 2: Saving Rates in Competitive Equilibrium and Optimal Long-Run Saving \& Capital Income Tax Rates: Low RA

\begin{tabular}{|c|c|c|c|}
\hline & $s_{0}(\eta)$ & $s_{\infty}^{*}$ & $\tau_{\infty}^{k^{*}}$ \\
\hline \multicolumn{4}{|c|}{ EZW-Preferences with $\rho=20, \sigma=2$} \\
\hline$\sigma_{\eta}=0$ & 0.38 & 0.41 & -0.13 \\
\hline$\sigma_{\eta}=0.25$ & 0.39 & 0.4 & -0.05 \\
\hline$\sigma_{\eta}=1$ & 0.464 & 0.35 & 0.43 \\
\hline$\sigma_{\eta}=2$ & 0.460 & 0.3 & 0.58 \\
\hline \multicolumn{4}{|c|}{ Log Utility } \\
\hline$\sigma_{\eta}=0$ & 0.21 & 0.29 & -0.88 \\
\hline$\sigma_{\eta}=2$ & 0.36 & 0.29 & 0.39 \\
\hline
\end{tabular}

Notes: Saving rates in the initial competitive equilibrium, $s_{0}(\eta)$, and optimal long-run saving, $s_{\infty}^{*}$, and capital income tax rates $\tau_{\infty}^{k^{*}}$ for $\alpha=0.2, \beta=0.8, \kappa=0.5, \quad \sigma_{\eta} \in\{0,0.25,1,2\}, \quad \theta=0.9$ and $\rho=20, \sigma=2$ as well as for logarithmic utility $(\sigma=\rho=1)$. 
Figure 5: Policy Transition for $\rho=20, \sigma=2$ and Log Utility $(\sigma=\rho=1)$

(a) $s_{t}$

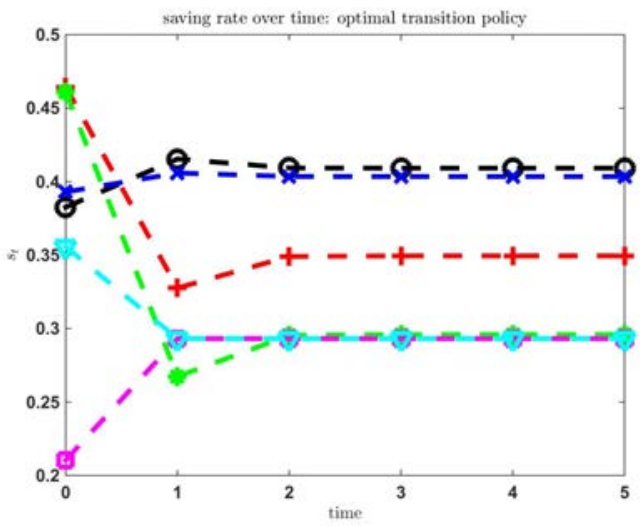

(c) $\tau_{t}^{k}$

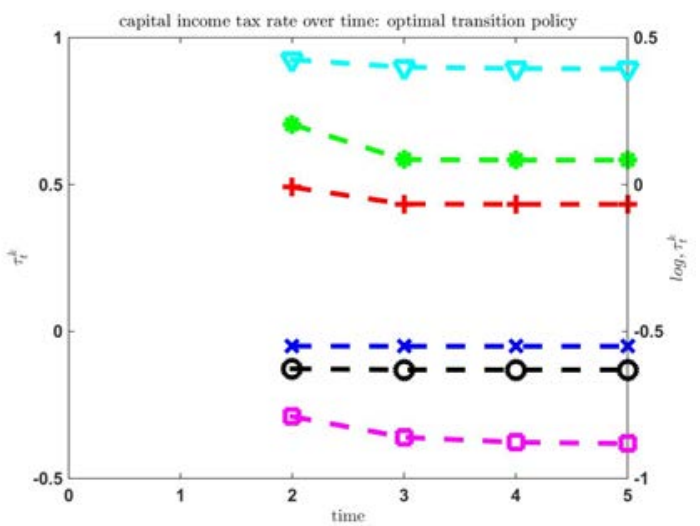

(b) $k_{t}$

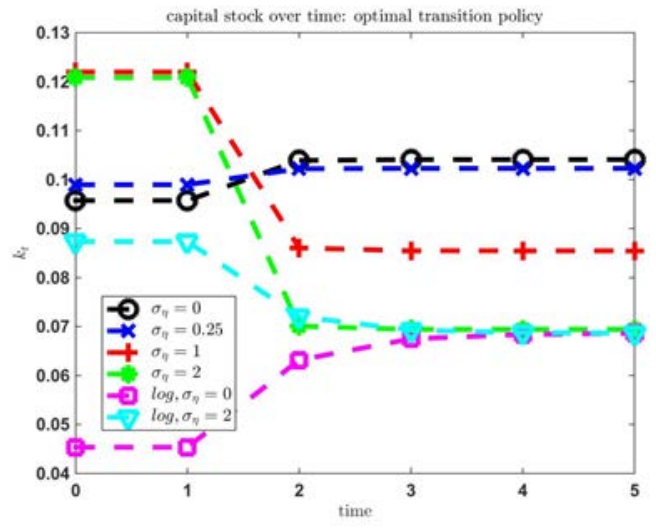

(d) $\Delta v_{t}$

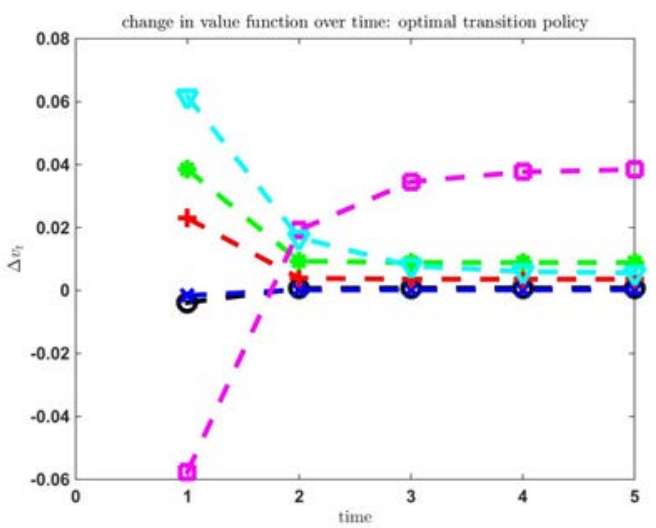

Notes: Initial and optimal saving rate, capital stock, optimal capital income tax rate and changes in lifetime utility in transition for $\alpha=0.2, \beta=0.8, \kappa=0.5, \quad \sigma_{\eta} \in\{0,0.25,1,2\}, \quad \theta=0.9$ and $\rho=20, \sigma=50$ as well as for logarithmic utility $(\rho=\sigma=1)$. 
Figure 6: Policy Functions for $\rho=0.5, \sigma=2$ and Log Utility $(\sigma=\rho=1)$

(a) $s^{*}(k)$

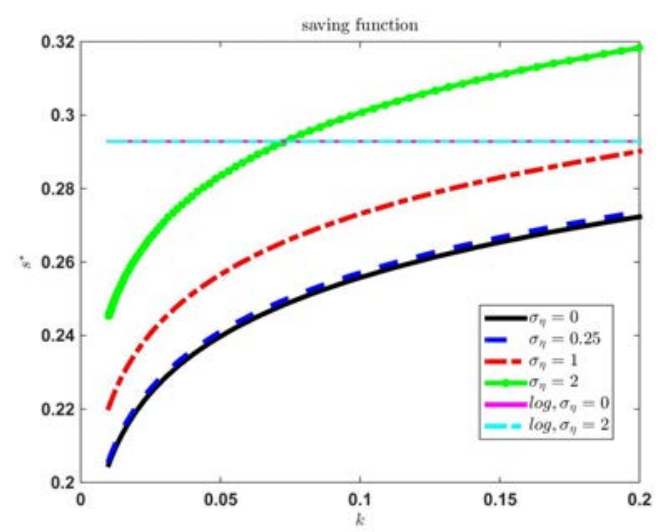

(b) $k^{\prime^{*}}(k)$

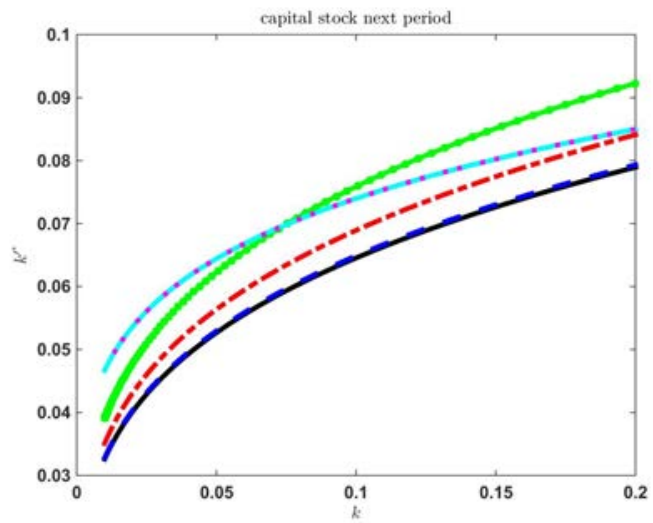

Notes: Policy function for optimal saving rate and next period capital stock for $\alpha=0.2, \beta=0.8$, $\kappa=0.5, \sigma_{\eta} \in\{0,0.25,1,2\}, \theta=0.9$ and $\rho=0.5, \sigma=2$ as well as for logarithmic utility $(\rho=\sigma=1)$.

Table 3: Saving Rates in Competitive Equilibrium and Optimal Long-Run Saving \& Capital Income Tax Rates: Low IES, Low RA

\begin{tabular}{|c|c|c|c|}
\hline & $s_{0}(\eta)$ & $s_{T}^{*}$ & $\tau_{T}^{*}$ \\
\hline \multicolumn{4}{|c|}{ EZW-Preferences with $\rho=0.5, \sigma=2$} \\
\hline$\sigma_{\eta}=0$ & 0.13 & 0.24 & -2.02 \\
\hline$\sigma_{\eta}=0.25$ & 0.14 & 0.24 & -1.78 \\
\hline$\sigma_{\eta}=1$ & 0.24 & 0.26 & -0.26 \\
\hline$\sigma_{\eta}=2$ & 0.36 & 0.29 & 0.55 \\
\hline \multicolumn{4}{|l|}{ Log Utility } \\
\hline$\sigma_{\eta}=0$ & 0.21 & 0.29 & -0.88 \\
\hline$\sigma_{\eta}=2$ & 0.36 & 0.29 & 0.39 \\
\hline
\end{tabular}

Notes: Saving rates in the initial competitive equilibrium, $s_{0}(\eta)$, and optimal long-run saving, $s_{\infty}^{*}$, and capital income tax rates $\tau_{\infty}^{k^{*}}$ for $\alpha=0.2, \beta=0.8, \kappa=0.5, \quad \sigma_{\eta} \in\{0,0.25,1,2\}, \quad \theta=0.9$ and $\rho=0.5, \sigma=2$ as well as for logarithmic utility $(\sigma=\rho=1)$. 
Figure 7: Policy Transition for EZW with $\rho=0.5, \sigma=2$ and Log Utility

(a) $k_{t}$

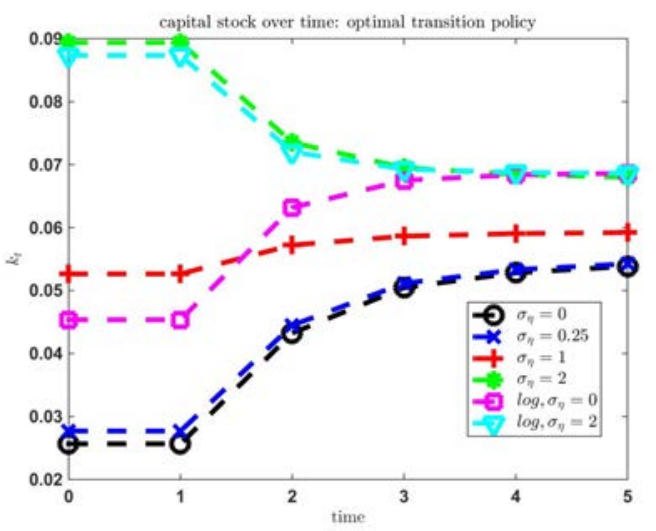

(c) $\tau_{t}^{k}$

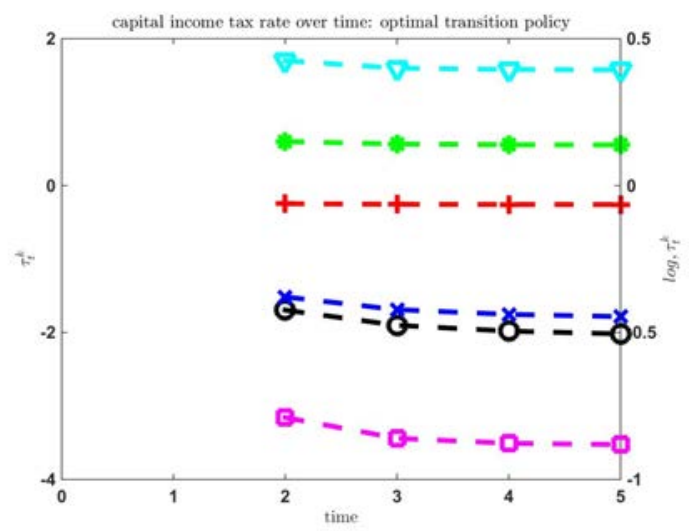

(b) $s_{t}$

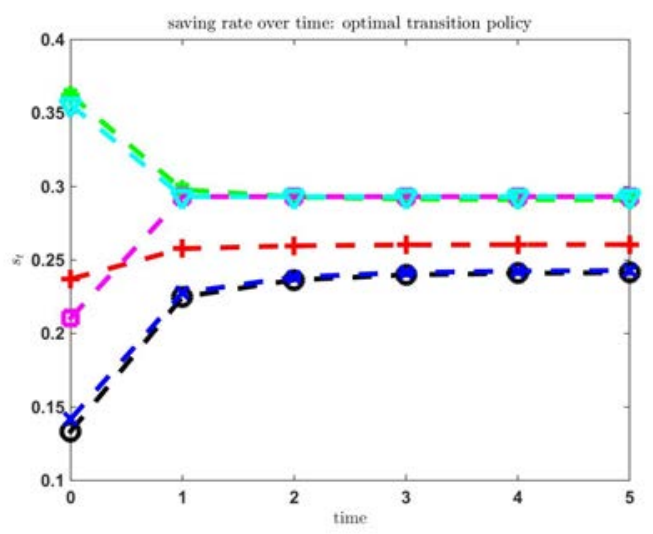

(d) $\Delta v_{t}$

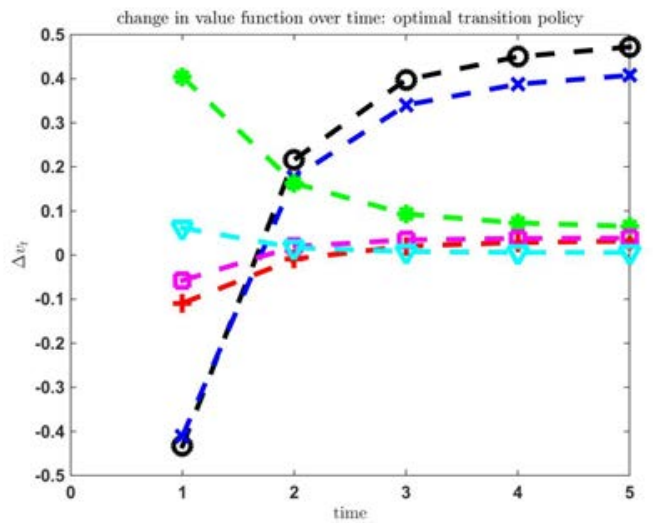

Notes: Capital stock, saving rate, capital income tax rate and changes in lifetime utility in transition for for $\alpha=0.2, \beta=0.8, \kappa=0.5, \sigma_{\eta} \in\{0,0.25,1,4\}, \theta=0.9$ and $\sigma=2, \rho=0.5$ as well as for logarithmic utility. 